Comprehensive Summaries of Uppsala Dissertations

from the Faculty of Medicine 649

\title{
Biochemical Markers of Myocardial \\ Damage for Early Diagnosis and Prognosis in Patients with Acute Coronary Syndromes
}

BY

BERTIL LINDAHL

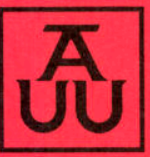

ACTA UNIVERSITATIS UPSALIENSIS

UPPSALA 1996 
Wh:

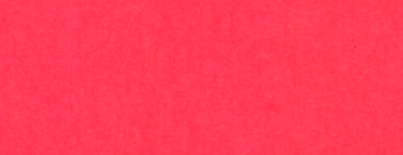

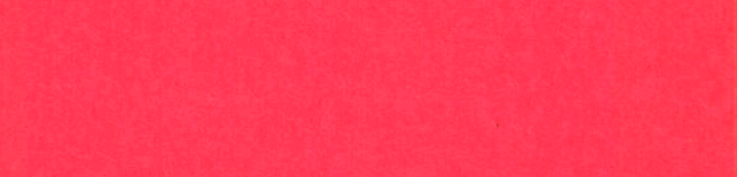

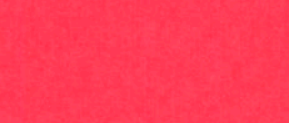

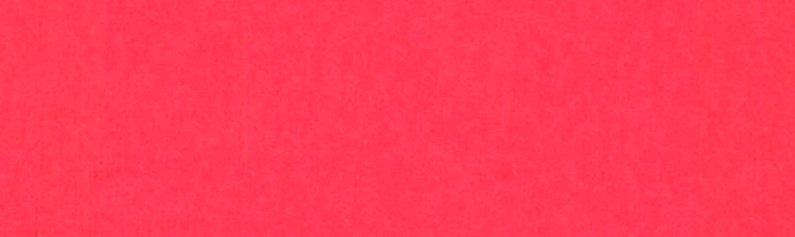

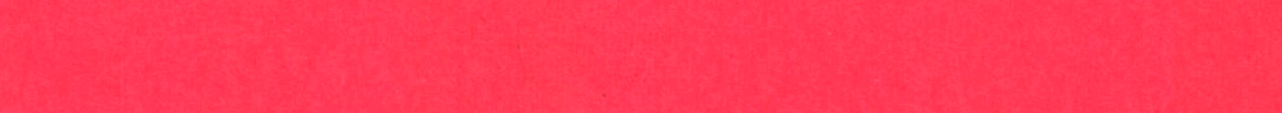

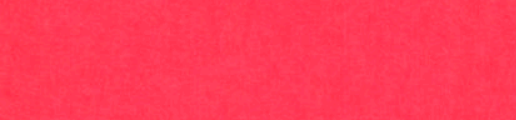

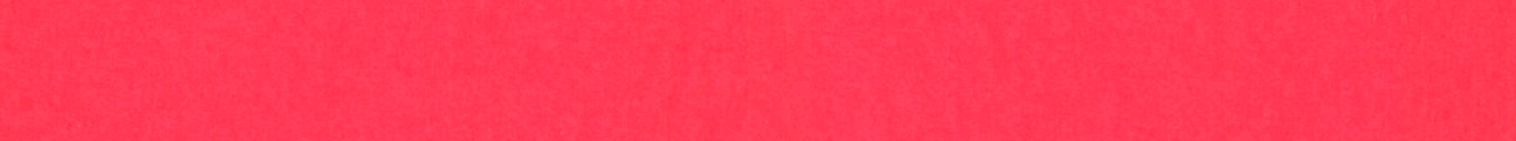

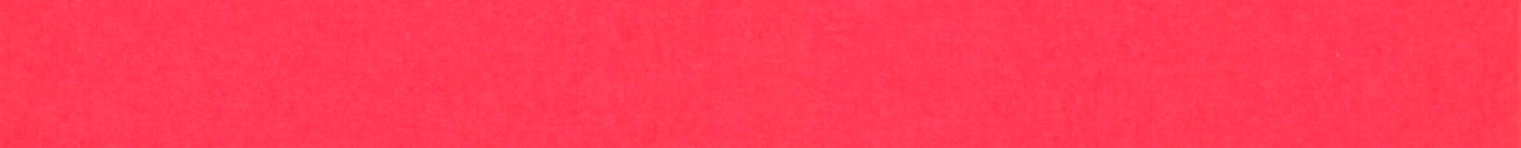
2. -

5.7. toris is

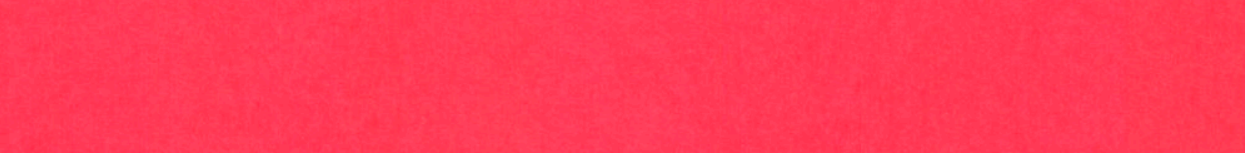

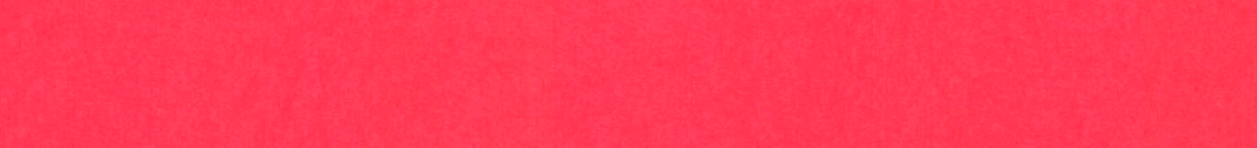

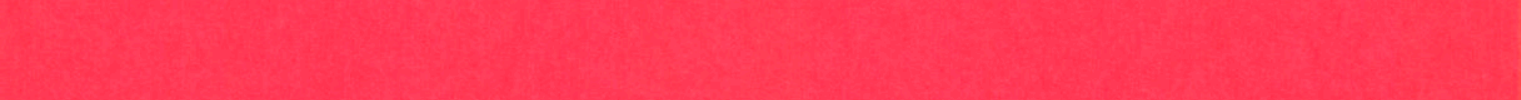
S. 1.7. 13.6.5.

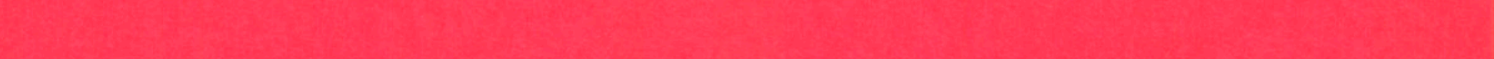

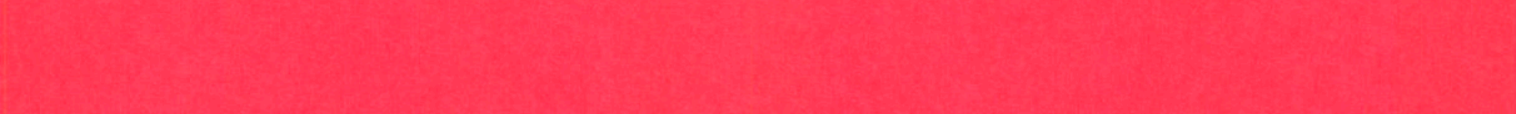

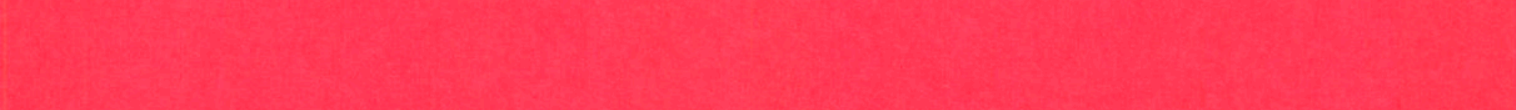

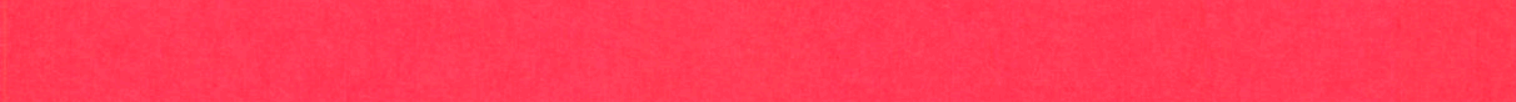

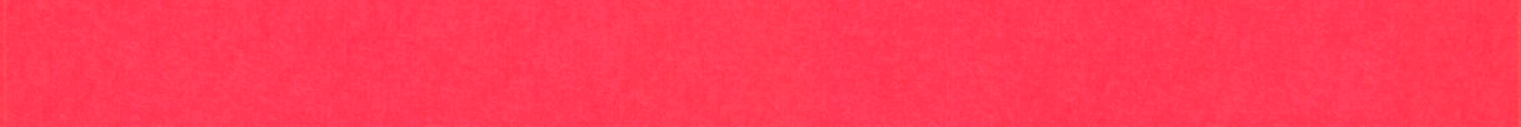

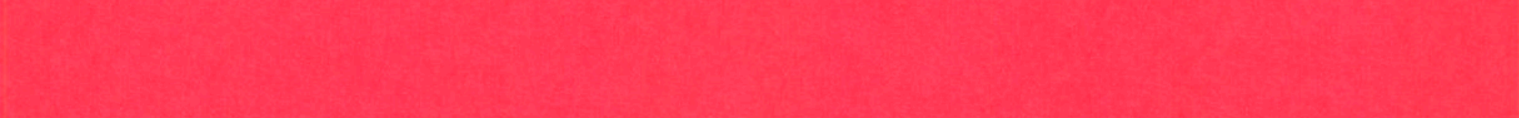

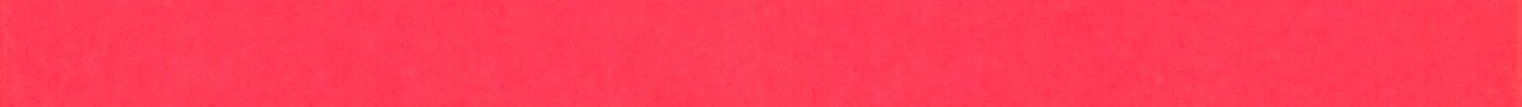




\title{
ACTA UNIVERSITATIS UPSALIENSIS
}

Comprehensive Summaries of Uppsala Dissertations from the Faculty of Medicine 649

Distributor: Almqvist \& Wiksell International, Stockholm, Sweden

\section{Bertil Lindahl \\ Biochemical markers of myocardial damage for early diagnosis and prognosis in patients with acute coronary syndromes}

\begin{abstract}
Akademisk avhandling som för avläggande av doktorsexamen i cardiologi i medicinsk vetenskap vid Uppsala universitet kommer att offentligt försvaras i Thoraxcentrums föreläsningssal, ing 40, Akademiska sjukhuset, fredagen den 25 oktober 1996, kl 09.15
\end{abstract}

\begin{abstract}
Lindahl, B. 1996. Biochemical markers of myocardial damage for early diagnosis and prognosis in patients with acute coronary syndromes. Acta Universitatis Upsaliensis. Comprehensive Summaries of Uppsala Dissertations from the Faculty of Medicine 649. 66 pp. Uppsala. ISBN 91-554-3847-4.
\end{abstract}

The present study evaluated the use of biochemical markers of myocardial damage for early diagnosis and prognosis in patients with acute coronary syndromes (ACS).

In 142 patients with chest pain ( $\leq 12$ hours) and nondiagnostic ECG, blood samples for analysis of CK-MB, myoglobin and troponin $\mathrm{T}(\mathrm{tn}-\mathrm{T})$ were obtained initially every 30 minutes. For diagnosis of AMI a combination of myoglobin and CK-MB had a sensitivity at entry of $59 \%$, which increased by $5-10 \%$ every 30 minutes and reached $92 \%$ after two hours and $98 \%$ after six hours with a specificity of $93 \%$. Acute MI was safely ruled-out in $64 \%$ of non-AMI patients already after 3 hours using myoglobin.

The ability of using neural networks (NN) together with biochemical monitoring was assessed in 88 patients with chest pain $(<8 \mathrm{~h})$. Fifty patients were used for training of the $\mathrm{NN}$ and 38 patients for evaluation and comparison with clinicians. The diagnostic capacity for detection of AMI were high both for the NN and the clinicians, but the NN detected MI earlier. The NN predicted infarct size very early with a high accuracy.

In a placebo controlled study of l.m.w. heparin in unstable CAD, 976 patients were followed for 5 months. The risk of cardiac events increased by increasing $\mathrm{tn}-\mathrm{T}$ levels. Patients with $\mathrm{tn}-\mathrm{T}<0.06$, $0.06-0.18$ and $\geq 0.18 \mu \mathrm{g} / \mathrm{L}$ had a $4.3,10.5$ and $16.1 \%$ risk of MI or death, respectively. Tn-T level was an independent predictor of death or MI. In the 766 patients with a predischarge exercise test (ET) both tn-T level and ET response were independent predictors and the combination allowed categorisation into groups with 1,7 and $20 \%$ death or MI, respectively. In those with tn-T $\geq 0.1 \mu \mathrm{g} /$ Lat inclusion, the event rate after 40 days treatment were 14.2 and $7.4 \%(\mathrm{p}<0.01)$ in the placebo and dalteparin group, respectively. In contrast, there was no beneficial effect of dalteparin in those with tn- $\mathrm{T}<0.1 \mu \mathrm{g} / \mathrm{L}$.

The results contribute new and extended knowledge regarding the use of biochemical markers for early diagnosis and prognosis, which might have a large impact on the handling and treatment of patients with ACS.

Key words: myocardial infarction, unstable angina, diagnosis, prognosis, CK-MB, myoglobin, troponin $\mathrm{T}$, neural networks, low molecular weight heparin.

Bertil Lindahl, Dept of Cardiology, University Hospital, S-751 85 Uppsala, Sweden 

Comprehensive Summaries of Uppsala Dissertations

from the Faculty of Medicine 649

\section{Biochemical Markers of Myocardial Damage for Early Diagnosis and Prognosis in Patients with Acute Coronary Syndromes}

BY

BERTIL LINDAHL

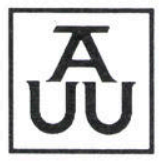

ACTA UNIVERSITATIS UPSALIENSIS

UPPSALA 1996 
Dissertation for the degree of medical science in Cardiology presented at Uppsala University in 1996

\section{ABSTRACT}

Lindahl, B. 1996. Biochemical markers of myocardial damage for early diagnosis and prognosis in patients with acute coronary syndromes. Acta Universitatis Upsaliensis. Comprehensive Summaries of Uppsala Dissertations from the Faculty of Medicine 649. 66 pp. Uppsala. ISBN 91-554-3847-4.

The present study evaluated the use of biochemical markers of myocardial damage for early diagnosis and prognosis in patients with acute coronary syndromes (ACS).

In 142 patients with chest pain ( $\leq 12$ hours) and nondiagnostic ECG, blood samples for analysis of CK-MB, myoglobin and troponin $\mathrm{T}(\mathrm{tn}-\mathrm{T})$ were obtained initially every 30 minutes. For diagnosis of AMI a combination of myoglobin and CK-MB had a sensitivity at entry of $59 \%$, which increased by 5 - $10 \%$ every 30 minutes and reached $92 \%$ after two hours and $98 \%$ after six hours with a specificity of $93 \%$. Acute MI was safely ruled-out in $64 \%$ of non-AMI patients already after 3 hours using myoglobin.

The ability of using neural networks $(\mathrm{NN})$ together with biochemical monitoring was assessed in 88 patients with chest pain $(<8 \mathrm{~h})$. Fifty patients were used for training of the NN and 38 patients for evaluation and comparison with clinicians. The diagnostic capacity for detection of AMI were high both for the NN and the clinicians, but the NN detected MI earlier. The NN predicted infarct size very early with a high accuracy.

In a placebo controlled study of l.m.w. heparin in unstable CAD, 976 patients were followed for 5 months. The risk of cardiac events increased by increasing tn-T levels. Patients with $\mathrm{tn}-\mathrm{T}<0.06,0.06-0.18$ and $\geq 0.18 \mu \mathrm{g} / \mathrm{L}$ had a $4.3,10.5$ and $16.1 \%$ risk of MI or death, respectively. Tn-T level was an independent predictor of death or MI. In the 766 patients with a predischarge exercise test (ET) both tn-T level and ET response were independent predictors and the combination allowed categorisation into groups with 1 , 7 and $20 \%$ death or MI, respectively. In those with $\mathrm{tn}-\mathrm{T} \geq 0.1 \mu \mathrm{g} / \mathrm{L}$ at inclusion, the event rate after 40 days treatment were 14.2 and $7.4 \%(\mathrm{p}<0.01)$ in the placebo and dalteparin group, respectively. In contrast, there was no beneficial effect of dalteparin in those with tn-T<0.1 $\mu \mathrm{g} / \mathrm{L}$.

The results contribute new and extended knowledge regarding the use of biochemical markers for early diagnosis and prognosis, which might have a large impact on the handling and treatment of patients with ACS.

Key words: myocardial infarction, unstable angina, diagnosis, prognosis, CK-MB, myoglobin, troponin $\mathrm{T}$, neural networks, low molecular weight heparin.

Bertil Lindahl, Department of Cardiology, University Hospital, S-751 85 Uppsala, Sweden

(C) Bertil Lindahl, 1996

ISSN 0282-7476

ISBN 91-554-3847-4

Printed in Sweden by Eklundshofs Grafiska AB, Uppsala 1996 
To my colleagues and patients,

Decision-making is ...

something which concerns all of us, both as makers of the choice and as suffers of the consequences.

$D$ Lindley 



\section{LIST OF PAPERS}

This thesis is based on the following papers, which will be referred to by their Roman numerals:

I Early diagnosis and exclusion of acute myocardial infarction using biochemical monitoring. Lindahl B, Venge P, Wallentin L, BIOMACS study group. Coronary Artery Disease 1995; 6: 321-328.

II Early assessment of patients with suspected acute myocardial infarction by biochemical monitoring and neural network analysis. Ellenius J, Groth T, Lindahl B, Wallentin L. Submitted, 1996.

III Relation between Troponin $\mathrm{T}$ and the risk of subsequent cardiac events in unstable coronary artery disease. Lindahl B, Venge P, Wallentin L, FRISC study group. Circulation 1996; 93: 1651-1657.

IV Risk stratification in unstable coronary artery disease: Additative value of troponin $\mathrm{T}$ determinations and predischarge exercise tests. Lindahl B, Andrén B, Ohlsson J, Venge P, Wallentin L, FRISC study group. Accepted for publication in European Heart Journal, 1996.

V Troponin T identifies patients with unstable coronary artery disease who benefit from long term antithrombotic protection. Lindahl B, Venge P, Wallentin L, FRISC study group. Accepted for publication in Journal of American College of Cardiology, 1996.

Reprints were made with permissions from the publishers 



\section{CONTENTS}

ABBREVIATIONS

INTRODUCTION

BACKGROUND

Definition of acute coronary syndromes (ACS) 9

Pathogenesis of ACS $\quad 10$

Prognosis in ACS $\quad 12$

Treatment alternatives in ACS 13

Biochemical markers of myocardial damage $\quad 15$

ECG for diagnosis and prognosis in ACS 23

Stress tests for evaluation of prognosis in ACS 24

Coronary angiography for prognosis in ACS 25

Neural networks for diagnosis in ACS 25

AIMS OF THE STUDY $\quad 26$

MATERIAL AND METHODS 26

Patients with suspected AMI $\quad 26$

Patients with unstable coronary artery disease $\quad 27$

Definitions of diagnoses and endpoints $\quad 27$

Laboratory analyses $\quad 28$

Neural networks $\quad 30$

Statistics $\quad 31$

RESULTS 32

Early diagnosis in patients with suspected AMI $\quad 32$

Prognosis in unstable CAD 37

DISCUSSION 41

Early diagnosis in patients with suspected AMI $\quad 42$

Prognosis in unstable CAD $\quad 46$

SUMMARY AND CONCLUSIONS 52

ACKNOWLEDGEMENTS

REFERENCES 


\section{ABBREVIATIONS}

$\mathrm{ACS}=$ acute coronary syndromes

$\mathrm{IHD}=$ ischemic heart disease

$\mathrm{MI}=$ myocardial infarction

AMI = acute myocardial infarction

$\mathrm{UA}=$ unstable angina

$\mathrm{CAD}=$ coronary artery disease

$\mathrm{MMD}=$ minor myocardial damage

$\mathrm{CHF}=$ congestive heart failure

$\mathrm{CK}=$ creatine kinase

$\mathrm{CK}-\mathrm{MB}=$ creatine kinase $\mathrm{MB}$

$\mathrm{Tn}-\mathrm{T}=$ troponin $\mathrm{T}$

Tn-I = troponin I

PTCA = percutaneous transluminal coronary angioplasty

$\mathrm{CABG}=$ coronary artery by-pass grafting

$\mathrm{ET}=$ exercise test

$\mathrm{NN}=$ neural networks

ASA = acetylsalicylic acid 


\section{INTRODUCTION}

Acute coronary syndromes (ACS), i.e. acute myocardial infarction (AMI) and unstable angina (UA), are among the leading causes of morbidity and mortality in Sweden. Approximately $20 \%$ of all patients visiting the emergency room at the departments of internal medicine have chest pain or other symptoms suggestive of ACS and two thirds of those, amounting to about 100.000 patients/year, will be admitted (1). Among those admitted, two thirds will get a diagnosis of definite or possible ischemic heart disease (IHD), including approximately $20 \%$ with a diagnosis of AMI $(1,2)$. Apparently, this population is very heterogeneous both regarding cause of symptoms, severity of underlying disease and prognosis. Hence, early diagnosis and prognostic evaluation are essential for application of appropriate acute treatment and further management. This early choice of treatment strategy has large implications both for the individual patient and for the costs of health care.

\section{BACKGROUND}

\section{Definition of Acute Coronary Syn- dromes (ACS)}

Ischemic heart disease can be divided into stable coronary artery disease (CAD) and in ACS, respectively. In stable $\mathrm{CAD}$, the ischemia commonly results from predictable increases in myocardial oxygen demand that outweighs the ability of the stenosed coronary artery to increase its delivery (3). In contrast, the ACS are characterised by abrupt and unpredictable reductions in coronary blood flow causing myocardial ischemia at rest or decreasing levels of exertion. The ACS constitute a continuum and the delimitation between the different forms is somewhat arbitrary in clinical practice, e.g. the distinction between unstable angina (UA) and non-Q-wave MI depends on an arbitrary choice of biochemical markers and their decision limits. Therefore, UA and non-Q-wave $\mathrm{MI}$ are often considered together as unstable $\mathrm{CAD}$, emphasising that the common denominator of these entities is the underlying unstable plaque.

Unstable angina is defined clinically, in the absence of ECG or enzymatic changes diagnostic of AMI, in presence of (4): (a) recent onset ( $<4$ weeks) of angina, which is brought on by minimal exertion; (b) crescendo angina, i.e. more severe, prolonged or frequent angina superimposed on a pre-existing stable effort angina or (c) angina at rest. Signs of ischemia such as ST-segment or T-wave deviations in the 12-lead ECG are common and supportive for a diagnosis of UA, but not obligatory.

Myocardial infarction is defined as 
necrosis of the myocardium due to interruption of its blood supply and thus a histological diagnosis. However, under clinical conditions AMI is defined as the presence of at least two of the following criteria: a) ischemic chest pain of at least 20 minutes duration, b) diagnostic ECG changes c) significant increases of cardiac enzymes (5). MI might, at autopsy, be subclassified according to the extent of the necrosis, as subendocardial or transmural, and clinically, according to findings in 12-lead ECG, into Qwave and non-Q-wave MI. Another, clinically valuable classification is into ST-elevation and non-ST-elevation MI, based on findings in the initial ECG.

Sudden ischemic cardiac death is defined as sudden death, of probable or proven ischemic origin, occurring within one hour from onset of symptoms.

\section{Pathogenesis of ACS}

Development of acute coronary syndromes

Atherosclerotic plaques in the coronary arteries result from a complex interaction between blood elements, disturbed flow and vessel wall abnormalities involving inflammation, smooth muscle cell migration and proliferation, matrix synthesis, lipid accumulation, necrosis, calcification and thrombosis (6). Key events in the development of ACS, in most cases, are a disruption of an atherosclerotic plaque and thrombus formation, leading to reduction in coronary blood flow causing myocardial ischemia or infarction (7-9). Although an individual severe stenosis more often becomes occluded than a less severe stenosis (10), MI and UA most frequently evolve from plaques causing only mild to moderate stenosis $(11,12)$. Mechanical and/ or hemodynamic forces may trigger plaque rupture by stressing a vulnerable plaque (9). Several factors influence the vulnerability of the plaque to rupture such as size and consistency of the atheromatous core, thickness and collagen content of the fibrous cap, inflammation within the cap and the phenomenon of cap fatigue (9). The extent and duration of thrombus formation might be influenced by local and systemic factors such as degree of disruption, severity of stenosis, balance between the thrombogenic and fibrinolytic systems and volume of residual thrombus after spontaneous or pharmacological lysis $(3,9,13)$. Other mechanisms that alter the balance between myocardial oxygen supply and demand may also be involved in the pathogenesis of ACS, e.g. coronary vasoconstriction (14-16).

\section{The various manifestations of ACS} (Fig 1)

Unstable angina: A small disruption of an atherosclerotic plaque may lead to a sudden increase in the size of the 


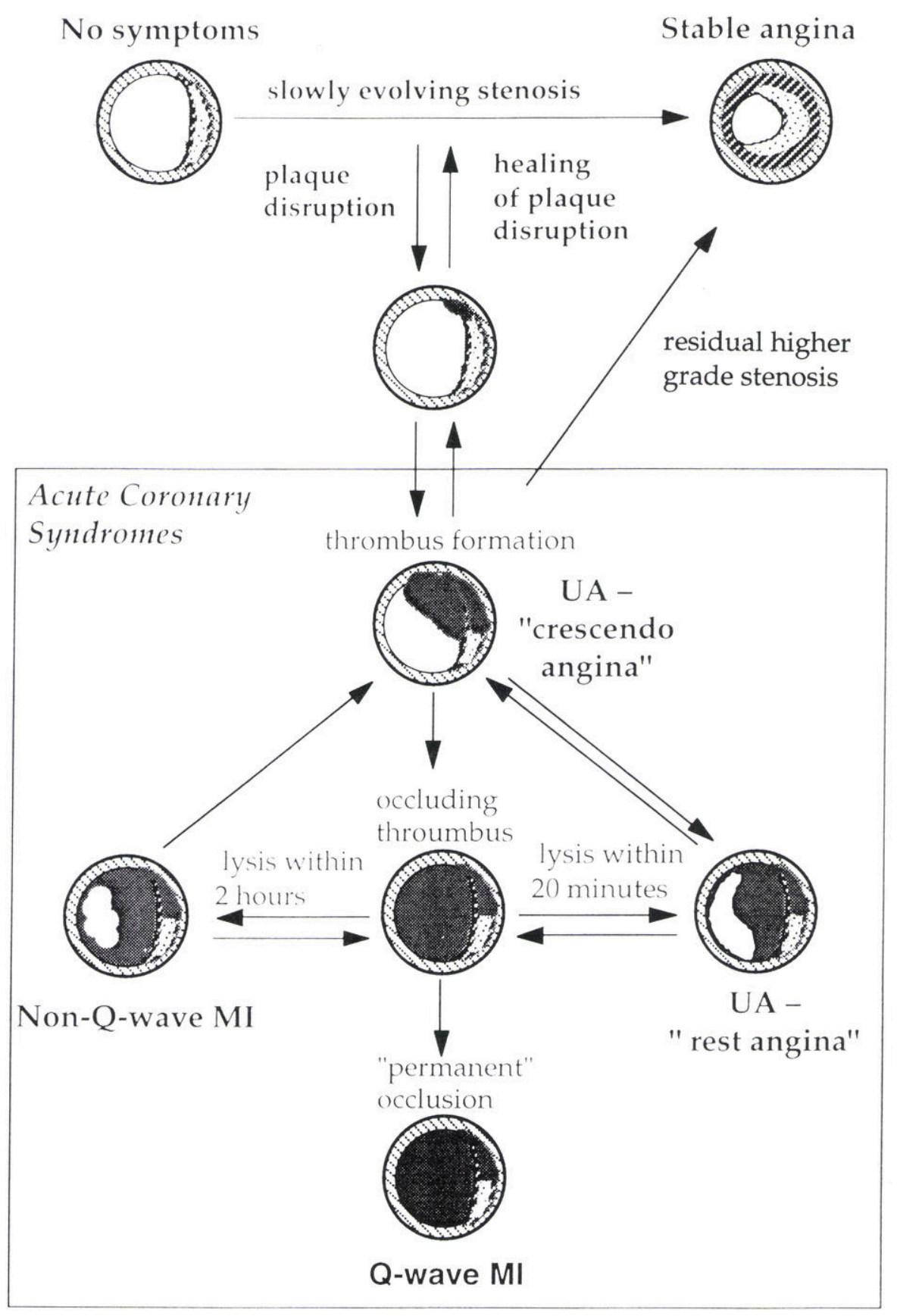

Figure 1. Development of acute coronary syndromes 
plaque impeding the coronary blood flow resulting in new or worsening symptoms of angina. A disruption complicated by a thrombus causing temporary and often recurrent occlusion, leads to episodes of angina at rest. These mechanisms probably accounts for two thirds of the episodes of UA. The rest might be caused by transient increase in myocardial oxygen demand or by complete occlusion of an artery with insufficient collateral supply (e.g. in postinfarction angina) $(3,17)$.

Non-Q-wave myocardial infarction: In non-Q-wave MI the thrombus is often larger, occlusive and less labile than in UA, probably because of worse plaque damage and/or presence of a more unfavourable balance between thrombogenic and fibrinolytic factors $(3,18)$. However, in about three fourths of patients with non-Q-wave MI the infarct-related artery is patent if coronary angiography is performed soon after the infarction (19). These findings, together with the changes in ECG:s and biochemical markers, suggest a pathophysiology with initial total thrombotic occlusion followed by spontaneous reperfusion before transmural necrosis has developed (3). In the remaining one fourth, the occlusion is permanent with protective collaterals limiting the infarct size $(19,20)$.
Q-wave myocardial infarction:In Q-wave MI there is typically a fixed, permanent, occlusive thrombus which, in the absence of adequate collaterals, leads to necrosis of the whole thickness of the involved myocardium (3, 21). However, development of Qwaves in the ECG does not always reflect transmural necrosis (22).

\section{Prognosis in acute coronary syn- dromes}

The risk of an unfavourable outcome varies not only between, but also within, the various clinical manifestations of ACS. Patients with UA seem to have a lower risk of death or MI than patients with non-Q wave MI (23). In a pooled analysis of 10 studies with almost 2000 patients with crescendo or rest angina, Betriu et al found a mean mortality of $4 \%$ (range $2-8 \%$ ) in-hospital and of $8 \%$ after 6 months. After one year the mortality was $10 \%$ and the rate of death or nonfatal MI 21 $\%$ (24). In a more recent large study of patients with UA or non-Q-wave MI the incidence of death and nonfatal MI after one year was 4.3 and $8.8 \%$, respectively (25). The in-hospital mortality is, in most comparative studies, higher in Q-wave than in non-Q-wave MI, whereas the long-term mortality seems to be equal $(26,27)$. The risk for development of reinfarction and UA are consistently higher after non- $Q$ wave MI (26-28). In a population based cohort study of prognosis after a first 
MI (28), the age and sex-adjusted oneyear risk was similar for death, 27.6 vs. $31.7 \%$; higher for reinfarction, 13.1 vs. 6.4, and lower for congestive heart failure, 10.1 vs. $19.3 \%$ in non-Q-wave compared to Q-wave MI.

\section{Treatment alternatives in acute coro- nary syndromes}

There are several goals of the treatment in ACS: amelioration of symptoms, limitation of myocardial damage, prevention of future cardiac events and progress of the underlying atherosclerotic process. Most patients are treated with a combination of antiischemic drugs, i.e. beta-blockers, organic nitrates, calcium inhibitors, and with thrombolytic and/or antithrombotic drugs and are also evaluated for the need of early revascularisation.

\section{Reperfusion treatment}

Reperfusion can be achieved either by lysing the occlusive thrombus by thrombolytic agents or by PTCA. With thrombolytic treatment some $40-80 \%$ of patients will have a patent infarct related vessel within 90 minutes from onset of treatment (29). Effective early reperfusion lowers mortality by reduction of the infarct size (30) and by other positive effects of an open artery, e.g. on the healing process and recovery of function (31). Thrombolytic treatment reduces the mortality by about $20 \%$ in AMI patients pre- senting with ST-segment elevation or bundle branch block (32). The earlier the treatment is given, the greater the benefit, but some benefit might be obtained up to 12 hours from onset of symptoms (32). Thrombolysis within the first two hours is particulary beneficial (33). Acute PTCA, at least performed at experienced centers, seems superior to thrombolytic treatment in reducing mortality, reinfarctions and stroke in patients with ST-segment elevation $(34,35)$.

No benefical effect of thrombolytic treatment was demonstrated in the limited number of patients studied withST-segment depression or T-wave inversion in the ISIS- 2 and GISSI-1 trials $(36,37)$. However, in a post-hoc analysis of the LATE-study, thrombolytic treatment in AMI patients presenting with $>2$ mm ST-segment depression was found to lower mortality (38). Thus, in the heterogeneous group of patients presenting with nondiagnostic ECG-changes, there may be subgroups with a developing large MI, who might benefit from thrombolytic treatment. Randomised trials with acute PTCA in AMI patients presenting with non-diagnostic ECG are lacking. Although most patients with UA have an ongoing thrombotic process, no beneficial effect of thrombolytic treatment on the risk of fatal or nonfatal MI has been shown $(39,40)$. 


\section{Antithrombotic treatment}

Antithrombotic agents, i.e. platelet and/or coagulation inhibitors, reduce thrombus formation, and might thereby prevent new cardiac events. The effectiveness of platelet inhibition by acetylsalicylic acid (ASA) in ACS is well documented $(36,41-43)$. Today ASA in doses of 75-325 mg daily, is part of the standard treatment. At present, several ongoing studies in ACS evaluate new platelet inhibitors e.g. inhibitors of glycoprotein IIb/ IIIa receptors, ADP receptors etc.

Heparin enhances the antithrombin III activity thereby accelerating its ability to inactivate thrombin, factor $\mathrm{Xa}$ and factor IXa. A pooled estimate from three studies $(42,44,45)$ in the acute phase of unstable CAD shows a $64 \%$ risk reduction of death or MI during heparin treatment in additon to ASA, compared to ASA alone (44). Low molecular weight heparins inhibit mainly factor Xa. They have a number of advantages over standard heparin, such as longer half-life, complete absorbtion after subcutaneous administration, more predictable anticoagulant response and probably less bleeding complications (46). In the FRISC trial the addition of subcutaneous l.m.w. heparin (dalteparin) twice daily reduced MI or death by $60 \%$ during the initial 6 days treatment in ASA treated patients with unstable CAD (47). Di- rect thrombin inhibitors offer a potential advantage over heparin as they are able to inhibit clot-bound thrombin. However, in two recent studies, infusion with direct thrombin inhibitors were not superior to heparin in ACS $(48,49)$. After cessation of heparin or other thrombin inhibitors a reactivation of thrombotic events has been documented $(50,51)$, suggesting a need for prolonged antithrombotic treatment in unstable CAD. Warfarin and other agents, inhibiting K-vitamin dependent coagulation factors, have been shown to have at least similar protective effect as ASA during long term treatment $(52,53)$.

\section{Revascularisation}

Revascularisation with either CABG or PTCA is effective in amelioration of symptoms in unstable CAD $(54,55)$. However, no difference in death or AMI was seen after two years in a study comparing medical and surgical treatment(CABG) for UA, although surgery was associated with a reduced mortality among patients with lower ejection fractions (56). Furthermore, the choice of an early conservative (intense medical treatment) or an early invasive strategy (mainly PTCA) did not influence the occurrence of death or AMI during follow up in the TIMI IIIB trial (25). The incidence of death or MI was fairly high, $12 \%$ after one year, suggesting that there is room for 
improvement, e.g. by a more intense long term antithrombotic treatment.

\section{Biochemical markers of myocardial} damage

\section{History}

Until the first report (1954) on glutamic oxaloacetic transaminase (ASAT) in AMI (57), the clinical diagnosis of MI relied solely on the history and on development of diagnostic Q-waves in the ECG. Since then, a number of enzymatic and non-enzymatic markers have been proposed for diagnosis of MI, e.g. lactic acid dehydrogenase (1956) (58) and creatine kinase (1960) (59). Today, biochemical markers are cornerstones in the diagnosis of MI, and timely obtained, almost a sine qua non (60).

\section{The ideal biochemical marker}

An ideal marker for diagnosis of MI should (adopted from 61): 1) exist in high concentration in the myocardium; 2) not exist in any other tissue, neither under normal, nor under pathological conditions; 3) not be measurable in plasma under normal conditions; 4) be released rapidly and completely after irreversible damage to the myocardium; 5) be released in direct proportion to the extent of myocardial necrosis; 6) persist in the plasma long enough to allow a convenient diagnostic time window; 7 ) be suitable for development of rapid, reliable and inexpensive methods for measurement.

However, an ideal marker for differing chest pain of ischemic origin from other causes and for prognostic use might demand other properties, e.g. be released also after reversible ischemic damage.

\section{Release of biochemical markers}

Myocardial ischemia, if not reversed, leads to a chain of cellular events ultimately ending with disruption of the cell membranes and cell death. When the cell membranes have lost their integrity, the cellular marker diffuses into the interstitium and, from there, into the capillaries (70-90\%) and lymphatics $(10-30 \%)(62,63)$. Whether the release of cytosolic markers always indicates cell death is controversial (61). There are several reports indicating that release also may occur from reversibly damaged cells (64-66). That a persistent release of structurally bound markers is due to irreversible damage is less controversial (67).

The appearance of the marker in the circulation depends on several factors: 1 ) size - smaller generally earlier than larger (62) (exception the large molecule glycogen phosphorylase-BB (68); 2) cellular localisation-cytosolic more rapidly than structurally bound (69); 3) solubility (61); 4) local degra- 
dation $(70) ; 5)$ regional lymphatic and blood flow $(71,72) ; 6)$ rate of clearance from the circulation (73).

\section{Specific markers}

\section{Creatine kinase / creatine kinase $M B$}

Creatine kinase $(\mathrm{CK})$ is an enzyme that catalyses the reaction Phosphocreatine $+\mathrm{ADP} \Leftrightarrow$ Creatine $+\mathrm{ATP}$. The $\mathrm{CK}$ activity is greatest in striated muscle, brain and heart muscle, but can also be found in other tissues. The enzyme is localised in the cytosol or associated with myofibrillar structures. The active form of $\mathrm{CK}$ is a dimer composed of two subunits, B ("brain") and $\mathrm{M}$ ("muscle"), respectively. Hence, three isoenzymes exists, all with a molecular weight of about $86 \mathrm{kD}$ : CK-BB (CK-1), CK-MB (CK-2) and CK-MM (CK-3) (Table 1). Furthermore, CK$\mathrm{MB}$ exists in two and CK-MM in three separate isoforms (Fig 2). A fourth, distinctly different isoenzyme (CK-Mt) located in the mitochondria is rarely observed in plasma. Macro CK, a complex of CK-BB and IgG or aggregates of mitochondrial CK, may be found in up to $4 \%$ of hospitalised patients (74).
The kinetics of CK is reasonably described by a two compartment model (73). There is no excretion of $\mathrm{CK}$ in the urine and the CK-level is not influenced by changes in renal or hepatic blood flow (73). CK is inactivated by proteolysis in lymph (71) and seems to be removed by the reticuloendothelial system (73).

In Sweden the catalytic activity of CK is analysed according to the IFCC/ ECCLS standards (75). For the isoenzyme, CK-MB, either the catalytic activity or the mass concentration is measured. For measurement of the catalytic activity, the immunoinhibition technique, in which the enzymatic activity of the M subunit is inhibited and the activity of the $\mathrm{B}$ subunit ("CK-B") is measured (76), is commonly used in Sweden. The mass concentration of CK-MB is determined by specific immunoassays. Numerous different immunoassays exist with variably reference ranges. Assays allowing determination of CK-MB in less than 10 minutes are available (77). The isoforms of CK-MB and CK-MM

Table 1. Isoenzymes of Creatine Kinase

\begin{tabular}{|c|c|c|c|}
\hline & CK-BB & CK-MB & CK-MM \\
\hline Tissue distribution & & & \\
\hline skeletal muscle & - & $<5 \% *$ & $>95 \%$ \\
\hline $\begin{array}{l}\text { heart muscle } \\
\text { other tissues** }\end{array}$ & & $25-45 \%$ & $55-75 \%$ \\
\hline $\begin{array}{l}\text { other tissues** } \\
\text { Isoforms }\end{array}$ & $>90 \%$ & - & $<10 \%$ \\
\hline Isoforms & none & $\mathrm{MB}_{2}+\mathrm{MB}_{1}$ & $\mathrm{MM}_{3}+\mathrm{MM}_{2}+\mathrm{MM}_{1}$ \\
\hline
\end{tabular}




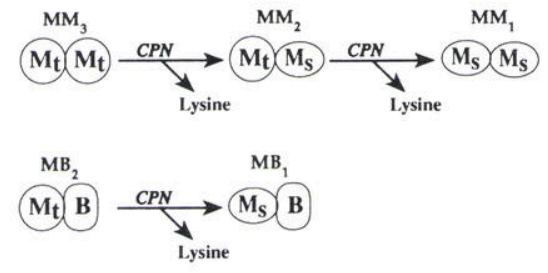

Figure 2. Isoforms of CK-MM and CK-MB. In blood the tissue isoform of CK-MM, $M M_{3}$ is converted to $M M_{1}$ via $M M_{2}$, and the tissue isoform of $C K-M B$, $M B_{2}$ is converted to $M B_{1}$ by plasma carboxypeptidase $N(C P N)$, which cleaves $C$-terminal lysine of tissuetype $M$ subunit. $B, B$ subunit; $M_{t}$ tissue-type $M$ subunit; $M_{s^{\prime}}$ serum-type $M$ subunit.

might be separated by electrophoresis, isoelectric focusing or chromatofocusing. A rapid high-voltage electrophoresis technique allows determination of CK-MB isoforms in less than 30 minutes (78).

\section{Myoglobin}

Myoglobin is a cytosolic oxygen binding protein with a molecular weight of $17.8 \mathrm{kD}$, found in skeletal and heart muscle, constituting $2 \%$ of the total muscle proteins. Myoglobin is cleared from the circulation by the kidneys (79). The kinetics of myoglobin is adequately described by a two compartment model (80). Under normal conditions the concentration in plasma is lower in females than in males, and increases with age and muscle mass (81). In the last years, immunoassays for rapid measurement ( $<15$ minutes) of Myoglobin have become available (82).
The troponins

The troponin complex, consisting of three subunits, $\mathrm{tn}-\mathrm{T}$, $\mathrm{tn}-\mathrm{I}$ and troponin $\mathrm{C}$, is located in the contractile apparatus of skeletal and heart muscle and regulates muscle contraction (Fig 3). The contractile proteins are sensitive to ischemia and damage to the proteins has been shown to occur already during the reversible phase of injury (83).

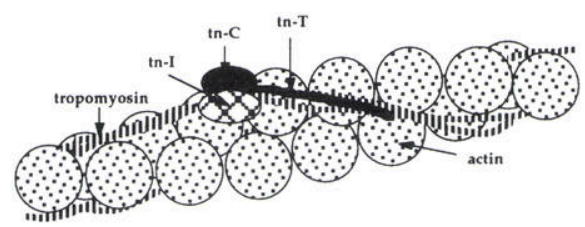

Figure 3. The troponin complex (tn-C, tn-I, tn-T) located on the thin filament of the contractile apparatus

Troponin $\mathrm{T}(\mathrm{tn}-\mathrm{T})$ is the tropomyosin binding subunit with a molecular weight of approximately $39 \mathrm{kD}$. It exists in three isoforms encoded by different genes in cardiac, slow and fast skeletal muscle (84). However, during fetal development the cardiac tn-T gene is also expressed in skeletal muscle. In experimental animals cardiac $\mathrm{tn}$ - $\mathrm{T}$ might be reexpressed in respond to skeletal muscle injury (85). Tn-T exists in an unbound cytosolic pool of approximately $6 \%$. The rest is structurally bound (86) explaining the biphasic release pattern and the wide 
Table 2. Definition of sensitivity, specificity, positive and negative predictive value

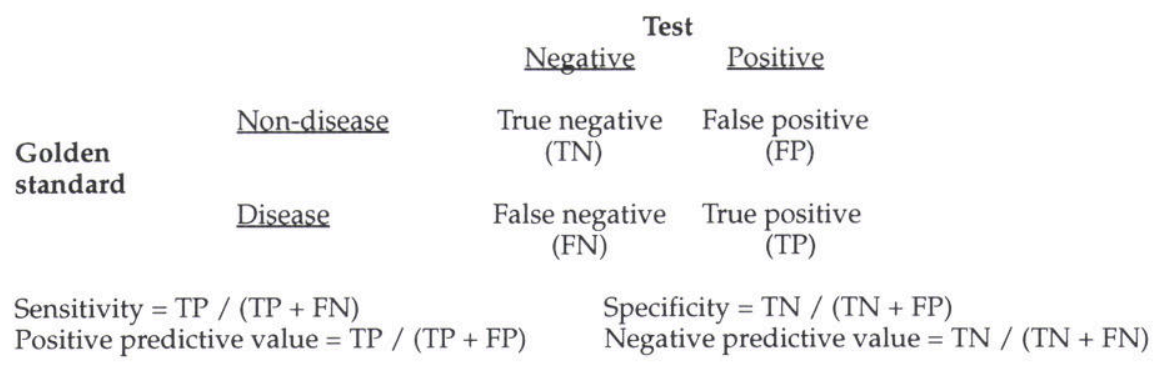

time window after myocardial injury, although the plasma half-life is only two hours (87). The only commercially available quantitative immunoassay for $t n-T$, which is based on the ELISA principle with two monoclonal antibodies, requires about 90 minutes (88). Recently, a rapid ( $<20 \mathrm{~min}$ ) qualitative assay for testing in whole blood has been developed (89).

Troponin I (tn-I) inhibits the actomyosin-ATPase. It also exists in three isoforms encoded by different genes in cardiac, slow and fast skeletal muscle (84). The molecular weight of cardiac tn-I is $22.5 \mathrm{kD}$. Cardiac tn-I is not expressed in skeletal muscle during fetal development (61). Tn-I also exists in a cytosolic pool, about 3-4\%, beside the structurally bound fraction $(90,91)$. There are now several different immunoassays commercially available. The detection limit and reference range varies substantially between the different assays $(61,92)$.

\section{Evaluation of diagnostic tests}

The sensitivity, specificity and predictive values (Table 2 ) of a test depend on several factors:

1) The comparator (golden standard) should ideally unequivocally define the disease. However, the golden standard for the diagnosis of $\mathrm{MI}$ is in mostevaluations the WHO-criteria (5), which are not very rigorously defined and might be inappropriate (60).

2) The study population - the size, the prevalence of the disease (Bayes' theorem) and the relevance of the tested population is important for the usefulness of the results. Use of only the "sickest of the sick" and the "wellest of the well" has to be avoided (93).

3) The decision threshold (Fig 4) unless the test completely separates the non-disease and disease populations, one has to choose a decision threshold that necessarily is a compromise. The optimal balance between sensitivity and specificity is a clinical decision depending on what 
are the relative costs of the false positive and false negative results (94). Combining several tests, e.g. two different biochemical markers, might be used to improve the diagnostic information. Requiring all tests in a combination to be positive, may increase the specificity, while requiring either test to be positive, may increase the sensitivity (95). Different decision thresholds might also be used for ruling-in and ruling-out the disease. Furthermore, the optimal decision threshold may vary with time, e.g. from onset of AMI (96). Receiver operating characteristic (ROC) curves are useful to elucidate decision thresholds (97).

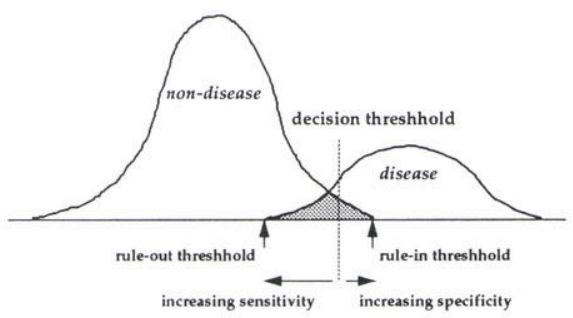

Figure 4. Relation between sensitivity and specificity

\section{Applications of biochemical markers}

Diagnosis of AMI

The usual times to initial elevation, peak value and normalisation of CK, CK-MB, myoglobin, tn-T and tn-I in AMI are summarised in Table 3. Typical examples of time curves for CKMB (mass), myoglobin and $\mathrm{tn}-\mathrm{T}$ in patients with MI are shown in Figure 5. Biochemical markers starts to increase earlier in patients with non-Q- wave MI and after reperfusion compared to non-reperfused Q-wave MI (100). The overall diagnostic sensitivity and specificity in patients with suspected MI is shown in Table 4 .

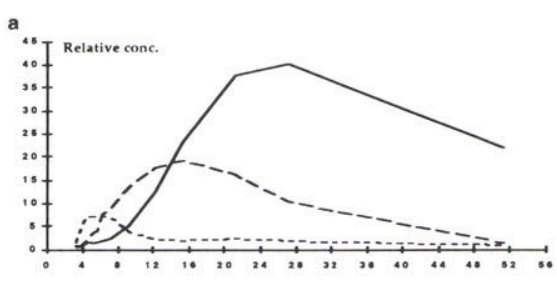

b

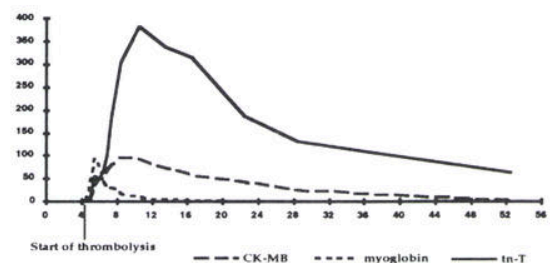

Figure 5. Representative time curves for $C K-M B$ (mass), myoglobin and troponin $T$ in patients with AMI. The $y$-axis shows relative concentration for each marker (acutal conc/upper reference limit), the $x$-axis time from onset of symptoms in hours. a) without thrombolytic treatment, $b$ ) with successful thrombolytic treatment

For retrospective confirmation of classical MI in a typical CCU population, the sensitivity and specificity of CKMB (mass) is satisfactory and sufficient as a sole marker, unless the patient is admitted very late (107). Despitehigher cardiospecificity than $\mathrm{CK}$ $\mathrm{MB}$, the troponins have a lower specificity due to the frequent elevations in patients with UA (87). This emphasises the arbitrary differentiation of MI from UA and the lack of an unequivocal golden standard. 
Table 3. Properties of biochemical markers used for diagnosis of acute MI $(61,92,98,99)$

\begin{tabular}{|c|c|c|c|}
\hline Marker & $\frac{\text { Time to initial }}{\text { elevation }}$ & $\begin{array}{l}\text { Time to peak } \\
\text { elevation }\end{array}$ & $\begin{array}{l}\text { Time to return } \\
\text { to normal }\end{array}$ \\
\hline CK & $4-8 h$ & $12-24 h$ & $3-4 d$ \\
\hline CK-MB(mass) & $3-9 h$ & $12-20 \mathrm{~h}$ & $48-72 h$ \\
\hline Myoglobin & $1-4 h$ & $6-12 h$ & $18-36 h$ \\
\hline Troponin $\mathrm{T}$ & $3-9 h$ & $12-24 h(4 d)$ & $6-14 d$ \\
\hline Troponin I & $3-9 h$ & $10-20 h$ & $4-8 d$ \\
\hline
\end{tabular}

Table 4. Summary of overall sensitivity and specificity for MI diagnosis (87, 90, 101-107)

$\begin{array}{lll}\text { Marker } & \text { Sensitivity } & \text { Specificity } \\ \text { CK } & 0.89-0.99 & 0.75-0.92 \\ \text { CK-MB (cat. activity) } & 0.85-0.98 & 0.90-0.92 \\ \text { CK-MB (mass) } & 0.89-1.00 & 0.79^{*}-1.00 \\ \text { Myoglobin (ref) } & 0.93-1.00 & 0.82-0.89 \\ \text { Troponin T } & 0.97-1.00 & 0.46^{*}-0.78 \\ \text { Troponin I } & 0.97 & 0.95\end{array}$

*Using very low cut-off levels of CK-MB $(5.0 \mu \mathrm{g} / \mathrm{L})$ and $\mathrm{tn}-\mathrm{T}(0.1 \mu \mathrm{g} / \mathrm{L})$, respectively

For very early diagnosis and exclusion of AMI, myoglobin, CK-MB isoforms and perhaps in the future, glycogen phosphorylase BB, seem to be the most promising markers. The diagnostic sensitivity and specificity of the markers in blood samples obtained at admission are summarised in Table 5 and the diagnostic sensitivity in relation to time since onset of symptoms in Table 6 . However, very little information is available on the use of different decision thresholds or on combinations of several markers for early diagnosis and exclusion of AMI.

\section{Prognosis in unstable angina}

Already in the seventies it was observed that many patients with UA had an increase of ASAT within the normal range (116). Also for total CK elevations in UA-patients were frequently observed (117). However, these transient, minor elevations are not possible to detect with "CK-B" (catalytic activity) probably because of a poor signal to noise ratio with the immunoinhibiton method $(117,118)$. With the use of more sensitive and cardiospecific markers up to $50 \%$ of patients with UA have minor elevations $(87,90,118-120)$. These elevations might either reflect "micro infarctions" or, possibly, reversible ischemic damage. The term "minor myocardial damage" (MMD) has therefore been proposed (121), further categorising the spectrum of acute coronary syndromes (Fig 6). In a few small trials MMD has been associated with an impaired short-term (122-124) 
Table 5. Sensitivity and specificity for MI diagnosis on admission in patients with suspected MI (82, 91, 99, 101, 108-111)

$\begin{array}{lll}\text { Marker } & \text { Sensitivity } & \text { Specificity } \\ \text { CK } & 0.15-0.46 & 0.79-0.98 \\ \text { CK-MB (cat. activity) } & 0.20-0.50 & 0.89-0.92 \\ \text { CK-MB (mass) } & 0.25-0.76 & 0.72-0.95 \\ \text { Myoglobin (ref) } & 0.30-0.75 & 0.83-1.00 \\ \text { Troponin T }(0.5 \mu \mathrm{g} / \mathrm{L}) & 0.28-0.64 & 0.72-0.96 \\ \text { Troponin I } & 0.23 & 0.94\end{array}$

Table 6. Diagnostic sensitivity for MI in relation to time since onset of pain $(69,78,82,91,99,106,112-115)$

$\underline{2 h} \quad \underline{4 h} \quad \underline{6 h}$

$\begin{array}{llll}\text { CK } & 0.08-0.46 & 0.19-0.65 & 0.39-0.88 \\ \text { CK-MB (activity) } & 0.00-0.18 & 0.14-0.40 & 0.19-0.88 \\ \text { CK-MB (mass) } & 0.25-0.49 & 0.42-0.71 & 0.58-1.00 \\ \text { CK-MB isoforms } & 0.08-0.13 & 0.56-0.59 & 0.92-0.96 \\ \text { Myoglobin } & 0.18-0.50 & 0.44-0.89 & 0.55-1.00 \\ \text { Tn-T } & 0.25-0.55 & 0.48-0.72 & 0.58-0.92 \\ \text { Tn-I } & 0.17-0.28 & 0.75 & 0.77-0.95\end{array}$

and long-term prognosis $(125,126)$, although its importance as an independent predictorhas been questioned (127). Hence, the prognostic value of tn-T needs to be confirmed in larger studies and compared with other known prognostic variables.

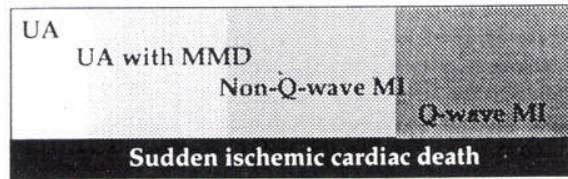

Figure 6. The spectrum of acute coronary syndromes

\section{Estimation of infarct size}

Assessment of infarct size by measurement of cumulative release of cardiac enzymes has been shown to closely correlate with histologic estimates of infarct size (128). However, the calculation of cumulative release is complicated and based on several assumptions (73), that may be affected by reperfusion therapy (129). In clinical praxis, needing only crude estimation of infarct size, the peak values allow qualitative estimates of infarct size (98). However, the higher peak values for the same infarct volume, in reperfused versus non reperfused patients (130) make the peak values less useful after thrombolysis. The release of structurally bound markers may be an alternative, i.e. the late peak of tn$\mathrm{T}$ day 3-5 correlated well with infarct size measured by scintigraphy regardless of reperfusion status (131).

For early prediction of infarct size the initial slope of the time curve for my- 
oglobin and CK, correlates well with the infarct size (132-134). However, no reliable and easily applicable method for early prediction of infart size has been clinically evaluated.

\section{Detection of reperfusion}

The rationale for biochemical monitoring to detect reperfusion is the accelerated release to the blood of the markers after successful reperfusion. The more rapid release may be due to an accelerated cellular leakage caused by the reperfusion, rather than increased regional blood flow (63). Of the markers the early rate of change of myoglobin and the isoforms of CK$\mathrm{MM}$ and CK-MB, have been most promising for detection of reperfusion, with a sensitivity and specificity of $>90$ and $>80 \%$, respectively $(135,136)$. However, in a recent prospective study of CK-MB, myoglobin, tn-T, CK-MB isoforms using all previously published cut-offs and algorithms, a considerable lower sensitivity and specificity was found (137). Thus, biochemical markers are at present not considered useful for early identification of reperfusion.

Causes of non-cardiac elevations of biochemical markers

Creatine kinase and CK-MB: After extreme exercise, larger muscle trauma (for total CK even minor muscle trauma), myositis and rhabdomyo- lysis, CK-MB originating from skeletal muscles might cause elevation in plasma levels (61). ACK-MB/totalCK ratio $>3-5 \%$ has been proposed to separate CK-MB elevations of cardiac origin from skeletal origin (138), but this has been questioned (139). Other causes of elevation are hypothyroidism (140) and renal failure (in about $5 \%$ (139)), as well as, brain damage, presence of macro-CK, gastrointestinal and prostate surgery, when analysing the catalytic activity with immunoinhibition technique (61).

Myoglobin: The only sources of myoglobin are heart and skeletal muscles. Strenuous exercise, trauma and diseases involving skeletal muscle cause elevation of myoglobin (100). Constant elevation is seen in renal failure (141).

Troponin T: With the development of new generations of the tn-T assay, the previously seen cross-reactivity with skeletal tn-Thas diminished (89). Thus, elevations of $\mathrm{tn}-\mathrm{T}$ in conjunction with acute trauma to healthy skeletal muscle, e.g. accidents or operations, are now rare. However, in patients with diseased and/or regenerating skeletal muscles there may be reexpression of cardiac $\mathrm{tn}-\mathrm{T}$ (85) giving false positive elevations, e.g. in polymyositis (142). Tn-T elevations of unknown origin 
are seen in about $30 \%$ of patients with chronic renal failure (143).

Troponin I: Tn-I seems to be highly specific to myocardial damage, no increase has been seen in patients without evidence of myocardial injury. Multiple trauma, chronic muscle diseases or chronic renal failure do not appear to affect Tn-I levels (61).

Causes of false negative results with biochemical markers

Inappropriate timing of the blood sampling is the principal cause of false negative results. The diagnostic time window is narrowest for myoglobin and widest for $\mathrm{tn}-\mathrm{T}$ (Table 3 ). The wide time window might, however, make it difficult to detect early reinfarctions. Inappropriate decision limits might be another cause, e.g. in the case of myoglobin, not having separate decision limits for men and women. High basal plasma concentration and large inter individual differences in concentration of a marker might make it difficult to detect elevations, e.g. for CK small infarctions may cause only elevation within the reference inter$\operatorname{val}(144)$.

\section{ECG for diagnosis and prognosis in}

\section{ACS}

\section{Diagnosis}

ECG-changes occur within seconds after onset of ischemia and make it possible to immediately detect, locate and estimate the extent of the ischemia/infarction. However, a single ECG recording shows only a snap shot of the very dynamic process of ischemia. In the early phase of ACS the ECG-changes frequently shift from one type to another (145). In some patients the usefulness of the ECG is limited by the occurrence of previous ECG-changes, e.g. bundle branch block.

Development of Q-waves is diagnostic of AMI and is part of the WHOcriteria (5). However, Q-waves do not develop until after several hours after an MI (146). Furthermore transient Qwaves might occur during ischemia (147). Initial ST-elevation is neither a prerequisite for or always associated with the development of Q-waves (148). On admission, ECG:s with STelevations, with or without Q-waves, are considered diagnostic of AMI. The specificity of ST-segment elevations is high, $>90 \%$ (149), but the sensitivity is poor, $<50 \%$ (150). The total sum of STelevation might be used for estimation of the extent of myocardium at risk of infarction (151). Other or no ECG-changes are considered as nondiagnostic ECG:s.

\section{Prognosis}

The prognostic significance of $Q$-wave versus non-Q-wave MI has been pointed out above. Increasing number of leads with ST-segment elevation 
and bundle branch blocks have been associated with a progressive increase in mortality and also with increasing benefit of early reperfusion $(32,152)$. In patients with non-Q-wave MI or UA the occurrence of ST-depression indicates an increased risk for adverse cardiac events (153).

\section{Continuous ECG monitoring}

In order to more closely follow the dynamic process of ischemia, different techniques for continuous ECG monitoring have been developed, i.e. Holter monitoring and on-line continuous 12-lead ECG or vector cardiographic(VCG)monitoring. These techniques have been used for detection of coronary artery disease (154), identification of reperfusion $(155,156)$ and prognostic evaluation of patients with IHD (157-159). In patients with ACS repeated episodes of ST-depression indicate an adverse prognosis (158160).

\section{Stress tests for evaluation of progno- sis in ACS}

\section{Exercise test}

The prognostic value of ET after an episode of unstable CAD has been convincingly demonstrated (161-165). A predischarge symptom limited ET can be safely done after an episode of unstable CAD (166) and has the same diagnostic value as an ET performed after one month (167). However, an early ET is more useful for prognostic evaluation, since the risk of new events is greatest the first few weeks after an episode of unstable CAD (167). The diagnostic and prognostic value is considerably greater in symptom limited compared to submaximal ET (168). Not only the occurrence of STdepression, but also several other parameters such as low work capacity, low rate-pressure product, blood pressure reaction and occurrence of chest pain are associated with an adverse outcome (162-165). A combination of ST-depression and limited work capacity has been shown to increase the prognostic value of the ET (165). A substantial proportion of patients with unstable CAD is unable to perform an ET. However, the inability to perform an ET itself indicates an adverse prognosis (169). No study in patients with unstable CAD has so far compared and combined the prognostic value of predischarge ET with that of the new sensitive biochemical markers.

\section{Myocardial scintigraphy}

Occurrence of perfusion defects on myocardial perfusion scintigraphy has been shown to relate to an adverse outcome in patients with ACS (170), although contradicting studies exist (171). Pharmacological stress is an alternative to dynamic exercise, especially in patients who are unable to exercise. SPECT thallium-201 scintigraphy has been shown to have additional prognostic value to an symp- 
tom limited exercise test in patients with unstable CAD (172) and to be superior to exercise echocardiography for prediction of new cardiac events in patients with UA (170).

\section{Stress echocardiography}

Stress echocardiography can be performed during or immediately after dynamic exercise or during pharmacological stress (173). Stress induced wall motion abnormalities have been shown to have prognostic significance in patients with ACS in most (174, 175), but not all studies (171).

\section{Coronary angiography for progno- sis in ACS}

The long term prognosis in patients with ACS depends on the extent of coronary lesions. Complex coronary morphology, multivessel disease, especially with associated left ventricular dysfunction are signs of an unfavourable prognosis $(56,176,177)$. However, coronary angiography has obvious limitations. It lacks sensitivity for detection of intracoronary thrombus and plaque rupture, which are important for prognosis (178). Furthermore, the site of a subsequent MI can not reliably be predicted by coronary angiography (12). Because of limited availability and resources coronary angiography is seldom used for routine risk stratification.
Neural networks for diagnosis in ACS

In the early management of patients with acute chest pain the clinician has to sort out a multitude of gradually incoming information in making decisions regarding diagnosis, treatment and prognosis. Therefore, some kind of decision support by a computer system, e.g. based on artificial neural network methodology, might be useful.

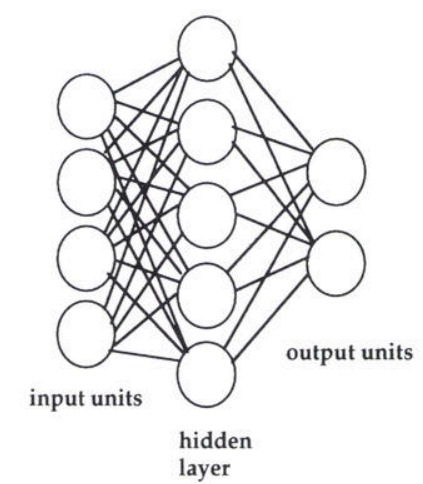

Figure 7. Schematic example of a neural network structure

An artificial neural network is a group of interconnected mathematical equations that accept input data and calculate an output conclusion (Fig 7)(179). The input-patterns of measured variables are classified as belonging to one of several pre-defined categories by pattern recognition. This is achieved by "training" of the network with use of a number of representative example cases and their corresponding correct classifications as defined by a 'golden standard'. The network will 
learn to correctly classify a major portion of the patterns in this training set by a technique called 'supervised learning'. When exposed to a new, not yet classified case, the network uses its previous training and its capability of generalisation when assigning it to a specific diagnostic category. Artificial neural networks have been applied for AMI diagnosis based on clinical data including ECG (180) and biochemical markers (181). However, so far no study has evaluated the use of neural networks for early diagnosis of AMI and infarct size prediction based on biochemical markers.

\section{AIMS OF THE STUDY}

In patients with suspected AMI:

evaluate if early frequent blood sampling ("monitoring") of CK-MB (mass), myoglobin and tn- $\mathrm{T}$ alone or in combination could provide a definite positive or negative diagnosis within the first few hours after admission in patients with nondiagnostic ECG (paper I);

evaluate neural network methodology, based on frequent measurement of biochemical markers of myocardial damage, for early diagnosis/exclusion of AMI, early prediction of infarct size, estimation of time from onset of infarction and assessment of minor myocardial damage (paper II).
In patients with unstable CAD:

elucidate the prognostic value of $\mathrm{tn}-\mathrm{T}$ in a large cohort of patients with unstable CAD, and to compare tn- $\mathrm{T}$ with other known early and widely available risk indicators (paper III);

evaluate, compare and combine the prognostic value of tn- $\mathrm{T}$ with a predischarge exercise test and other clinical findings in a large cohort of patients with unstable CAD (paper IV);

evaluate the protective effect of treatment with l.m.w. heparin (dalteparin) in relation to risk stratification by $\mathrm{tn}-\mathrm{T}$ levels in patients with unstable CAD (paper V).

\section{MATERIAL AND METHODS}

\section{Patients with suspected AMI (paper} I - II)

In the BIOMACS (BIOchemical Markers in Acute Coronary Syndromes) study, patients admitted to the coronary care units at six hospitals in Sweden were eligible for participation from December 1991 to June 1992. The inclusion criterion was a history of chest pain suggestive of AMI starting within the previous 12 hours. Exclusion criteria were anaemia $(\mathrm{Hb}<110$ $\mathrm{g} / \mathrm{l})$, systolic blood pressure below $100 \mathrm{~mm} \mathrm{Hg}$ on admission or refusal to participate. 
The 142 patients with nondiagnostic ECGchanges at admission constituted the study population in paper I and all 88 patients with onset of chest pain within the previous 8 hours and, in case of AMI, not given thrombolytic treatment, constituted the study population in paper II.

\section{Patients with unstable coronary ar- tery disease (paper III - V)}

The FRISC (FRagmin during InStability in Coronary artery disease) study - a double blind, randomised, placebo controlled trial of low molecular weight heparin (dalteparin sodium, Fragmin", Pharmacia AB, Sweden) included patients with unstable CAD at 23 hospitals in Sweden between May 1992 and October 1994 (47). In 15 hospitals the protocol included a special blood sampling schedule and from which the tn-T substudy patients were recruited. Eligible for inclusion were men or women aged over 40 years admitted to hospital because of myocardial ischemia demonstrated both by a) symptoms i.e. either new-onset angina pectoris last two months, increasing angina pectoris last two months or ongoing chest pain suggestive of MI and with the last episode of chest pain within 72 hours, and by b) signs of myocardial ischemia in 12 lead ECG at rest i.e. in two contiguous leads either ST-depression of $\geq 0.1 \mathrm{mV}$ or T-wave inversion, or both. The exclusion criteria were mainly related to increased risk of bleeding, indication for thrombolytic treatment and serious intercurrent diseases. The patient recruitment and study populations are outlined in Figure 8.

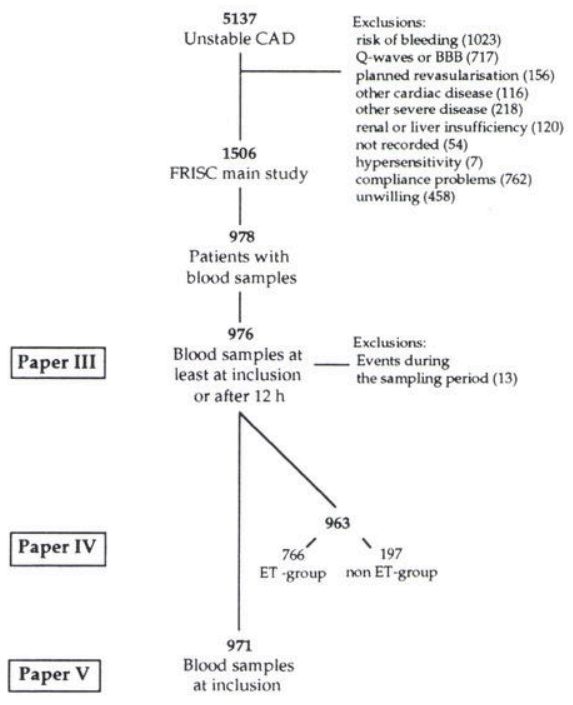

Figure 8. Patient recruitment and study populations in Paper III - V

Definitions of diagnoses and endpoints

\section{1) BIOMACS (paper I - II)}

a. AMI was considered present if at least two of three of the following criteria were fulfilled (182): chest pain lasting more than $20 \mathrm{~min}$; evolution of typical changes in at least two leads of the ECG; typical enzyme leakage, in at least one of the blood samples taken at $0,6,12,18$ or 24 hours after admission, i.e. a CK-MB $\geq 20 \mu \mathrm{g} / \mathrm{l}$; or a total creatine kinase for men $>6.0 \mu \mathrm{kat} / \mathrm{l}$, for women $>5,0 \mu \mathrm{kat} / 1$ together with a 
CK-MB $\geq 10 \mu \mathrm{g} / 1$; or in at least two blood samples a creatine kinase $>3.0$ $\mu \mathrm{kat} / 1$ (men) or $>2.5 \mu \mathrm{kat} / 1$ (women) together with in at least one sample a CK-MB $\geq 10 \mu \mathrm{g} / 1$.

b. IHD was considered present if the patienthad pathologicalST-or T-wave changes in the ECG at rest or a positive exercise test or had a history of prior MI, CABG, PTCA or diagnostic coronary angiography.

c. $\underline{\mathrm{MMD}}$ was considered present if $\mathrm{tn}$ $\mathrm{T}$ maximum was $\geq 0.2 \mu \mathrm{g} / \mathrm{L}$ and/or if $\mathrm{CK}-\mathrm{MB}$ maximum was $\geq 8.0 \mu \mathrm{g} / \mathrm{L}$.

d. The infarct size (paper II) was arbitrary labelled "major" if peak plasma $\mathrm{CK}-\mathrm{MB}$ mass conc. was $>80 \mu \mathrm{g} / \mathrm{L}$ and "minor" if peak CK-MB mass conc. was $\leq 80 \mu \mathrm{g} / \mathrm{L}$.

e. Onset of infarction (paper II): the stated time for onset of symptoms by the patient was critically examined by an expert clinician and possibly adjusted if found not to correspond with the expected time for onset of infarction based on the pattern of biochemical markers.

\section{2) FRISC (paper III - V)}

a. Index event: all patients with elevated maximal levels of creatine kinase-MB ( $n=666), C K(n=152), C K-B$ $(n=112)$ and ASAT $(n=45)$, were retro- spectively classified as having non-QMI, all other patients as having UA.

b. End points: all patients were followed while in hospital and thereafter by outpatient visits after 6 weeks and 5-6 months. Occurrence of and time for death, MI and revascularisation was recorded. All deaths and nonfatal MI:s were classified by an independent end point committee. MI was defined by conventional WHO criteria (5). Causes of death were, whenever possible, based on autopsies. Sudden death was considered cardiac.

\section{Laboratory analysis}

\section{Biochemical markers}

In BIOMACS (paper I - II) venous blood samples were drawn from an indwelling forearm venous catheter according to the time schedule in Figure 9. In FRISC (paper III - V) venous blood samples were obtained at inclusion and after 12, 24, 48 and 120 hours. In both studies the blood was collected in EDTA containing tubes and centrifuged. The plasma was frozen in aliquots and stored for subsequent central analysis.

Analyses of CK, CK-MB, myoglobin and $\mathrm{tn}-\mathrm{T}$ in BIOMACS, and of $\mathrm{tn}-\mathrm{T}$ in FRISC were done at one laboratory and without knowledge of the patients diagnosis and outcome. The methods of the analyses are summa- 
Table 7. Methods for analyses and upper reference limits of the biochemical markers $(75,88,183,184)$

$\begin{array}{llll}\text { Marker } & \text { Method } & \begin{array}{l}\text { Upper reference limit } \\ \text { men } 3.0 \mu \mathrm{kat} / \mathrm{L} \\ \text { women } 2.5 \mu \mathrm{kat} / \mathrm{L}\end{array} & \text { I - II } \\ \text { CK-MB } & \begin{array}{l}\text { IFCC/ECCLS } \\ \text { standards (ref) }\end{array} & \begin{array}{l}\text { NovoClone system } \\ \text { (Novo BioLabs) }\end{array} & \text { I - II } \\ \text { Tn-T } & \begin{array}{l}\text { Enzymun-Test system } \\ \text { (Boehringer Mannheim) }\end{array} & \begin{array}{l}0.2 \mu \mathrm{g} / \mathrm{L}^{*} \\ 0.06 \mu \mathrm{g} / \mathrm{L}\end{array} & \text { I - II } \\ \text { Myoglobin } & \text { RIA-method (ref) } & \text { III - V } \\ & & \text { men } 90 \mu \mathrm{g} / \mathrm{L} & \\ & & & \text { I - II }\end{array}$

*discrimination limit

rised in Table 7. In FRISC, analyses of S-CK-MB (mass), S-CK-B, S-CK or SASAT were done locally at each participating hospital in connection with the index event according to local routines and the maximal value were noted in the case record forms.

\section{ECG at rest}

Standard 12-lead ECGs were obtained on admission and after 24 and 48 hours in BIOMACS (paper I-II), and at inclusion, after 24 hours and at time for the ET (day 5 - 8) in FRISC (paper III-I).
All ECGs were interpreted centrally according to a modification of the Minesota code (182) and without knowledge of the patients diagnosis and outcome.

\section{Exercise test}

In BIOMACS a symptom limited exercise test was performed before discharge in most patients without verified -AMI. In the FRISC trial a predischarge symptom limited ET was performed day 5-8 in all patients without any contraindications. All ET:s

Hours from admission

$\begin{array}{lllllllllll}0 & 1 & 2 & 3 & 4 & 6 & 9 & 12 & 18 & 24 & 48\end{array}$

Blood samples

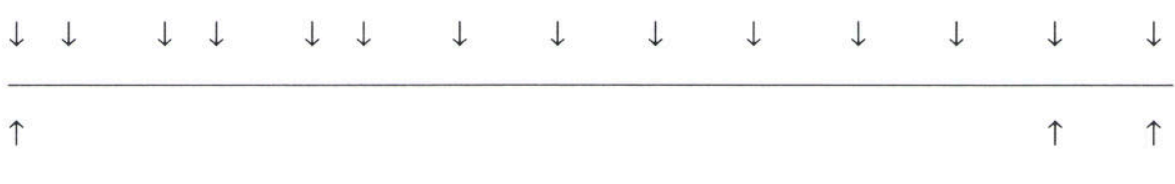

ECG:s

Figure 9. Schedule of blood and ECG sampling in Paper I - II 
were performed on electrically braked bicycle ergometers according to a standardised, previously presented, procedure $(165,185)$ and were interpreted centrally. Computer-aided systems and thus, averaged ECG complexes were used if available (in almost all ET:s in the FRISC study). The ST segment was measured $0.06 \mathrm{sec}-$ onds after the J-point and related to the PQ segment. In case of ST-depression at rest, the changes were related to the ST-level in the ECG immediately before the start of the test. Contraindications to an ET were: MI less than four days before the ET, appearance of new ECG-changes last two days, ongoing chest pain, recurrent episodes of chest pain at rest or at slight effort, overt heart failure at time of the ET, physical handicap or other conditions precluding an ET.

In BIOMACS a positive exercise test was defined as typical chest pain and/ or development of ST-depression of at least $0.1 \mathrm{mV} 60 \mathrm{~ms}$ after the J-point during or immediately after exercise. In FRISC a combination of a low maximal work load and the number of leads with ST-depression was used to define, according to previous experiences $(165,185)$, "high risk exercise test response" = low maximal work load in combination with ST-depression of $\geq 0.1 \mathrm{mV}$ in $\geq 3$ leads; "intermediate risk exercise test response" = either a low maximal work load or ST- depression of $\geq 0.1 \mathrm{mV}$ in $\geq 3$ leads and "low risk exercise test response" = neither low maximal work load nor ST-depression of $\geq 0.1 \mathrm{mV}$ in $\geq 3$ leads. A low maximal work load was defined as a work load below the 33rd percentile of the distribution for men $(90 \mathrm{~W})$ and women $(70 \mathrm{~W})$, respectively, in the total patient material.

\section{Neural networks (paper II)}

The method was implemented in a computer system designed in a modular fashion, where each module performs a specific task of computation (Fig 10). The pre-processed measurement values were first taken as input to computational modules that were used for the detection of AMI. Different methods were used depending on whether the measurement was the first one from that patient or not. If AMI was detected, the system made a prediction of the infarct size, and an esti-

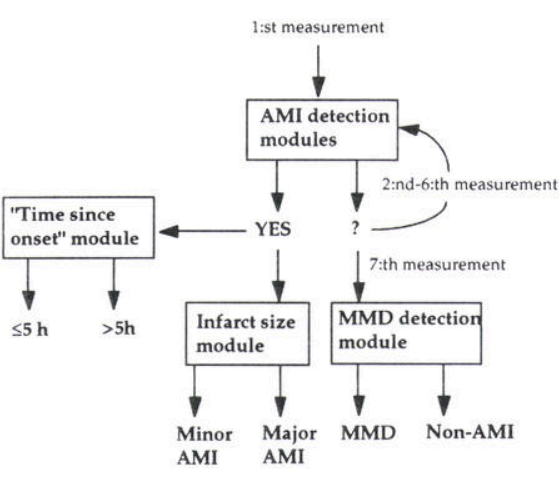

Figure 10. Design of the computer method using different modules for different tasks 
Table 8. Neural network structures used in the computations

\section{Type of classification}

AMI/non-AMI

on first measurement

on repeated measurements

Major/Minor AMI

MMD/non-MMD

Time from onset

\section{Neural Network Structure}

Multiple single-layer perceptrons

Elman recurrent network

Single-layer perceptron

Elman recurrent network

Multiple single-layer perceptrons
Input Variables

normalised and fuzzified Myo, CKMB, TnT

normalised and fuzzified Myo, CKMB, TnT

normalised

Myo, CKMB, TnT $\delta \mathrm{Myo}, \delta \mathrm{CKMB}, \delta \mathrm{TnT}$

normalised and fuzzified Myo, CKMB, TnT

normalised and fuzzified Myo, CKMB mate of the time that had elapsed since onset of infarction. If, however, AMI was not detected after a predefined optimal period of monitoring ( 3 hours), AMI was excluded from the list of possible diagnoses. In this case the remaining task for the system was to make an assessment of whether the patient was suffering from an MMD. The types of neural network structures and sets of input variables for the various classification problems are summarised in Table 8.

The 88 patients included in this study were divided into one 'training set' of 50 patients, and one 'test set' of 38 patients. The data in the test set were only used for the evaluation process. The performance of the computer method was compared to the assessment by three experienced clinicians and to the diagnostic rules proposed in paper I. The clinicians, in contrast to the neural networks, had access to data about age, gender, time since onset of symptoms and ECG on admission, in addition to the results of the biochemical markers.

For assessment of the time since onset of myocardial infarction the training and test sets, were both extended for the training and evaluation of theneuralnetwork module. Each of the first 7 measurements (with 30 min intervals) of these AMI patients was counted as a separate case, increasing the number of cases in the test set from 11 to 77 . This artificial extension changed the prevalence with regard to arrival times from onset of symptoms. Therefore the predictive values were corrected to the prevalences derived from the Uppsala University Hospital/CCU database (RiksHIA) for the same category of patients admitted to the CCU during 1994.

\section{Statistics}

At-test was used to compare means of numeric data. For non-parametric unrelated data the Mann-Whitney test 
was used. Differences in proportions were judged by chi-square analysis or binomial tests as appropriate.

The clinical usefulness of the tested methods regarding diagnosis was evaluated by calculation of diagnostic sensitivity, specificity, positive predictive value and negative predictive value in comparison to the diagnosis according to "golden standard".

The cumulative hazard curves were constructed using the Kaplan-Meier method. Statistical assessment was performed using the log-rank test.

To identify variables of prognostic importance, simple and forward stepwise multiple logistic regression analyses were used.

In paper $V$ all analyses were performed according to the intention-to-treat principle in comparisons between the placebo and dalteparin groups. The relative risk ratio (RR) and the 95\% confidence interval (CI) were calculated as appropriate. Test for interaction between dalteparin/placebo treatment and tn-T level on the risk of death or MI was done by a multiple logistic regression analysis.

A significant difference was considered to exist at the $\mathrm{p}<0.05$ level.All statistical analyses were performed by a computer utilising the SPSS system (Statistical Package for the Social Sciences, 1990 and 1994).

\section{RESULTS}

Early diagnosis in patients with suspected AMI (paper I \&II)

Frequent analyses and combinations of biochemical markers (paper I)

\section{Ruling in AMI}

Clinical characteristics of the patients included are shown in Table 9.

Table 9. Base-line characteristics in patients with and without acute myocardial infarction (AMI) in paper I. Number of patients (\% of group)

$\begin{array}{lccc} & \begin{array}{c}\text { No AMI } \\ (\mathbf{n}=\mathbf{8 3})\end{array} & \begin{array}{c}\text { AMI } \\ (\mathbf{n}=59)\end{array} & \\ \text { Age, mean } \pm \text { s.d. } & 67 \pm 9.4 & 68 \pm 11 & \\ \text { Male } & 55(66) & 47(80) & \\ \text { Previous myocardial infarction } & 28(34) & 22(37) & \\ \text { Hours since onset of chest pain } & 6.1 \pm 2.9 & 6.0 \pm 3.0 & \\ \text { till first blood sample, mean } \pm \text { s.d. } & & & \\ \begin{array}{l}\text { Admission electrocardiogram } \\ \quad \text { Bundle branch block }\end{array} & 9(11) & 15(25) & \mathrm{p}<0.05 \\ \quad \text { ST-depression and T-inversion } & 24(29) & 29(49) & \mathrm{p}<0.05 \\ \quad \text { Only ST-depression } & 5(6) & 7(12) & \\ \quad \text { Only T-inversion } & 17(21) & 3(5) & \mathrm{p}<0.01 \\ \quad \text { No sign of ischemia } & 28(34) & 5(9) & \mathrm{p}<0.001 \\ \text { Thrombolytic therapy } & 9(11) & 25(42) & \mathrm{p}<0.001 \\ \text { Defibrillation } & 0(0) & 0(0) & \\ \text { Deaths during hospital stay } & 0(0) & 7(12) & \mathrm{p}<0.001\end{array}$


Table 10. Cumulative sensitivity / specificity for diagnosis of acute MI at different time points after admission for the different markers and for different cut-off levels (*men/women)

Marker

$\underline{0 \mathrm{~h}}$

Conventional cut-off levels

CK-MB $(20 \mu \mathrm{g} / \mathrm{L})$

tn-T $(0.5 \mu \mathrm{g} / \mathrm{L})$

myoglobin $(108 / 68 \mu \mathrm{g} / \mathrm{L})^{*}$

Low cut-off levels

CK-MB $(10 \mu \mathrm{g} / \mathrm{L})$

tn-T $(0.2 \mu \mathrm{g} / \mathrm{L})$

myoglobin $(90 / 57 \mu \mathrm{g} / \mathrm{L})^{*}$
$0.41 / 1.00$

$0.24 / 0.98$

$0.83 / 0.81$

$0.59 / 0.93$

$0.59 / 0.83$

$0.89 / 0.73$

Cumulative sensitivity and specificity for different cut-off levels of myoglobin, CK-MB, tn-T and for different combinations of the markers at different time points were evaluated up to six hours after admission. The sensitivity and specificity for detecting AMI using "conventional" and "low" cut-off levels of myoglobin, CK$\mathrm{MB}$ and $\mathrm{tn}-\mathrm{T}$, are shown in Table 10. Partly because of our definition of AMI there was no false positive case for CK-MB using "conventional" cut-off levels. For $\mathrm{tn}-\mathrm{T}$ the false positive cases were found entirely in the IHD-group, while there were also some false positives in the group without evidence of IHD for myoglobin. The increase in sensitivity using "low" cut-off levels was at the expense of a decrease in specificity. However, for CK-MB all and for tn- $\mathrm{T}$ all except one, of the "false positive" cases were found in the group with IHD.

A combination of myoglobin and CK$\mathrm{MB}$ (MyCK) and a combination of

Time from admission

$3 \mathrm{~h}$

$6 \mathrm{~h}$

$\begin{array}{ll}0.90 / 1.00 & 0.93 / 1.00 \\ 0.80 / 0.93 & 0.92 / 0.88 \\ 0.92 / 0.72 & 0.95 / 0.71 \\ & \\ & \\ 0.95 / 0.81 & 0.98 / 0.78 \\ 0.92 / 0.69 & 0.98 / 0.66 \\ 0.98 / 0.64 & 0.98 / 0.60\end{array}$

myoglobin and $\mathrm{tn}-\mathrm{T}$ (MyT) were tested (Fig 11). For MyCK the sensitivity was 0.59 in the first sample, 0.92 at two hours and 0.98 at six hours, the corresponding results for MyT were 0.59, 0.82 and 0.98 , respectively. Correspondingly the specificities of MyCK and MyT decreased from 0.98 and 0.94 , respectively, for the first blood sample to 0.93 and 0.82 , respectively, after six hours. For MyCK all, and for MyT all but one, of the false positive cases were found in the group with ischemic heart disease. The sensitivity using the MyCK-combination in patients with $\leq 4,4-8$ and $>8$ hours delay from onset of symptoms until admission, are shown in Figure 12. No significant difference could be shown in sensitivity between patients with and without thrombolytic treatment in these three groups.

\section{Ruling out AMI}

Based on the fact that the decision threshold for ruling out might be different from that for ruling in a diagno- 


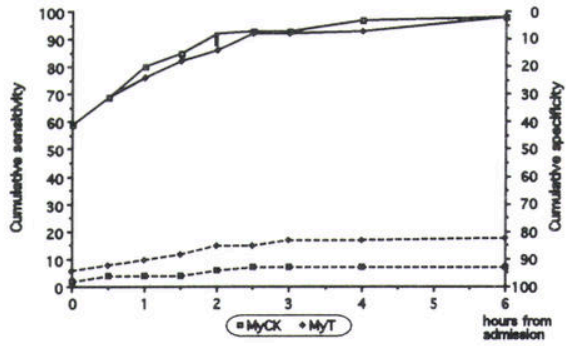

Figure 11. Cumulative diagnostic sensitivity (solid line) and specificity (broken line) for MyCK and MyT, respectively, during the first 6 hours after admission. MyCK: (1) CK-MB $\geq 20 \mu \mathrm{g} / \mathrm{L}$ or (2) myoglobin $>90 \mu \mathrm{g} / \mathrm{L} />57 \mu \mathrm{g} / \mathrm{l}$ (men/women) and $C K-M B \geq 10 \mu g ; M y T$ : (1) $t n-T \geq 0.5 \mu \mathrm{g} / \mathrm{L}$ or (2) myoglobin $>90 \mu \mathrm{g} / \mathrm{L} />57 \mu \mathrm{g} / \mathrm{l}$ and $t n-T \geq 0.2$

sis (compare Fig 5), criteria for rulingout AMI were developed and tested after three and six hours of monitoring. The criteria and the proportion correctly ruled-out and falsely ruledout after 3 and 6 hours of monitoring, respectively, are shown in Figure 13.

\section{Neural network methodology and bio- chemical monitoring (paper II)}

Comparison with clinicians

Clinical characteristics of the patients included are shown in Table 11.

The computer method identified AMI earlier than the clinicians (Table 12). Sensitivity, specificity and predictive values for detection of AMI were high and not significantly different for the computer method and the clinicians (Table 13).

The computer method detected MMD faster and with a higher sensitivity and higher positive predictive value

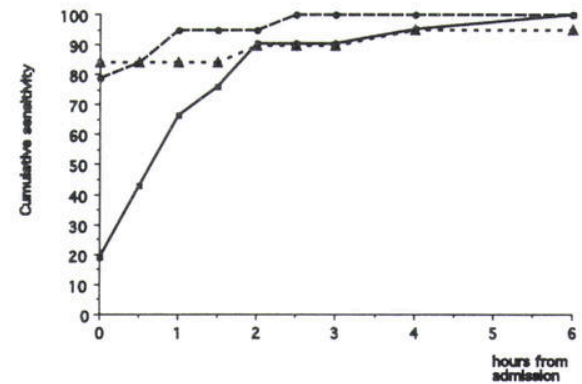

Figure 12. Cumulative diagnostic sensitivity for MyCK in patients with onset of symptoms $\geq 4 \mathrm{~h}$ (solid line), 4-8h (broken line) and 8-12 h (dotted line). For definition of MyCK, see Figure 11.

than the clinicians (Table $12 \& 13$ ). The computer method correctly assessed MMD in 5 of 8 patients whereas for the clinicians, the best single result was 3 correct assessments.

The clinicians excluded AMI and MMD within 0-540 minutes with an average of 130 minutes compared to 180 minutes in all cases for the compu-

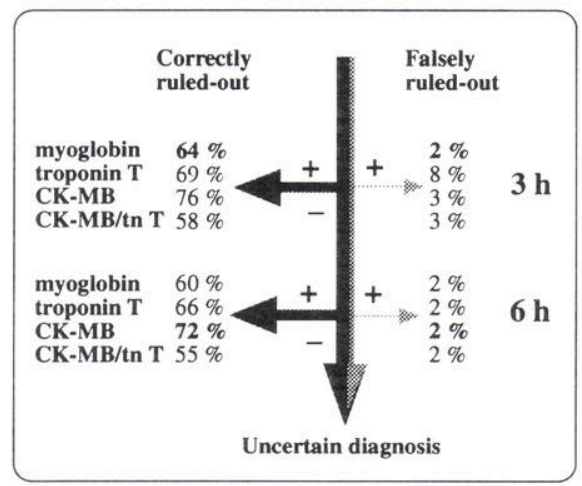

Figure 13. Percentage of correctly and falsely excluded AMI in all patients 3 and 6 hours after admission. Tested criteria for ruling out AMI: 1) no sample of myoglobin $\geq 90 \mu \mathrm{g} / \mathrm{L}$ ( $\geq 57$ for women), 2) no sample of $t n-T \geq 0.2 \mu \mathrm{g} / \mathrm{L}, 3)$ no sample of $C K-M B \geq 10 \mu \mathrm{g} / \mathrm{L}$, and 4) no sample of $C K-M B \geq 8 \mu \mathrm{g} / \mathrm{L}$ or $\mathrm{tn}-\mathrm{T} \geq 0.2 \mu \mathrm{g} / \mathrm{L}$. 
Table 11. Clinical characteristics in patients in the training and test set in paper II. Percentage in brackets.

\author{
Age (years) \\ Male \\ Previous myocardial infarction \\ Previous CHF \\ Angina pectoris \\ Diabetes \\ Hours since onset of chest pain \\ until first blood sample \\ ECG on admission \\ Q-wave \\ ST-segment elevation \\ ST-segment depression \\ T-inversion \\ Bundle branch block \\ No signs of ischemia

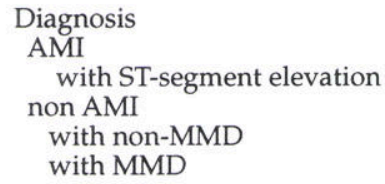

Deaths during hospital stay

ter method (Table 12). The specificity and the positive predictive value for the computer method were higher than for the clinicians (Table 13).

\section{Comparison with diagnostic rules}

The sensitivity and specificity in the test set were exactly the same for the diagnostic rules for early diagnosis of AMI and the computer system, 1.0 and 0.93 , respectively. However, the diagnostic rule required a slightly longer time to diagnosis, the mean time delay to AMI diagnosis was 14 compared to 6 minutes. At 3 hours after admission, the computer system had correctly ruled-out $89 \%$ of the patients in the test set with non-AMI,

$\begin{array}{cc}\begin{array}{c}\text { Training set } \\ \mathrm{n}=50\end{array} & \begin{array}{c}\text { Test set } \\ \mathrm{n}=38\end{array} \\ 68 \pm 8 & 66 \pm 11 \\ 41(82) & 28(74) \\ 16(32) & 19(50) \\ 12(24) & 7(18) \\ 45(70) & 26(68) \\ 2(4) & 7(18) \\ & \\ 4.3 \pm 1.8 & 4.5 \pm 1.5 \\ & \\ 9(18) & 12(32) \\ 8(16) & 11(29) \\ 23(46) & 16(42) \\ 31(62) & 17(45) \\ 6(12) & 5(13) \\ 6(12) & 8(21) \\ & \\ 18(36) & 11(29) \\ 6(12) & 4(8) \\ 32(64) & 27(71) \\ 17(34) & 19(50) \\ 15(30) & 8(21) \\ & \\ 3(6) & 1(3)\end{array}$

none had an uncertain diagnosis while the remaining $11 \%$ were incorrectly classified as AMI in the previous step. The same figures for the diagnostic rules 3 hours after admission were 63 $\%, 26 \%$ and $11 \%$, respectively.

\section{Prediction of infarct size}

The computer method needed 30 and 38 minutes of monitoring time to make a correct prediction while the clinicians required 119 and 260 minutes on the average, for a correct prediction of major and minor infarctions, respectively. The computer method and the clinicians did not differ significantly in terms of sensitivity (1.0 vs. 0.83 ), specificity ( $0.80 \mathrm{vs} .0 .93$ ) and positive 
Table 12. Time delay, expressed as number of measurements and minutes since start of measurements, to a correct diagnosis for the computer method and the clinicians. Turnaround time for laboratory analysis is not included. The range is given in brackets.

\begin{tabular}{|c|c|c|c|c|}
\hline \multirow[b]{2}{*}{ Test for } & \multicolumn{2}{|c|}{ Computer method } & \multicolumn{2}{|c|}{ Clinicians' assessment } \\
\hline & $\begin{array}{l}\text { Number of } \\
\text { measurements }\end{array}$ & Time delay & $\begin{array}{l}\text { Number of } \\
\text { measurements }\end{array}$ & Time delay \\
\hline AMI & $\begin{array}{l}1 \\
{[1,2]}\end{array}$ & $\begin{array}{l}6 \min \\
{[0,30]}\end{array}$ & $\begin{array}{l}2 \\
{[1,5]}\end{array}$ & $\begin{array}{l}20 \min \\
{[0,120]}\end{array}$ \\
\hline Non-AMI with MMD & $\begin{array}{l}7 \\
{[7,7]}\end{array}$ & $\begin{array}{l}180 \min \\
{[180,180]}\end{array}$ & $\begin{array}{l}8 \\
{[2,11]}\end{array}$ & $\begin{array}{l}573 \mathrm{~min} \\
{[30,1080]}\end{array}$ \\
\hline $\begin{array}{l}\text { Non-AMI without } \\
\text { MMD }\end{array}$ & $\begin{array}{l}7 \\
{[7,7]}\end{array}$ & $\begin{array}{l}180 \min \\
{[180,180]}\end{array}$ & $\begin{array}{l}5 \\
{[1,10]}\end{array}$ & $\begin{array}{l}130 \mathrm{~min} \\
{[0,540]}\end{array}$ \\
\hline
\end{tabular}

Table 13. Diagnostic performance of the computer method and the clinicians. Results are expressed as average and range (in brackets).

Test for

\section{Measures of diagnostic performance}

AMI

sensitivity

specificity

pos. predictive value

neg. predictive value

Non-AMI with MMD

$$
\text { sensitivity }
$$

specificity

pos. predictive value

neg. predictive value

Non-AMI without MMD

sensitivity

specificity

pos. predictive value

neg. predictive value

\section{Computer method}

1.00

[11/11]

0.93

[25/27]

0.85

1.00

0.62

$[5 / 8]$

1.00

[30/30]

1.00

0.91

1.00

[19/19]

0.95

[18/19]

0.95

1.00
Clinicians' assessment

1.00

[11/11, 11/11]

0.95

$[25 / 27,26 / 27]$

0.90

$[0.85,0.92]$

1.00

$[1.00,1.00]$

0.34

$[2 / 8,3 / 8]$

0.98

$[29 / 30,30 / 30]$

0.83

$[0.75,1.00]$

0.84

$[0.83,0.85]$

0.97

[18/19, 19/19]

0.79

[14/19, 16/19]

0.82

$[0.79,0.86]$

0.96

$[0.94,1.00]$ 
( 0.86 vs. 0.95 ) and negative predictive values (1.0 vs. 0.85$)$ for prediction of major infarct.

Estimation of "time since onset of infarction"

Sensitivity, specificity, positive and negative predictive value for the computer method to identify patients with $\leq 5$ hours from "onset of infarction" were $0.51,0.91,0.91$ and 0.51 , respectively. The positive predictive value implied that a positive test result has a high probability of being true and therefore might be considered in the clinical decision making. However, the negative predictive value was low.

\section{Prognosis in unstable CAD (paper III-V)}

Clinical characteristics of the patients included in paper III-V are shown in Table 14.

\section{Tn-T for early risk assessment (paper} III)

The prognostic value of tn-T was evaluated on the basis of the maximal tn-T value obtained during the first 24 hours. The median $\mathrm{tn}$-T maximum was $0.33 \mu \mathrm{g} / 1$ (range: $<0.04-19.0$ ) and the first, second, third and fourth quintiles were $0.06,0.18,0.62$ and $2.12 \mu \mathrm{g} / \mathrm{L}$, respectively. An increase in the rate of cardiac death or MI was seen from lower to higher quintiles of $\mathrm{tn}$ - $\mathrm{T}$ (Fig 14). A low risk group (the lowest quintile), an intermediate risk group (the second quintile) and a high risk group (the three upper quintiles) for cardiac death or MI were thus identified (Table 15). Also the five month risk for cardiac death alone increased from the lowest to the highest quintile, $0,2.0,2.1,6.8$ and $8.8 \%$, respectively (pooled log rank $\mathrm{p}<0.0001$ ). The risk of cardiac death or MI was higher in patients with the index event classified as non-Q compared to UA, 17.6 versus $9.5 \%(p<0.001)$. However, even within the UA group there was an increase of cardiac death or MI from lower to higher levels of tn-T (Table 15).

The prognostic value of $\mathrm{tn}$-T was compared to other early and easily available clinical or laboratory variables, using the univariate and multivariate forward stepwise logistic regression analysis. Tn-T level, number of anti anginal drugs at admission, increas-

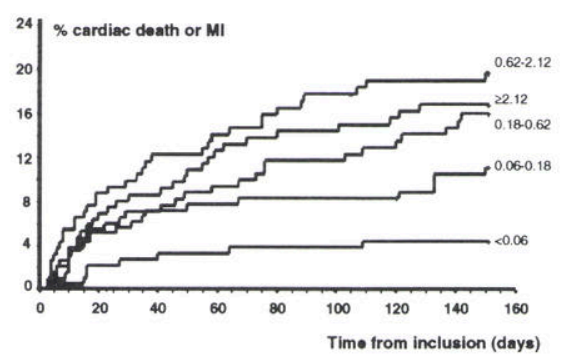

Figure 14. Cumulative risk and time of occurrence of cardiac death or MI in groups based on quintiles of maximal troponin T levels $(\mu \mathrm{g} / \mathrm{L})$. The number of patients in each group (lowest through highest quintile) was 187, 201, 190, 191 and 194, respectively. Pooled log rank $p<0.0001$. 
Table 14. Clinical characteristics of the study populations in papers III-V. Statistical comparisons are made between the ET and non-ET group (IV), and between the placebo and dalteparin group in each tn- $T$ subset $(V)$. All figures are given as percentage unless for median age and median delay.

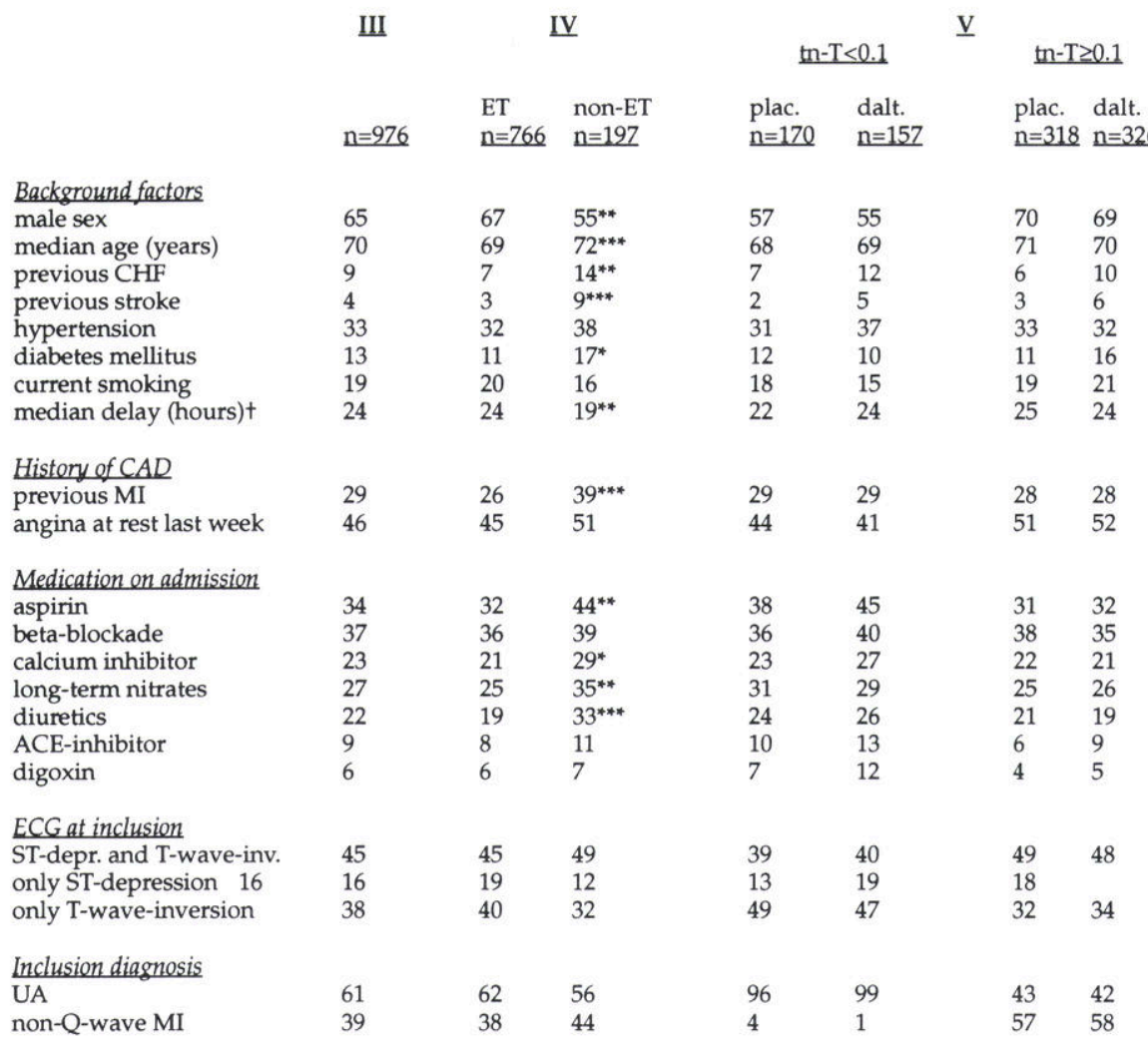

ing age, ST-depression in the 12-lead ECG at inclusion and hypertension were identified as independent prognostic variables for MI or cardiac death at 5 months. The inclusion diagnosis (non-Q-MI or UA) did not add any independent prognostic information. The prognostic value of $\mathrm{tn}-\mathrm{T}$ was also compard to CKMB.CK-MB (mass) was analysed by the Imx method (Abbott Laboratories) at the local hospital immediately following the index event in 620 patients. The incidence of car- diac death or MI was $8.7 \%$ in those with CK-MB below the upper reference limit in healthy persons $(6 \mu \mathrm{g} / \mathrm{L})$, $15,8 \%$ in those with CK-MB 6-15 $\mu \mathrm{g} /$ $\mathrm{L}$ and $16.9 \%$ in those with CK-MB above the discrimination limit for AMI diagnosis $(15 \mu \mathrm{g} / \mathrm{L})$. In the group of patients with $\mathrm{CKMB}<6 \mu \mathrm{g} / \mathrm{L}$ there was a higher risk of cardiac death or MI, 13.0 versus $4.6 \%(\mathrm{p}<0.05)$, among those with $\mathrm{tn}-\mathrm{T} 0.06-0.18 \mu \mathrm{g} / \mathrm{L}(\mathrm{n}=108)$ compared to those with tn- $\mathrm{T}<0.06$ $\mu \mathrm{g} / \mathrm{L}(\mathrm{n}=109)$. 
Comparison and combination of $t n-T$ and predischarge ET (paper IV)

During the five months follow-up 73 and 23 (10 and $13 \%$, NS) patients suffered an AMI, 22 and 13 (2.9 and 7.2 $\%, \mathrm{p}<0.01)$ patients died a cardiac death, and 243 and 83 (32 and $42 \%$, $\mathrm{p}<0.01$ ) had CABG or PTCA among the 766 patients in the ET group and among the 181 patients with contraindications to the ET in the non-ET group, respectively.

A "low", "intermediate" and "high risk" ET response was present in 361 (47\%), 325 (42\%) and 80 (10\%) patients, respectively. $\mathrm{Tn}-\mathrm{T}$ maximum $<0.06,0.06-0.2$ and $\geq 0.2 \mu \mathrm{g} / \mathrm{L}$ was observed in 154 (20\%), 175 (23\%) and $437(57 \%)$ patients, respectively. With increasing risk category, both of maximal $\mathrm{tn}-\mathrm{T}$ and ET response, there was a successive increase in the rates of cardiac death alone and in the combined endpoint MI or cardiac death after five months. However, the rates of CABG or PTCA increased only in relation to the ET response (Table 16).
In the forward stepwise multiple logistic regression analyses regarding cardiac death or MI at 5 months only the categories of exercise test response and maximal $\mathrm{tn}$ - $\mathrm{T}$ level were identified as variables of independent prognostic value. The incidence of cardiac death or MI after five months in subsets divided according to a combination of the ET response and the maximal tn-T level are shown in Figure 15. The subset with $1 \%$ risk might be considered a definite low risk group, the four subsets with $5-10 \%$ risk might be summarised into an intermediate risk group and the four subsets with $>15 \%$ risk into a high risk group. The rates of cardiac death or MI were 1, 7 and $20 \%$ after five months in these low, intermediate and high risk groups, respectively. In the non-ET group the incidence of cardiac death or MI were $3 \%, 16 \%$ and $27 \%$ after five month (pooled log rank, $\mathrm{p}=0.01$ ), in patients with maximal troponin $\mathrm{T}$ level $<0.06,0.06-0.2$ and $\geq 0.2 \mu \mathrm{g} / \mathrm{L}$, respectively.

Table 15. Incidence of cardiac death or MI (\%) during 5-months follow up in relation to tn-T levels in the whole study population and in those with UA as index event, respectively.

Index event

UA or MI (n=963)

$\mathrm{UA}(\mathrm{n}=581)$

$$
<0.06 \mu \mathrm{g} / \mathrm{L}
$$

4.3

4.4

\section{Tn-T levels}

$0.06-0.18 \mu \mathrm{g} / \mathrm{L} \quad \geq 0.18 \mu \mathrm{g} / \mathrm{L}$

$10.5+$

$11.4+$
$16.1^{*}$

$14.1 \ddagger$

Log rank ${ }^{*} p=0.05,+p<0.05$, each group compared to the group on its left.

Log rank $\ddagger p<0.01$, each group compared to the second group on its left.

$\mathrm{UA}=$ unstable angina; $\mathrm{MI}=$ myocardial infarction. 
Table 16. Comparison of tn-T and ET regarding different endpoints after five months in the ET-group $(n=766)(\%)$

\begin{tabular}{|c|c|c|c|c|c|c|}
\hline & $\begin{array}{l}<0.06 \\
\mu \mathrm{g} / \mathrm{L} \\
\mathrm{n}=154\end{array}$ & $\begin{array}{l}\text { Troponin } \\
0.06-0.2 \\
\mu \mathrm{g} / \mathrm{L} \\
\mathrm{n}=175\end{array}$ & $\begin{array}{l}\geq 0.2 \\
\mu \mathrm{g} / \mathrm{L} \\
\mathrm{n}=437\end{array}$ & $\begin{array}{l}\text { low risk } \\
\text { response } \\
\mathrm{n}=361\end{array}$ & $\begin{array}{l}\text { Exercise test } \\
\text { interm. ris } \\
\text { response } \\
n=325\end{array}$ & $\begin{array}{l}\text { high risk } \\
\text { response } \\
n=80\end{array}$ \\
\hline $\begin{array}{l}\text { Cardiac death } \\
\text { Cardiac death/MI } \\
\text { CABG/PTCA }\end{array}$ & $\begin{array}{l}0(0) \\
7(5) \\
42(27)\end{array}$ & $\begin{array}{l}3(2) \\
16(9) \\
61(35)\end{array}$ & $\begin{array}{l}19(4)+\dagger \\
58(13)+\dagger \\
140(32)\end{array}$ & $\begin{array}{l}3(1) \\
17(5) \\
70(19)\end{array}$ & $\begin{array}{l}11(3)^{*} \\
41(13)^{* * * *} \\
123(38)^{* * *}\end{array}$ & $\begin{array}{l}8(10)^{*++t+} \\
23(29)^{* * *++t+} \\
50(63)^{* * *++t}\end{array}$ \\
\hline
\end{tabular}

${ }^{*} p<0.05,{ }^{* *} p<0.01,{ }^{* * *} p<0.001$, each group compared to the group on its left

$+\mathrm{p}<0.05,++\mathrm{p}<0.01,+++\mathrm{p}<0.001$, each group compared to the second group on its left

Effects of dalteparin treatment in relation to troponin T level (paper $V$ )

To study the treatment effect of dalteparin in relation to the $\mathrm{tn}-\mathrm{T}$, the patients were first divided into tertiles of the $t n-T$ level at inclusion, i.e. below the $33 \mathrm{rd}$ percentile $(<0.1 \mu \mathrm{g} / \mathrm{L})$, between the 33rd and 66th percentile (0.1-0.64 $\mu \mathrm{g} / \mathrm{L})$ and above the 66th percentile $(\geq 0.64 \mu \mathrm{g} / \mathrm{L})$. At termination of the long-term treatment, day 40 , there was no beneficial effect in the lowest $\mathrm{tn}$ - $\mathrm{T}$ tertile, while there seemed to be a similar decrease in death or MI in the middle and highest tertile. Thus, for the further analyses the patients

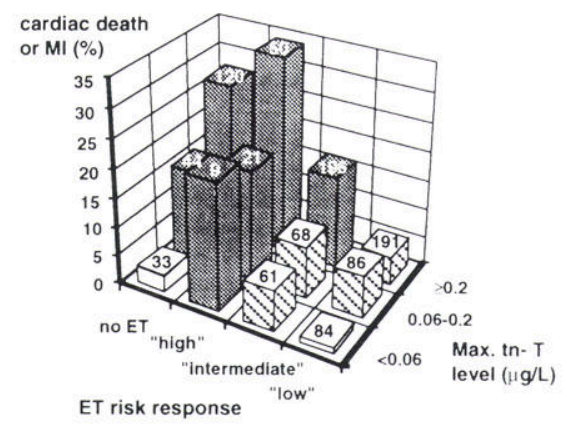

Figure 15. Five months risk of cardiac death or MI in relation to exercise test response and maximal troponin T levels. The numbers on the bars denote the number of patients in each group. were divided according to tn-T level $<0.1$ and $\geq 0.1 \mu \mathrm{g} / \mathrm{L}$.

In patients with $\operatorname{tn}-\mathrm{T} \geq 0.1 \mu \mathrm{g} / \mathrm{L}$, the difference in endpoint rate between the placebo and dalteparin group was significant already after the acute phase, and increased further during the long-term treatment. In contrast, in patients with $\mathrm{tn}-\mathrm{T}<0.1 \mu \mathrm{g} / \mathrm{L}$, there was no difference between dalteparin and placebo during long-term treatment (Table 17 and Fig 16). The interaction between treatment and tn- $\mathrm{T}$ level and the tn-T level alone, but not the treatment alone, remained as statistically significant indicators of the risk of death or MI after 40 days in a multivariate logistic regression analysis. After termination of the randomised treatment, the difference in deaths or MIbetween the dalteparin and placebo groups of patients with tn- $\mathrm{T} \geq 0.1 \mu \mathrm{g} /$ L slowly decreased and only a trend of benefit in the dalteparin group remained at the last follow up after 150 days ( 16.0 vs. $20.4 \%$; RR 0.78, $95 \%$ CI 0.56-1.09). 
Table 17. Endpoint rate (\%) in relation to tn-T level at inclusion in patients with placebo (Pl) and dalteparin (Da) treatment, respectively $(n=971) . R R=$ relative risk. $C I=$ confidence interval

\begin{tabular}{|c|c|c|c|c|c|c|c|c|c|}
\hline \multirow{2}{*}{$\begin{array}{l}\text { tn-T } \\
(\mathrm{Pl} / \mathrm{Da})\end{array}$} & \multicolumn{3}{|c|}{$\begin{array}{l}\text { death/MI } \\
\text { day } 6\end{array}$} & \multicolumn{3}{|c|}{$\begin{array}{l}\text { death/MI } \\
\text { day } 40\end{array}$} & \multicolumn{3}{|c|}{$\begin{array}{l}\text { revascularisation } \\
\text { day } 40\end{array}$} \\
\hline & $\mathrm{Pl}$ & $\mathrm{Da}$ & $\begin{array}{c}\text { RR } \\
(95 \% \mathrm{CI})\end{array}$ & $\mathrm{Pl}$ & $\mathrm{Da}$ & $\begin{array}{c}\mathrm{RR} \\
(95 \% \mathrm{CI})\end{array}$ & $\mathrm{Pl}$ & $\mathrm{Da}$ & $\begin{array}{c}\mathrm{RR} \\
(95 \% \mathrm{CI})\end{array}$ \\
\hline $\begin{array}{l}<0.1 \mu g / \mathrm{L} \\
(170 / 157)\end{array}$ & 2.4 & 0 & ${ }^{*} \mathrm{p}=0.12$ & 4.7 & 5.7 & $\begin{array}{c}1.22 \\
(0.48-3.1)\end{array}$ & 20.6 & 17.8 & $\begin{array}{c}0.87 \\
(0.55-1.35)\end{array}$ \\
\hline $\begin{array}{l}\geq 0.1 \mu \mathrm{g} / \mathrm{L} \\
(318 / 326)\end{array}$ & 6.0 & 2.5 & $\begin{array}{c}0.41 \\
(0.18-0.92)\end{array}$ & 14.2 & 7.4 & $\begin{array}{c}0.52 \\
(0.32-0.83)\end{array}$ & 17.9 & 12.3 & $\begin{array}{c}0.68 \\
(0.47-0.99)\end{array}$ \\
\hline
\end{tabular}

*p-value is given since RR can not be calculated with zero events in one of the groups

\section{DISCUSSION}

Our understanding of the pathophysiology in ACS has improved impressively in the last two decades as outlined in the background. Simultaneously a number of new and effective treatment alternatives have been introduced, e.g. beta blockers, aspirin, heparin, thrombolysis, and early revascularisation by PTCA and CABG. In AMI, these new therapies and the understanding of the critical role of a short time delay for their success, have urged a change in "diagnostic mindset" (186), away from only retrospective confirmation of the diagnosis to-

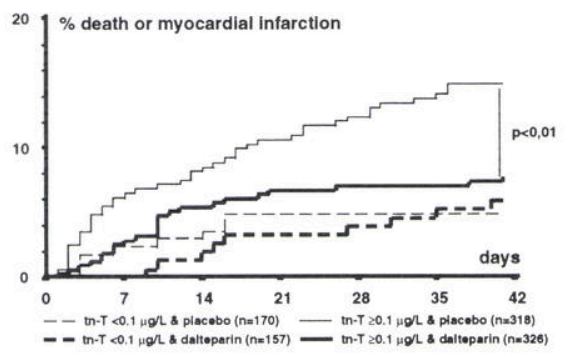

Figure 16. Cumulative hazard curves for death or MI in patients with and without dalteparin treatment with and without elevation of troponin $T$, respectively. wards earliest possible detection of the infarction in all chest pain patients. This new "diagnostic mind-set" is also necessitated by the economic restrictions in the health care systems. Early ruling-out of AMI will ensure a more cost-effective use of critical care resources as a majority (60-70\%) of patients admitted to CCU will not have AMI (187).

A new "prognostic mind-set" is also needed. Unstable CAD encompasses a wide range of patients, with a variable short-term prognosis. The treatment should ideally be tailored according to proper considerations about prognosis and underlying pathophysiology. The number of patients per year with a diagnosis of UA has steadily increased and is today almost as many as those hospitalised with a diagnosis of MI (188). Thus, risk evaluation during the first few days is of great importance for optimal treatment. The role of biochemical markers in these new "diagnostic and prognostic mindsets" is controversial (189). 
Early diagnosis in patients with suspected AMI (paper I \&II)

Frequent analyses and combinations of biochemical markers (paper I)

Methodological considerations

The value of frequent blood sampling and analyse of $\mathrm{tn}-\mathrm{T}, \mathrm{CK}-\mathrm{MB}$ (mass) and myoglobin for early rule-in and rule-out of AMI was evaluated in patients admitted without diagnostic ECG-changes. In these patients the current used diagnostic procedure is too time consuming. The clinical characteristics (Table 9) were representative for this large group of patients, except that a rather high proportion of the patients received thrombolytic treatment, despite absence of ST-segment elevations on admission. However, whether or not the patients were treated with thrombolysis, did not influence the results.

The assays used for CK-MB and $\mathrm{tn}-\mathrm{T}$, respectively, are commercially widely used assays. The RIA-assay for myoglobin is well described and its precision is comparable with commercially available methods (190). However, the analyses of the markers in the present study were done afterwards and not "on-line". Therefore, the impact of an early diagnosis or exclusion on the handling, treatment of and cost for these patients could not be assessed.
Ruling-in AMI

The sensitivities of $\mathrm{tn}-\mathrm{T}$ and CK-MB using a single blood sample on admission were low in accordance with other studies $(99,112)$. However, myoglobin had a relatively high sensitivity already at entry in the present as in some although not all previous studies $(101,112,191)$. The present study demonstrated a rapid increase in sensitivity obtained by frequent blood sampling. The rapid rise in diagnostic yield was especially noteworthy in candidates for reperfusion treatment with less than four hours delay. In this group the sensitivities of CK-MB and tn-T increased by approximately 10 $20 \%$ every half-hour during the first $2,5-3$ hours reaching $\geq 95 \%$ for all three markers after three hours. Thus, using "biochemical monitoring" almost all patients with ongoing AMI can be identified within three hours from admission.

The specificity of a diagnostic test should be high, especially in patients with a relatively low pre-test likelihood of AMI, such as patients with chest pain and a nondiagnostic ECG. Myoglobin, and low cut-off levels for $\mathrm{CK}-\mathrm{MB}$ and $\mathrm{tn}-\mathrm{T}$, respectively, gave unacceptably low specificities in accordance with most previous studies $(99,112,192)$. There was a considerable number of false positive cases even in the group with no evidence of 
IHD with myoglobin. In contrast the false positive cases with CK-MB and $\mathrm{tn}$-T were found among patients with IHD. However, using a combination of markers increased the specificity, while maintaining a high sensitivity. The combination of CK-MB and myoglobin (MyCK) was most favourable with $93-98 \%$ sensitivity and $93-93 \%$ specificity after 3-6 hours monitoring which seems considerably better than for any previously suggested combination (111). Since the study was performed the $\mathrm{tn}$ - $\mathrm{T}$ assay has been improved, both regarding analyticalsensitivity and cardiospecificity (89), and therefore, the diagnostic capacity of the combination of tn- T and myoglobin might have improved.

\section{Ruling-out AMI}

Based on the present and previous results (112), it is impossible to ruleout AMI with any single or combination of blood tests on admission. The conventional approach to rule-out AMI is to wait until all possible cases of AMI are diagnosed. The present, not previously evaluated, approach was to create a criterion of non-AMI, i.e. if fulfilled, AMI is ruled-out; while if not, the diagnosis will remain uncertain (provided the previous positive criteria for AMI are not fulfilled). With this approach, AMI could be ruled out in a substantial proportion of non-AMI patients after only 3-6 hours of monitoring without falsely ruling-out any patient with AMI (except one with repeated episodes of chest pain and the first elevation of the markers after 24 hours, indicating start of the infarction $>12$ hours after admission). For very early rule-out myoglobin was preferable and could safely exclude AMI after three hours (in $64 \%$ of non-AMI patients). After six hours tn-T or CK-MB seemed equally safe and ruled-out a slightly higher proportion.

\section{Clinical implications}

Using the currently recommended routine of blood sampling on admission and every sixth hour (193), with analysis of CK-MB (mass) (194) and obtaining the result from the central laboratory after 1.5 - 2 hours, the biochemical diagnosis of AMI in patients subsequently diagnosed as having infarcts will be made in no patient during the first two hours, in approximately $40 \%$ after two hours and in almost all patients after 8 hours from admission. Our suggested alternative approach (Fig 17) of obtaining blood samples for immediate analysis of myoglobin and CK-MB or tn-T every 30 minutes during the first hours will allow a definite diagnosis of AMI in around $60 \%$ on admission, $80 \%$ within one hour and above $90 \%$ within two hours (i. e. earlier than any patient is diagnosed with today's routine). It will also allow on-going AMI to be safely ruled-out in a substantial pro- 
portion of patients with non-AMI within 3-6 hours. Provided clinically stable these patients might safely be transferred from the CCU.

Although the assays used in the present study required 60 - 90 minutes, newer methods for analysis of CK-MB, tn-T and myoglobin can deliver the results within 30 minutes. Easy-to-use bedside instruments, with results within 15 minutes, probably soon will be available. Our approach might then be especially valuable for chest pain units, in which rapid assessment of the patients is mandatory (195). Furthermore, it might have a large impact on future studies evaluating treatment alternatives in AMI patients with nondiagnostic ECGs (196). The increased costs for the frequent sampling and rapid analysis

Population admitted with chest pain

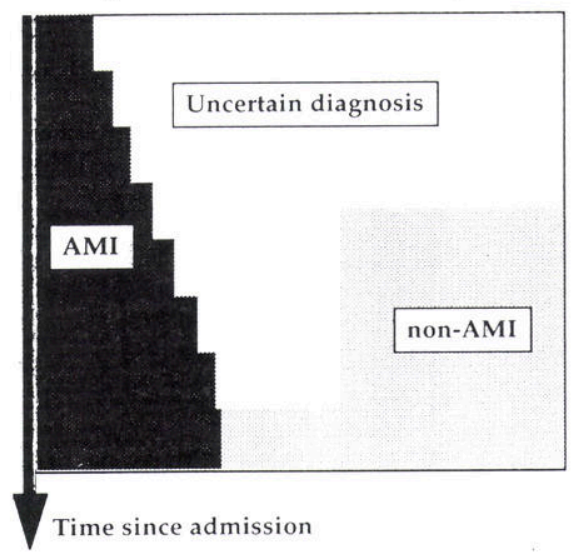

Figure 17. A proposed model for early rule-in and rule-out of AMI by frequent blood sampling and analyses of biochemical markers and using different criteria for ruling-in and ruling-out will be compensated for by the shorter stay in CCU and in-hospital of patients without AMI.

Neural network methodology and biochemical monitoring (paper II)

\section{Methodological considerations}

We selected neural networkstructures of minimal complexity in the design of the computational method in order to minimise the risk for the network to lose its capability of generalisation (197). We also incorporated knowledge of the time-distribution of data: the module for detection of AMI on first measurement used the fact that the concentration levels of the biochemical markers for AMI patients have a characteristic development over time. This fact was taken into account by training several networks, making each one of them specialised to recognise patterns of measured biochemical markers at a specific time interval after onset of symptoms. From the second measurement onward, however, a single recurrent neural network structure was used, thus selecting a structure that was suitable for the recognition of temporal patterns.

Although the patients were representative for a CCU population and unique with the early frequent blood sampling, the number of patients was limited in both the test and training 
sets. Therefore, the results must be interpreted with caution and regarded as indicative of the potential benefit of a neural network-based computer system in the early assessment of patients with acute chest pain. Since the clinicians, in contrast to the computer system, had access to data about age, gender, time since onset of symptoms and ECG on admission, in addition to the results of the biochemical markers, the comparison probably underestimated the advantages of the computer system. Further studies in larger groups are clearly needed.

Detection and exclusion of AMI and MMD

Patients with an AMI were generally correctly classified both by the computer system and the clinicians. However, the mean time was shorter and the variation smaller for the computer. The diagnostic performance of both the computer system and the clinicians waslower for correct classification of patients suffering from MMD than from the other two groups. This is not surprising since MMD is in the grey-zone between non-AMI and minor AMI. However, it was in these difficult cases the computer system proved its potential with a higher diagnostic sensitivity and positive predictive value in the test for MMD. Another consequence was that the clinicians had a lower diagnostic specificity and positive predictive value than the computer system in the test for non-AMI without MMD. This was due to the fact that most cases of MMD which were incorrectly classified by the clinicians as non-AMI without MMD.

In comparison with the diagnostic rules based on CK-MB and myoglobin the neural networks showed a comparable capacity for detection of AMI. However, for exclusion of AMI the computer method was superior.

\section{Prediction of infarct size}

The computer system was designed to perform a crude prediction of infarct size, requiring at most one more measurement after the detection of AMI. The computer system predicted infarct size approximately on the second measurement and 10 out of 11 patients were correctly evaluated by the system. In contrast, the clinicians required a considerably longer time than the computer system. Thus, these results indicate that a crude early estimate of infarct size is feasible with the computer method, but not by clinicians.

Estimation of "time since onset of infarction"

Some patients have difficulties in stating the time for onset of chest pain. Furthermore, the onset of chest pain 
might be an uncertain estimate for onset of infarction in the individual patient (198). Therefore, a "second opinion" from the computer, based on the pattern of biochemical markers, might be of value, e.g. for the decision to of thrombolysis. The computer method seemed to provide an estimate of the time from onset of infarction very early and with reasonable reliability.

\section{Clinical implications}

The decision-making process in the assessment of chest pain patients may be time consuming and is heavily dependent on the individual clinician's knowledge and experience. Therefore, some kind of decision support might be useful, e.g. by artificial neural networks. A combined approach for early diagnosis, infarct size prediction and estimation of onset of infarction might be of particular clinical relevance in patients without ST-elevation, since the cost-benefit ratio of reperfusion therapy is dependent on a correct diagnosis, time since onset and on the size of myocardium at risk $(32,152)$. Although thrombolytic treatment is only proven to be beneficial in patients with ST-segment elevation or bundle branch block on admission (32) a recent analysis of the data from the LATE study showed benefits of thrombolytic treatment also in patients presenting with ST-segment depression (38). Thus, thrombolysis might well be of benefit in certain subgroups of patients with non-diagnostic ECGs, e.g. patients with short delay and an impending large infarction. The possibility to select such subgroups, e.g. by the use of biochemical monitoring and neural network technology, seems to open new opportunities for evaluation of benefit of thrombolytic treatment in new subgroups of AMI patients(196).

\section{Prognosis in unstable CAD (paper III-V)}

\section{Methodological considerations}

The patients in the present study, with advanced age, history of increasing or rest angina pectoris and ST-depression or T-wave inversion in 12-lead ECG, had a high risk of subsequent cardiac events in accordance with previous experiences of unstable CAD $(199,200)$. The risk is most pronounced early after the initial event. In the present study approximately one fourth of the events occurred during the first 6 days and more than half during the first six weeks, emphasising the need for early risk assessment in order to properly select further investigations and treatment.

Patients unable to stabilise during the first hours after admission, in spite of adequate medication, might not have been included in the present study because of the need for immediate coronary angiography. However, in 
those patients there is hardly any need for additional prognostic information.

$\mathrm{Tn}$ - $\mathrm{T}$ was chosen as a prognostic indicator because of its wide time window and high sensitivity and specificity for myocardial damage. These properties are especially useful in unstable CAD patients with their often fluctuating symptoms. The discriminator values of $\mathrm{tn}-\mathrm{T}$ used for detection of myocardial damage have been gradually lowered as the $\mathrm{tn}$ - $\mathrm{T}$ assay has been improved, from $0.5 \mathrm{~g} / \mathrm{L}$ (87), to 0.2 $\mu \mathrm{g} / \mathrm{L}(122)$ and further to $0.1 \mu \mathrm{g} / \mathrm{L}$ (105). However, even lower discriminator levels for the detection of myocardial damage, as in the presentstudy, might be justified since the upper reference level in healthy blood donors is $0.06 \mu \mathrm{g} / \mathrm{L}(184)$.

Although the patients were admitted to hospital with a median delay of 5 hours from onset of last episode of chest pain, the median delay to inclusion (and first blood sample) was 24 hours. Hence, the inclusion samples of tn-T obtained in the present study might not in clinical practice be translated into admission samples, but rather to samples obtained during the first 24 hours after admission.

The prognostic value of $\mathrm{tn}-\mathrm{T}$ was primarily evaluated on the basis of the maximal value obtained during the first 24 hours. In order to avoid confu- sion between the prognostic and diagnostic capacity of $\mathrm{tn}-\mathrm{T}$, only patients without events during the first 24 hours and one day thereafter were considered in the prognostic evaluation. However, in the evaluation of the effect of the dalteparin treatment in relation to the tn-T level, only the sample obtained before the start of the randomised treatment (the inclusion sample) was used for two reasons: firstly, to avoid potential interference of the dalteparin treatment on the subsequent tn-T levels and, secondly, in the clinical situation, the decision whether to start therapy with heparin is preferably made as soon as possible.

\section{Prognostic value of t $n-T$}

The present study demonstrated for the first time that the risk of subsequent cardiac events gradually increases with increasing maximal levels of tn-T in patients with unstable CAD. A significant increase in the risk was shown already at very low levels of $\mathrm{tn}$ - $\mathrm{T}$, from $4.3 \%$ of cardiac death or $\mathrm{MI}$ in patients with $\mathrm{tn}-\mathrm{T}<0.06 \mu \mathrm{g} / \mathrm{L}$ to $10.5 \%$ in patients with $\mathrm{tn}-\mathrm{T}$ between $0.06-0.18 \mu \mathrm{g} / \mathrm{L}$, the increase was in fact evident already in patients with tn-T 0.06-0.10 $\mu \mathrm{g} / \mathrm{L}$ in whom $11 / 109$ (10.1\%) suffered an event. Tn-T levels of $<0.06,0.06-0.18$ and $\geq 0.18 \mu \mathrm{g} / \mathrm{L}$, identified groups with low, intermediate and high risk of MI or cardiac death, respectively, both in the total 
material and in the UA-group separately. The present study alone included almost as many UA patients as was included in a recently published meta analysis of seven studies regarding the prognostic value of $\mathrm{tn}-\mathrm{T}$ (107). Using $0.06 \mu \mathrm{g} / \mathrm{L}$ as cut-off, the relative risk ratio of 2.7 (CI, 1.3-5.7) for $\mathrm{UA}$ patients with elevated tn-T in our study lies just below the lower border of the $95 \%$ confidence interval of the odds ratio of $4.3(\mathrm{CI}, 2.8-6.8)$ in the metaanalysis. The results from the present study and a number of other published studies (122-126, 201-203) of the prognostic values of tn-T and other biochemical markers in UA patients or chest pain patients without MI, are summarised in Table 18. These studies show a consistent pattern of increased risk of cardiac events in patients with elevation of tn-T. In contrast to Hamm et al (122) we did not find any significant rise of in-hospital risk of cardiac death or $\mathrm{MI}$ in those with elevated $\mathrm{tn}-\mathrm{T}$ in the UA-group. These minor discrepancies from previous studies might be explained by slightly different study populations and our careful separation of index and subsequent events. In addition to previous findings, we also found a higher risk for cardiac death alone with higher levels of $\mathrm{tn}-\mathrm{T}$, both in the whole study population and if the analysis was restricted to UA patients. In accordance with most previous studies $(123,125,126)$ a minor increase of CK-MB (mass) also indicated a higher risk of subsequent cardiac events, although it did not reach statistical significance in the present study(Table 18). However, in the group with $\mathrm{CK}-\mathrm{MB}$ levels below the upper reference limit, it was still possible to demonstrate minor elevations of $\mathrm{tn}-\mathrm{T}$ in a large proportion of patients. These patients alsohad a significantly higher risk of cardiac events. Thus, $\mathrm{tn}$-T seems superior to CK-MB (mass) for risk stratification.

In the multivariate analysis the $\mathrm{tn}-\mathrm{T}$ level was a strong, consistent and independent prognostic variable concerning cardiac death or MI in the present study. This contrasts to a recent report (126) where tn-T level did not add any independent prognostic information when ST-T abnormalities were present at admission. The inclusion diagnosis did not add any independent prognostic information in contrast to the tn-T level. There was no significant difference in the incidence of cardiac events between those with UA and non-Q-wave MI in the same interval of tn-T elevation, suggesting that the tn-T level gives better prognostic information than the crude separation of unstable CAD-patients into UA or non-Q-wave MI according to conventional criteria. 
Table 18. Rate of death or MI during follow up in patients with UA or chest pain without MI in subgroups with high and low levels, respectively, of different biochemical markers (122-126, 201-203).

\begin{tabular}{|c|c|c|c|c|c|}
\hline Study & Follow-up & $\begin{array}{l}\text { Marker; } \\
\text { cut-off }(\mu \mathrm{g} / \mathrm{L})\end{array}$ & $\begin{array}{l}\text { High } \\
(\%)\end{array}$ & $\begin{array}{l}\text { Low } \\
(\%)\end{array}$ & p-valu \\
\hline Hamm et al & in-hospital & $\operatorname{tn}-\mathrm{T} ; 0.2$ & $10 / 33(30)$ & $1 / 51(2)$ & $<0.001$ \\
\hline Pettersson et al & 48 months & $\mathrm{CK}-\mathrm{MB} ;{ }^{*}$ & $9 / 14(64)+$ & $2 / 39(5)+$ & $<0.001$ \\
\hline Markenward et al & 6 months & CK-MB; 10 & $8 / 29$ (28)\# & $3 / 71(4) \#$ & $<0.001$ \\
\hline Ravkilde et al & 6 months & $\operatorname{tn}-\mathrm{T} ; 0.2$ & $6 / 44(14)$ & $3 / 83(4)$ & $<0.05$ \\
\hline \multirow[t]{2}{*}{ Ravkilde et al } & 28 months & $\mathrm{tn}-\mathrm{T} ; 0.2$ & $6 / 25(24)$ & $5 / 99(5)$ & $<0.01$ \\
\hline & & CK-MB; 6 & $8 / 35(23)$ & $3 / 89(3)$ & $<0.001$ \\
\hline Stubbs et al & 34 months & $\operatorname{tn}-\mathrm{T} ; 0.2$ & $18 / 62(29)$ & $21 / 121(17)$ & $<0.05$ \\
\hline \multirow[t]{2}{*}{ Wu et al } & 3 weeks & $\mathrm{tn}-\mathrm{T} ; 0.1$ & $8 / 27(30)$ & $3 / 104(3)$ & $<0.00$ \\
\hline & & CK-MB; 10 & $5 / 8(63)$ & $6 / 123(5)$ & NS \\
\hline \multirow[t]{2}{*}{ de Winter et al } & 6 months & $\operatorname{tn}-\mathrm{T} ; 0.1$ & $8 / 24(33) a$ & $16 / 104(15)$ & $<0.05$ \\
\hline & & CK-MB; 7.5 & $4 / 13(31) a$ & $20 / 115(17)$ & NS \\
\hline \multirow[t]{3}{*}{ FRISC § } & 5 months & $\mathrm{tn}-\mathrm{T} ; 0.06$ & $48 / 403(12)$ & $8 / 184(4)$ & $<0.01$ \\
\hline & & $\mathrm{tn}-\mathrm{T} ; 0.2$ & $26 / 192(14)$ & $30 / 395$ (8) & $<0.05$ \\
\hline & & CK-MB; 6.0 & $14 / 80(15)$ & $25 / 246(9)$ & $=0.13$ \\
\hline
\end{tabular}

* difference between two adjacent samples $>1.5-2 \mu \mathrm{g} / \mathrm{L}$, depending on which of the three assays was used; + rate of death; \# rate of $\mathrm{MI} ;$ a rate of $\mathrm{MI} /$ car diac death/revascularisation; $\S$ only patients with an index diagnosis of UA

\section{Comparison with exercise test}

Apredischarge ET could be performed in a large proportion of patients (80 $\%)$. The findings at the ET were comparable to previous findings in similar populations $(162,165,185)$. The prognostic value of a combination of ST-depression and/or a low exercise tolerance at an early ET in the present study is in accordance with most (161$163,165)$, although not all (169), previous studies. Although the rate of revascularisation was influenced by the ET response (in accordance with the protocol), which might beexpected to influence the event rate, the prog- nostic value of the ET response regarding cardiac death or MI remained impressive (Table 16).

In the multivariate analysis, both ET response and maximal tn-T level were independent risk indicators for cardiac death or MI. The present study demonstrated, for the first time, that the combination of an early symptom limited ET and tn-T determinations further improved the risk stratification compared to either test alone and made it possible to identify subgroups of patients with very low risk and very high risk of death or MI (Fig 15). 
The $20 \%$ of patients with contraindications against the ET were older and had more severe cardiovascular disease than those in the ET group. Consequently, the incidence of cardiac events was somewhat higher, in accordance with previous experiences (204). However, tn-T determinations, which can be made in all patients, were prognostically useful also in this subset of patients.

In contrast to an ET, the risk assessment by $\mathrm{tn}-\mathrm{T}$ can be done very early. This is important, since a number of patients will suffer an event (in the present study 29 of 976 patients) before an ET can be performed. Therefore, tests for ischemia that can be performed during the first day, e.g. continuous ECG-monitoring, have a potential to further improve or becomplementary in the risk evaluation (158, 159). The prognostic value of continuous ECG monitoring in comparison with tn-T determinations, 12-lead ECG at rest and ET is at present under evaluation.

\section{Effects of dalteparin treatment in re- lation to troponin T level}

The event rate in the total dalteparin group compared to the placebo group was reduced by approximately $65 \%$ during the acute phase treatment. During long term treatment the absolute reduction was maintained, but there was no further reduction (47).
However, in the subgroup with tn-T levels $\geq 0.1 \mu \mathrm{g} / \mathrm{L}$ there was an effect of dalteparin treatment not only during the acute, but also an additive effect during the long term treatment. In contrast, there seemed to be no protective effect of long-term dalteparin in patients with very low or no detectable levels of $\mathrm{tn}-\mathrm{T}(<0.1 \mu \mathrm{g} / \mathrm{L})$. The treatment with dalteparin reduced the risk of events in patients with tn-T $\geq 0.1$ almost to the same level as in the "low risk" patients with tn- $\mathrm{T}<0.1 \mu \mathrm{g} /$ $\mathrm{L}$ (Fig 14). There were no differences in clinical characteristics between the placebo and dalteparin group within each tn-T subset that could explain these results. The interaction analysis further supported that there was a real difference in effect of dalteparin treatment in patients with and without elevation of $\mathrm{tn}-\mathrm{T}$. These findings differ from what was found in the RISCstudy comparing aspirin with placebo, in which the absolute risk reduction of aspirin treatment during one year was comparable for death or MI in subgroups with high and low risk ET response (205). The use of $\mathrm{tn}-\mathrm{T}$ for identifying unstable CAD patients for long term antithrombotic treatment and/or other medical or interventional therapies is at present being evaluated in prospective trials.

\section{Pathophysiological speculations}

In patients with stable angina and documented $C A D$, no elevation of $\mathrm{tn}$ - 
T could be demonstrated after induction of severe ischemia by atrial pacing (206). Probably, minor elevations of $\mathrm{tn}-\mathrm{T}$ are due to an, at least transient, embolic or thrombotic occlusion of a coronary artery, with flow interrupted longenough to cause myocardial damage. The gradually increased risk for future myocardial infarctions by increasing tn-T levels, might possibly be explained by $\mathrm{tn}-\mathrm{T}$ level reflecting the liability of thrombus formation at the unstable plaque (207). Another possible explaination is that the $\mathrm{tn}-\mathrm{T}$ level reflects the severity of ischemia, which is supported by the more frequent occurrence of left ventricular dysfunction during anginal attacks in UApatients with, rather than without, tnT elevation (208). On the other hand, ischemic ECG-changes at the ET indicate a severe stenosis in the coronary vessels impeding the ability to match the raised oxygen demand with increased supply (209), without necessarily implying a thrombotic condition. Furthermore, a low exercise tolerance together with ST-depression during exercise, increases the probability of multivessel disease (185) and diastolic dysfunction (210). Thus, the independent prognostic values of tn$\mathrm{T}$ determinations and ETs might be a reflection of different pathophysiological mechanisms in unstable CAD. Thereby, the substantially increased risk in patients with both elevation of tn-T and a high riskET response might be explained by an ongoing thrombotic condition in severely diseased coronary arteries.

An embolising or at least temporary occluding red thrombus is probably the main mechanism, which responds to treatment with l.m.w. heparin in patients with elevation of tn-T (18, 207). On the other hand, in patients without tn-T elevation this process might be less prominent and therefore less responsive to this kind of therapy. In such patients other mechanisms might cause the symptoms, e.g. coronary vasoconstriction, due to impaired endothelial vasoactive function in the atherosclerotic coronary arteries (14, 15). However, it can not be ruled out, that the lack of prophylactic long term effect of dalteparin in the group with $\mathrm{tn}-\mathrm{T}<0.1 \mu \mathrm{g} / \mathrm{L}$ was only a play of chance, since it is necessarily more difficult to show a beneficial effect of any treatment in groups with such a low risk.

\section{Clinical implications}

For risk stratification in patients with suspected unstable CAD a strategy based on tn- $\mathrm{T}$ determined on admission and after 12-24 hours, findings on ECGat rest (or if available contineouos vector cardiography or 12-lead ECG monitoring) and an early ET might be proposed. Patients clinically stabilised and with low or undetectable tn-T levels, have a low risk for cardiac death 
or MI both in hospital and during the subsequent five months and might on appropriate medication be discharged early and further evaluated in the outpatient clinic. Clinically stabilised patients with a minor increase in tn- $T$ level and without ST-segment depression (or episods of ST-changes) might also be further treated and evaluated in the out-patient clinic, while patients with a minor increase in $\mathrm{tn}-\mathrm{T}$ level and ST-segment depression (or episods of ST-changes) need further evaluation and treatment while still in hospital. Patients with more definite elevations of $\operatorname{tn}-\mathrm{T}(>0.2 \mu \mathrm{g} / \mathrm{L})$ should be further investigated and have intense medical and/or interventional treatment while still in hospital. In most patients a symptom limited predischarge ET is preferably done a few days after clinical stabilisation, but in low risk patients as defined above, the ET might be done as an out-patient procedure. Patients with both low risk ET and no tn-T elevation, have a very low risk for cardiac death or MI during the subsequent months and further evaluation and invasive procedures seems unwarranted in the absence of incapacitating symptoms. In contrast, in patients with high risk ET response, or intermediate risk response and $\mathrm{tn}-\mathrm{T}$ $\geq 0.2 \mu \mathrm{g} / \mathrm{L}$, the severe short term prognosis warrants early consideration of revascularisation. The intermediate category often can be handled with intense long term protective medica- tion and continuous evaluation of the individual risk-benefit ratio of a revascularisation procedure during follow-up. In patients unable to perform an ET, alternative techniques such as dobutamin echocardiography or dypiridamole scintigraphy should be considered, especially in patients with elevated $\mathrm{tn}-\mathrm{T}$.

In patients admitted with suspicion of unstable CAD and any objective signs of ischemia, high dose dalteparin or heparin infusion should be initiated. In patients with elevation of $\mathrm{tn}-\mathrm{T}$ continuation of the dalteparin treatment with low-dose injections, once daily, might be considered, especially in patients scheduled for coronary angiography and revascularisation procedures .

\section{SUMMARYANDCONCLUSIONS}

In patients with suspected AMI

Monitoring of a combination of myoglobin and CK-MB or tn-T allowed ruling-in AMI within 2-3 hours and ruling-out AMI within 3-6 hours in almost all patients admitted with chest pain and a nondiagnostic ECG. This might have a large impact on the early handling and treatment of these patients.

The neural network methodology, with monitoring of myoglobin, CK$\mathrm{MB}$ and $\mathrm{tn}-\mathrm{T}$ allowed, within the first 
three hours, reliable diagnosis/exclusion of AMI/MMD, prediction of infarct size and a crude estimate of time since "onset of infarction" in patients admitted with suspicion of AMI. The computer system was faster than both clinicians and clinical rules. Thus, neural network methodology might be a useful support for the early assessment of patients with suspected myocardial infarction.

\section{In patients with unstable $C A D$}

The risk of subsequent cardiac events is increased by increasing maximal levels of tn-T obtained during the initial 24 hours. Thereby a normal, a slightly elevated and a clearly elevated tn-T level identified a low, intermediate and high risk group, respectively, for MI or death. The tn-T level was an independent prognostic variable for MI or death in a multivariate analysis comparing other early available risk indicators. Furthermore, tn-T seemed to be superior to CK-MB (mass) for risk stratification.

In patients able to perform a predischarge ET both the tn-T level and the ET response were independent prognostic indicators for MI or death. The combination of $\mathrm{tn}-\mathrm{T}$ and the ET response allowed a further improved risk stratification.
In patients with tn-T elevation at inclusion, prolonged dalteparin treatment was beneficial. However, in patients without $\mathrm{tn}$-Televation, long term dalteparin treatment had no protective effect.

Thus, $\mathrm{tn}$ - $\mathrm{T}$ determination provides independent and important prognostic information in unstable CAD. In the selection of treatment strategy for the individual patient, this simple, inexpensive and early available biochemical test might be useful. 


\section{ACKNOWLEDGEMENTS}

I wish to express my sincere gratitude and appreciation to all who contributed in the present study with special attention to

Lars Wallentin, my supervisor and friend, for having an open mind and an open door and for his never failing creativeness, enthusiasm and patience.

Per Venge, my co-supervisor, for support, encouragement and constructive criticism.

Torgny Groth, my co-supervisor, for introducing me to the strange field of neural networks and for many fruitful discussions.

Jan Ohlsson, Dept of Clinical Physiology, Jönköping, and Bertil Andrén, Dept of Clinical Physiology, Uppsala, co-authors in paper IV.

Johan Ellenius, co-author in paper II, for bringing me perspectives from an engineer.

Henrik Toss, friend, collegue and member of the FRISC study group - there will always be another dead-line...

Hans Nilsson, Dept of Internal Medicine, Fagersta, who made me interested in clinical cardiology.

Research nurses Gunilla Lindström, Eva Svensson and Gerd Ålsjö, for maintaining order in chaos.

Helene Strömbom, for her expertise in the design and lay-out of this thesis.

The Faculty of Medicine and its predecessor, professor Sverker Ljunghall, for providing the necessary background.

All my collegues and ward staff at the Dept of Cardiology, Uppsala.

All patients and collegues participating in the BIOMACS and FRISC trials.

My friend Mats Bojestig, with whom virtually every aspect of life, including research, can and has been discussed.

My wife Agneta, for having patience and being my best friend.

My children Hanna, Gustaf and Karin, for always reminding me what really is important in life...

Financial support for the present study was obtained from

Swedish Heart and Lung Foundation

the Uppsala County Association Against Heart and Lung Diseases, Sweden

the Selander's Foundation, Uppsala, Sweden

the European Commision under its AIM (Advanced Informatics in Medicine) Programme Pharmacia Biosensor AB, Uppsala, Sweden

Pharmacia AB, Stockholm, Sweden 


\section{REFERENSER}

1. Karlson BW, Herlitz J, Pettersson P, Ekvall HE, Hjalmarson A. Patients admitted to the emergency room with symptoms indicative of acute myocardial infarction. J Intern Med 1991; 230: 251-8.

2. Karlson BW, Herlitz J, Wiklund O, Richter A, Hjalmarson A. Early pre-diction of acute myocardial infarction from clinical history, examination and electrocardiogram in the emergency room. Am J Cardiol 1991; 68: 171-5.

3. Fuster V, Badimon L, Badimon J, Chesebro J. The pathogenesis of coronary artery disease and the acute coronary syndromes (second of two parts). N Engl J Med 1992; 326: 310-18.

4. Rutherford JD, Braunwald E. Chronic ischemic heart disease. In: Braunwald E, ed. Heart disease. A textbook of cardiovascular medicine. Philadelphia: WB Saunders Company, 1992: 12931364.

5. Hypertension and coronary heart disease. Classification and criteria for epidemiologicalstudies. World Health Organization Technical Series 1681959: 3.

6. Fuster V, Badimon L, Badimon J, Chesebro J. The pathogenesis of coronary artery disease and the acute coronary syndromes (first of two parts). N Engl J Med 1992; 326: 242-50.

7. Falk E. Plaque rupture with severe pre-existing stenosis precipitating coro-nary thrombosis. Characteristics of coronary atherosclerotic plaques underlying fatal occlusive thrombi. $\mathrm{Br}$ Heart J 1983; 50: 127-34.

8. Davies MJ, Thomas AC. Plaque fissuring: the cause of acute myocardial infarction, sudden ischemic death, and crescendo angina. Br Heart J 1985; 53: 363-73.

9. Falk E, Shah PK, Fuster V. Coronary plaque disruption. Circulation 1995; 92: 657-71.
10. Alderman EL, Corley SD, Fisher LD, et al. Five-year angiographic follow-up of factors associated with progression of coronary artery disease in the Coronary Artery Surgery Study (CASS). CASS Participating Investigators and Staff. J Am Coll Cardiol 1993; 22: 1141-54.

11. Ambrose JA, Tannenbaum MA, Alexopoulos D, et al. Angiographic progression of coronary artery disease and the development of myocardial infarction. J Am Coll Cardiol 1988; 12: 56-62.

12. Giroud D, Li JM, Urban P, Meier B, Rutishauer W. Relation of the site of acute myocardial infarction to the most severe coronary arterial stenosis at prior angiography [seecomments]. Am J Cardiol 1992; 69: 729-32.

13. Thompson SG, Kienast J, Pyke SD, Haverkate F, van de Loo JC. Hemostatic factors and the risk of myo-cardial infarction or sudden death in patients with angina pectoris. European Concerted Action on Thrombo-sis and Disabilities Angina Pectoris Study Group. N Engl J Med 1995; 332: 635-41.

14. Maseri A, L'Abbate A, Baroldi G, et al. Coronary vasospasm as a possible cause of myocardial infarction: a conclusion derived from the study of "preinfarction" angina. N Engl J Med 1978; 299: 1271-7.

15. Zeiher AM, Drexler H, Wollschlager H, Just H. Modulation of coronary vasomotor tone in humans. Progressive endothelial dysfunction with different early stages of coronary atherosclerosis. Circulation 1991; 83: 391-401.

16. Hackett D, Davies G, Chierchia S, Maseri A. Intermittent coronary occlusion in acute myocardial infarction: value of combined thrombolytic and vasodilatory therapy. $\mathrm{N}$ Engl J Med 1987; 317: 1055-9.

17. de Feyter PJ, Ozaki Y, Baptista J, et al. Ischemia-related lesion characteristics in patients with stable or unstable angina. A study with intracoronary angioscopy and ultrasound. Circulation 1995; 92: 1408-13. 
18. Ambrose JA. Plaque disruption and the acute coronary syndromes of unstable angina and myocardial infarction: if the substrate is similar, why is the clinical presentation different? [editorial]. J Am Coll Cardiol 1992; 19: 1653-8.

19. DeWood MA, Stifter WF, Simpson CS, et al. Coronary arteriographic findings soon after non-Q-wave myocardial infarction. NEngl J Med 1986;315: 41723.

20. Charney R, Cohen M. The role of the coronary collateral circulation in limiting myocardial ischemia and infarct size. Am Heart J 1993; 126: 937-45.

21. DeWood MA, Spores J, Notske R, et al. Prevalence of total coronary occlu-sion during the early hours of transmural infarction. NEngl J Med 1980;303: 897902.

22. Phibbs B. "Transmural" versus "subendocardial" myocardial infarction: an electrocardiographic myth. J Am Coll Cardiol 1983; 1: 561-564.

23. Cohen M, Xiong J, Parry G, et al. Prospective comparison of unstable angina versus non- $Q$ wave myocardial infarction during antithrombotic therapy. Antithrombotic Therapy in Acute Coronary Syndromes Research Group. J Am Coll Cardiol 1993; 22: 1338-43.

24. Betriu A, Heras M, Cohen M, Fuster V. Unstable angina: outcome according to clinical presentation. J Am Coll Cardiol 1992; 19: 1659-63.

25. Anderson HV, Cannon CP, Stone PH, et al. One-year results of the Thrombolysis in Myocardial Infarction (TIMI) IIIB clinical trial. A randomized comparison of tissue-type plasminogen activator versus placebo and early invasive versus early conservative strategies in unstable angina and nonQ wave myocardial infarction. J Am Coll Cardiol 1995; 26: 1643-50.

26. André-Fouet $X$, Pillot $M$, Leizorovicz A, Finet G, Gayet C, Milon H. "Non-Q wave", alias "nontransmural", myocardial infarction: a specific entity. Am Heart J 1989; 117: 892-900.
27. Nicod P, Gilpin E, Dittrich H, et al Short- and long-tern clinical outcome after $\mathrm{Q}$ wave and non-Q wave myocardial infarction in a large patient population. Circulation 1989; 79: 528536.

28. Berger CJ, Murabito JM, Evans JC, Anderson KM, Levy D. Prognosis after first myocardial infarction. Comparison of Q-wave and non-Q-wave myocardial infarction in the Framingham Heart Study. JAMA 1992;268: 1545-51.

29. Lincoff AM, Topol EJ. Illusion of reperfusion. Does anyone achieve optimal reperfusion during acute myocardial infarction? Circulation 1993; 88: 1361-74.

30. Koren GT, Hasin Y, Appelbaum D, et al. Prevention of myocardial damage in acute myocardial ischemia by early treatment with intravenous streptokinase. N Engl J Med 1985; 313: 1384 89.

31. Nidorf SM, Siu SC, Galambos G, Weyman AE, Picard MH. Benefit of late coronary reperfusion on ventricular morphology and function after myocardial infarction. J Am Coll Cardiol 1993; 21: 683-91.

32. Fibrinolytic Therapy Trialists' (FTT) Collaborative Group. Indications for fibrinolytic therapy in suspected acute myocardial infarction: collaborative overview of early mortality and major morbidity results from all rando-mised trials of more than 1000 patients. Lancet 1994; 343: 311-22.

33. Rawles J. What is the likely benefit of earlier thrombolysis? Eur Heart J1996; 17: 991-95.

34. de Boer MJ, Hoorntje JC, Ottervanger JP, Reiffers S, Suryapranata H, Zijlstra F. Immediate coronary angioplasty versus intravenous streptokinase in acute myocardial infarction: left ventricular ejection fraction, hospital mortality and reinfarction. J Am Coll Cardiol 1994; 23: 1004-8.

35. VaitkusPT. Percutaneous transluminal coronary angioplasty versus thrombolysis in acute myocardial infarction: a meta-analysis. Clin Cardiol 1995; 18: 35-8. 
36. ISIS-2 (Second International Study of Infarct Survival) Collaborative Group. Randomised trial of intravenous streptokinase, oral aspirin, both, or neither among 17,187 cases of suspected acute myocardial infarction: ISIS-2. Lancet 1988; 1: 349-360.

37. Gruppo Italiano per lo Studio della Strep tochinasi nell'Infarto miocardico (GISSI). Effectiveness of intravenous thrombolytic treatment in acute myocardial infarction. Lancet 1986; 2: 349360.

38. Langer A, Goodman S, Topol E, et al. Late assessment of thrombolytic Efficacy (LATE) study: Prognosis in patients with non-Q wave myocardial infarction. J Am Coll Cardiol 1996; 27: 1327-32.

39. Karlsson J-E, Berglund U, Björkholm A, et al. Thrombolysis with recombinant human tissue-type plasminogen activator during instability in coronary artery disease: Effect on myocardial ischemia and need for coronary revascularization. Am Heart J 1992; 124: 1419-26.

40. Effects of tissue plasminogen activator and a comparison of early invasive and conservative strategies in unstable angina and non-Q-wave myocardial infarction. Results of the TIMIIIIB Trial. Thrombolysis in Myocardial Ischemia. Circulation 1994; 89: 1545-56.

41. Lewis D, JW D, Archibald D, et al. Protective effects of aspirin against acute myocardial infarction and death in men with unstable angina. N Engl J Med 1983; 309: 396-403.

42. The RISC Group. Risk of myocardial infarction and death during treatment with low dose aspirin and intravenous heparin in men with unstable coronary artery disease. Lancet 1990; 336: 82730.

43. Antiplatelet Trialists' Collaboration. Collaborative overview of randomised trials of antiplatelet therapy-I: Prevention of death, myocardial infarction, and stroke by prolonged antiplatelet therapy in various categories of patients. Br Med J 1994; 308: 81-106.
44. Cohen M, Adams PC, Parry G, et al. Combination antithrombotic therapy in unstable rest angina and non-Qwave infarction in nonprior aspirin users. Primary end points analysis from the ATACS trial. Antithrombotic Therapy in Acute Coronary Syndromes Research Group. Circulation 1994; 89: 81-8.

45. Theroux $\mathrm{P}$, Ouimet $\mathrm{H}, \mathrm{McC}$ ans J, et al. Aspirin, heparin, or both to treat acute unstable angina. N Engl J Med 1988; 319: 1105-1111.

46. Dunn CJ, Sorkin EM. Dalteparin sodium. A review of its pharmacology and clinical use in the prevention and treatment of thromboembolic disorders. Drugs 1996; 52: 276-305.

47. Fragmin during instability in coronary artery disease (FRISC) study group. Low molecular weight heparin during instability in coronary artery disease. Lancet 1996; 347: 561-68.

48. The global use of strategies to open occluded coronary arteries (GUSTO) $\mathrm{IIb}$ investigateors. A comparison of recombinant hirudin with heparin for the treatment of acute coronary syndromes. N Engl J Med 1996; 335: $775-82$.

49. Antman EM, for the TIMI 9B investigators. Hirudin in acute myocardial infarction. Thrombolysis and thrombin inhibition in myocardial infarction (TIMI) 9B trial. Circulation 1996; 94: 911-21.

50. Théroux $P$, Waters $D$, Lam J, et al. Reactivation of unstable angina after the discontinuation of heparin. NEngl J Med 1992; 327: 141-5.

51. Gold HK, Torres FW, Garabedian HD, et al. Evidence for a rebound coagulation phenomenon after cessation of a 4-hour infusion of a specific thrombin inhibitor in patients with unstable angina pectoris. J Am Coll Cardiol 1993; 21: 1039-47.

52. Smith $\mathrm{P}$, Arnesen $\mathrm{H}$, HolmeI. The effect of warfarin on mortality and reinfarction after myocardial infarction. N Engl J Med 1990; 323: 147-52. 
53. Cohen M,Adams PC, Hawkins L, Bach M, Fuster V. Usefulness of antithrombotic therapy in resting angina pectoris or non-Q-wave myocardial infarction in preventing death and myocardial infarction (a pilot study from the Antithrombotic Therapy in Acute Coronary Synd-romes Study Group). Am J Cardiol 1990; 66: 128792.

54. RahimtolaSH, Nunley D, Grunkemeir G, Tepley J, Lampert L, Starr A. Tenyear survival after coronary bypass surgery for unstable angina. $\mathrm{N} \mathrm{Engl} \mathrm{J}$ Med 1983; 308: 676-81.

55. Myler RK, Shaw RE, Stertzer SH, et al. Unstable angina and coronary angioplasty. Circulation 1990; 82: 1188-1195.

56. Luchi R, Scott S, Deupree R, and the principal investigators and their associates of veterans administration cooperative study no. 28. Comparison of medical and surgical treatment for unstable angina pectoris. NEngl J Med 1987; 316: 977-84.

57. Karmen A, Wroblewski F, LaDue JS. Transaminase activity in human blood. J Clin Invest 1954; 34: 126-33.

58. Wroblewski F, LaDue JS. Lactic dehydrogenase activity in blood. Proc Soc Exp Biol Med 1955; 90: 210-3.

59. Dreyfus JC, Schapira G, Resnais J, Scebat L. La créatine-kinase sérique dans le diagnostic de l'infarctus myocardique. Rev Franc Etudes Clin Biol 1960; V: 386-387.

60. Roberts R. The two out of three criteria for diagnosis of infarction. Is it passe? (Editorial). Chest 1984; 86: 511-13.

61. Adams Jd, Abendschein DR, Jaffe AS. Biochemical markers of myocardial injury. Is MB creatine kinase the choice for the 1990s? Circulation 1993; 88:75063.

62. Spieckermann PG, Nordbeck H, Preusse CJ. From heart to plasma. In: Hearse DJ, ed. Enzymes in cardiology. Chichester: John Wiley \& sons, 1979: 81-95.

63. van Kreel B, van der Veen F, Willems GM,Hermens WT. Circulatory models in assessment of cardiac enzyme release in dogs. Am J Physiol 1993; 264: H747-54.
64. Piper HM, Schwartz P, Spahr R, Hutter JF, Spieckermann PG. Early enzyme release from myocardial cells is not due to irreversible cell damage. J Mol Cell Cardiol 1984; 16: 385-8.

65. Heyndrickx GR, Amano J, Kenna T, et al. Creatine kinase release not associated with myocardial necrosis after short periods of coronary artery occlusion in conscious baboons. J Am Coll Cardiol 1985; 6: 1299-303.

66. Remppis A, Scheffold T, Greten J, et al. Intracellular compartmentation of troponin T: release kinetics after global ischemia and calcium paradox in the isolated perfused rat heart. J Mol Cell Cardiol 1995; 27: 793-803.

67. Mair J, Dienstl F, Puschendorf B. Cardiac troponin $\mathrm{T}$ in the diagnosis of myocardial injury. Crit Rev Clin Lab Sci 1992; 29: 31-57.

68. Rabitzsch G, Mair J, Lechleitner P, et al. Immunoenzymometric assay of human glycogen phosphorylase isoenzyme BB in diagnosis of ischemic myocardial injury [seecomments]. Clin Chem 1995; 41: 966-78.

69. Mair J, Thome-Kromer B, Wagner I, et al. Concentration time courses of troponin and myosin subunits after acute myocardial infarction. Coron Artery Dis 1994; 5: 865-872.

70. Sobel BE, Markham J, Karlsberg RP, Roberts $R$. The nature of disappearance of creatine kinase from the circulation and its influence on enzymativ estimation of infarct size. Circ Res 1977; 41: 836-844.

71. Clark GL, Robison AK, Gnepp DR, Roberts R, Sobel BE. Effects of lymphatic transport of enzyme on plasma creatine kinase time-activity curves after myocardial infarction in dogs. Circ Res 1978; 43: 162-169.

72. Blanke $\mathrm{H}$, von Hardenberg D, Cohen $\mathrm{M}$, et al. Paterns of creatine kinase release during acute myocardial infarction after nonsurgival reperfu-sion: Comparison with conventional treatment and correlation with infarct size. J Am Coll Cardiol 1984; 3: 675-680.

73. Roberts R, Sobel BE. The distribution, inactivation and clearance of enzymes. In: Hearse DJ, ed. Enzymes in Cardiology. Chichester: John Wiley \& sons, 1979: 97-114. 
74. Pesce MA. The CK and LD macroenzymes. Lab Management 1984; 22: 29-41.

75. Gerhardt W, Bullock D, Duggan P, et al. ECCLS standards for enzyme determinations. Creatine Kinase, Aspartate Aminotransferase, Alanine Aminotransferase and gammaGlutamyltransferase. Klinisk Kemi i Norden (ed. K. Hellsing) 1990; suppl vol 2: 5-88.

76. Gerhardt W, Ljungdahl L, Borjesson J, etal.Creatine kinase B-subunit activity in human serum. I. Development of an immunoinhibition method for routine determination of S-creatine kinase Bsubunit activity. Clin Chim Acta 1977; 78: 29-41.

77. Wu AH, Gornet TG, Harker CC, Chen HL. Role of rapid immunoassays for urgent ("stat") determinations of creatine kinase isoenyme MB. Clin Chem 1989; 35: 1752-6.

78. Puleo PR, Guadagno PA, Roberts R, et al. Early diagnosis of acute myocardial infarction based on assay for subforms of creatine kinase-MB. Circulation 1990; 82: 759-64.

79. Klocke FJ, Copley DP, Krawczyk JA, Reichlin M. Rapid renal clearance of immunoreactive canine plasma myoglobin. Circulation 1982; 65: 1522-1528.

80. Groth T, Sylvén C. Myoglobin kinetics in patients suffering from acute myocardial infarction in its early phase - as studied by the single injection methodw. Scand J Clin Lab Invest 1981; 41: 79-85.

81. Roxin L-E, Venge P, Friman G, Hällgren R. Radioimmuneassays of human myoglobin in serum and urine. Scand. J Clin Lab Invest 1979; 39: 37-46.

82. Mair J, Artner DE, Lechleitner P, et al. Early diagnosis of acute myocardial infarction by a newly developed rapid immunoturbidimetric assay for myoglobin. Br Heart J 1992; 68: 462-8.

83. Hein S, Scheffold T, Schaper J. Ischemia induces early changes to cyto-skeletal and contractile proteins in diseased human myocardium. J Thorac Cardiovasc Surg 1995; 110: 89-98.
84. Katus HA, Scheffold T, Remppis A, Zehlein J. Proteins of the troponin complex. Laboratory Medicine 1992; 23: 311-17.

85. Saggin L, Gorza L, Ausoni S, Schiaffino S. Cardiac troponin T in developing, regenerating and denervated rat skeletal muscle. Development 1990; 110: 547-54.

86. Katus HA, Remppis A, Scheffold T, Diederich KW, Kuebler W. Intracellular compartmentation of cardiac troponin $\mathrm{T}$ and its release kinetics in patients with reperfused and nonreperfused myocardial infarction. Am J Cardiol 1991; 67: 1360-7.

87. Katus HA, Remppis A, Neumann FJ et al. Diagnostic efficiency of troponin $\mathrm{T}$ measurements in acute myocardial infarction. Circulation 1991;83:902-12.

88. Katus HA, Looser S, Hallermayer K, et al. Development and in vitro characterization of a new immunoassay of cardiac troponin T. Clin Chem 1992; 38: 386-93.

89. Müller-Bardoff M, Müller G, Hallermayer K, etal. Development and characterization of a specific immunoassay for cardiac troponin $\mathrm{T}$. Eur Heart J 1994; 15: 4 (abstract).

90. Adams JE, Schechtman KB, Landt $Y$, Ladenson JH, Jaffe AS. Comparable detection of acute myocardial infarction by creatine kinase $\mathrm{MB}$ isoenzyme and cardiac troponin I. Clin Chem 1994; 40: 1291-95.

91. Mair J, Genser N, Morandell D, et al. Cardiac troponin I in the diagnosis of myocardial injury and infarction. Clinica Chimica Acta 1996; 245: 19-38.

92. Larue C, Calzolari C, Bertinchant JP, Leclercq F, Grolleau R, Pau B. Cardiacspecific immunoenzymometric assay of troponin I in the early phase of acute myocardial infarction. Clin Chem 1993; 39: 972-9.

93. Sox HC, Blatt MA, Higins MC, Marton KI. Medical decision making. Boston: Butterworths, 1988.

94. Groth TL, Ljunghall S, De Verdier CH. Optimal screening for patients with hyperparathyroidism with use of serum calcium observations. A decisiontheoretical analysis. Scand J Clin Lab Invest 1983; 43: 699-707. 
95. Cebul RD, Hershey JC, Williams SV. Using multiple tests: series and parallel approaches. Clin Lab Med 1982; 2: 87190.

96. Leung FY, Galbraith LV, Jablonsky G, Henderson AR. Re-evaluation of the diagnostic utility of serum total creatine kinase and creatine kinase- 2 in myocardial infarction. Clin Chem 1989; 35: 1435-40.

97. Zweig MH, Campbell G. Receiveroperating characteristics (ROC) plots: A fundamental evaluation tool in clinical medicine. Clin Chem 1993; 39: 561-77.

98. Lee TH, Goldman L. Serum enzyme assays in the diagnosis of acute myocardial infarction. Recommendations based on a quantitative analysis. Ann Intern Med 1986; 105: 221-33.

99. Mair J, Artner DE, Dienstl A, et al. Early detection of acute myocardial infarction by measurement of mass concentration of creatine kinase-MB. Am J Cardiol 1991; 68: 1545-50.

100. Bhayana V, Henderson AR. Biochemical markers of myocardial damage. Clin Biochem 1995; 28: 1-29.

101. Roxin LE, Cullhed I, Groth T, Hallgren $T$, Venge $P$. The value of serum myoglobin determinations in the early diagnosis of acute myocardial infarction. Acta Med Scand 1984; 215: 417-25.

102. Collinson PO, Ramhamadany EM, Rosalki SB, et al. Diagnosis of acute myocardial infarction from sequential enzyme measurements obtained within 12 hours of admission to hospital. J Clin Pathol 1989; 42: 1126-31.

103. Wu AH, Gornet TG, Bretaudiere JP, Panfili PR. Comparison of enzyme immunoassay and immunoprecipitation for creatine kinase MB in diagnosis of acute myocardial infarction. Clin Chim 1985; 31: 470-474.

104. Kock TR, Mehta UJ, Nipper HC. Clinical and analytical evaluation of kits for measurements of creatine kinase isoenzyme MB. Clim Chem 1986; 32: 186-191.

105. Wu AH, Valdes RJ, Apple FS, et al. Cardiac troponin- $\mathrm{T}$ immunoassay for diagnosis of acute myocardial infarction. Clin Chem 1994; 40: 900-7.
106. McComb JM, McMaster EA, Mac Kenzie G, Adgey AA. Myoglobin and creatine kinase in acute myocardial infarction. Br Heart J 1984; 51: 189-94.

107. Wu AH, Lane PL. Metaanalysis in clinical chemistry: validation of cardiac troponin $\mathrm{T}$ as a marker for ischemic heart diseases. Clin Chem 1995; 41: 1228-33.

108. Lee HS, Cross SJ, Garthwaite P, et al Comparison of the value of novel rapid measurement of myoglobin, creatine kinase, and creatine kinase$\mathrm{MB}$ with the electrocardiogram for the diagnosis of acute myocardial infarction. Br Heart J 1994; 71: 311-5.

109. Bakker AJ, Koelemay MJ, Gorgels JP, et al. Troponin $\mathrm{T}$ and myoglobin at admission: value of early diagnosis of acute myocardial infarction. Eur Heart J 1994; 15: 45-53.

110. Marin MM, Teichman SL. Use of rapid serial sampling of creatine kinase $\mathrm{MB}$ for very early detection of myo-cardial infarction in patients with acute chest pain. Am Heart J 1992; 123: 354-61.

111. Van Blerk M, Maes V, Huyghens L, Derde MP, Meert R, Gorus FK. Analytical and clinical evaluation of creatine kinase $\mathrm{MB}$ mass assay by IMx: comparison with MB isoenzyme activity and serum myoglobin for early diagnosis of myocardial infarction. Clin Chem 1992; 38: 2380-6.

112. Bakker AJ, Koelemay MJW, Gorgels JPMC, et al. Failure of new biochemical markers to exclude acute myocardial infarction at admission. Lancet 1993; 342: $1220-22$.

113. Antman EM, Grudzien C, Sacks DB. Evaluation of a rapid bedside assay for detection of serum cardiac troponin $\mathrm{T}$. JAMA 1995; 273: 1279-82.

114. Puleo PR, Meyer D, Wathen C, et al. Use of a rapid assay of subforms of creatine kinase-MB to diagnose or rule out acute myocardial infarction. NEngl J Med 1994; 331: 561-6.

115. Bodor GS, Porter S, Landt Y, Ladenson JH. Development of monoclonal antibodies for an assay of cardiac troponin-I and preliminary results in suspected cases of myocardial infarction. Clin Chem 1992; 38: 2203-14. 
116. Donsky MS, Curry GC, Parkey RW, et al. Unstable angina pectoris. Clinical, angiographic, and myocardial scintigraphic observations. Br Heart J 1976; 38: 257-63.

117. Thygesen K, Hørder M, Krøll L, Hyltoft Petersen P, Haghfelt T. Creatine kinase and creatine kinase B-subunit in stable and unstable angina pectoris. Eur J Clin Invest 1986;16: 1-4.

118. Botker HE, Ravkilde J, Sogaard P, Jorgensen PJ, Horder M, Thygesen K. Gradation of unstable angina based on a sensitive immunoassay for serum creatine kinase MB. Br Heart J1991; 65: 72-6.

119. Isakov A, Shapira I, Burke M, Almog C. Serum myoglobin levels in patients with ischemic myocardial insult. Arch Intern Med 1988; 148: 1762-5.

120. Katus HA, Diederich KW, Hoberg E, Kubler W. Circulating cardiac myosin light chains in patients with angina at rest: identification of a high risk subgroup. J Am Coll Cardiol 1988; 11: 48793.

121. Gerhardt W, Katus H, Ravkilde J, et al. S-troponin T in suspected ischemic myocardial injury compared with mass and catalytic concentrations of Screatine kinase isoenzyme MB. Clin Chem 1991; 37: 1405-11.

122. Hamm CW, Ravkilde J, Gerhardt W, et al. The prognostic value of serum troponin T in unstable angina. N Engl J Med 1992; 327: 146-50.

123. Markenvard J, Dellborg M, Jagenburg $\mathrm{R}$, Swedberg K. The predictive value of CKMB mass concentration in unstable angina pectoris: preliminary report. J Intern Med 1992; 231: 433-6.

124. Ravkilde J, Horder M, Gerhardt W, et al. Diagnostic performance and prognostic value of serum troponin $\mathrm{T}$ in suspected acute myocardial infarction. Scand J Clin Lab Invest 1993; 53: 677-85.

125. Pettersson T, Ohlsson O, Tryding N. Increased CKMB (mass concentration) in patients without traditional evidence of acute myocardial infarc-tion. A risk indicator of coronary death. Eur Heart J 1992; 13: 1387-92.
126. Ravkilde J, Nissen $H$, Hörder $M$, Thygesen $\mathrm{K}$. Independent prognostic value of serum creatine kinase isoenzyme MB mass, cardiac troponin T and myosin light chain levels in suspected acute myocardial infarction. Analysis of 28 months of follow-up in 196 patients. J Am Coll Cardiol 1995; 25: 574-81.

127. White RD, Grande P, Califf L, Palmeri ST, Califf RM, Wagner GS. Diagnostic and prognostic significance of minimally elevated creatine kinase-MB in suspected acute myocardial infarction. Am J Cardiol 1985; 55: 1478-84.

128. Hackel DB, Reimar KA, Ideker RE, et al. Comparison of enzymatic and anatomic estimates of myocardial infarct size in man. Circulation 1984; 70: 824-35.

129. Roberts R. Enzymatic estimation of infarct size. Thrombolysis induced its demise: will it now rekindle its renaissance? Circulation 1990; 81: 707-10.

130. Kawaguchi $\mathrm{K}$, Sone T, Tsuboi $\mathrm{H}$, et al. Quantitative estimation of infarct size by simultaneous dual radionuclide single photon emission computed tomography: comparison with peak serum creatine kinase activity. Am Heart J 1991; 121: 1353-60.

131. Omura T, Teragaki M, Tani T, et al. Estimation of infarct size using serum troponin $\mathrm{T}$ concentration in patients with acute myocardial infarction. Jpn Circ J 1993; 57: 1062-70.

132. Devries SR, Jaffe AS, Geltman EM, Sobel BE, Abendschein DR. Enzymatic estimation of the extent of irreversible myocardial injury early after reperfusion. Am Heart J 1989; 117: 31-6.

133. Groth T, Hakman M, Sylven C. Prediction of myocardial infarct size from early serum myoglobin observations. Scand J Clin Lab Invest 1987; 47: 599-603.

134. Yamashita T, Abe S, Arima S, et al. Myocardial infarct size can be estimated from serial plasma myoglobin measurements within 4 hours of reperfusion. Circulation 1993; 87: 18409. 
135. Zabel M, Hohnloser SH, Köster W, Prinz M, Kasper W, Just H. Analysis of creatine kinase, CK-MB, myoglobin, and troponin $\mathrm{T}$ time-activity curves for early assessment of coronary artery reperfusion after intravenous thrombolysis. Circulation 1993;87:1542-1550.

136. Puleo PR, Perryman MB. Noninvasive detection of reperfusion in acute myocardial infarction based on plasma activity of creatine kinase MB subforms. J Am Coll Cardiol 1991; 17: 1047 -52 .

137. Laperche T, Steg PG, Dehoux M, et al. A study of biochemical markers of reperfusion early after thrombolysis for acute myocardial infarction. The PERM Study Group. Prospective Evaluation of Reperfusion Markers. Circulation 1995; 92: 2079-86.

138. Lott JA. Serum enzyme determinations in the diagnosis of acute myocardial infarction: an update. Hum Pathol 1984;15: 706-16.

139. Adams JD, Bodor GS, Davila RV, et al. Cardiac troponin I. A marker with high specificity for cardiac injury. Circulation 1993; 88: 101-6.

140. Karlsberg RP, Roberts R. Effect of altered thyroid function in plasma creatine kinase clearance in the dog. Am J Physiol 1978; 235: 614-618.

141. Hällgren R, Cullhed I, Roxin LE, Venge P. Myoglobinemia after myocardial infarction; influence of renal function. Eur J Cardiol 1978; 8: 607-16.

142. Kobayashi S, Tanaka M, Tamura N, Hashimoto $\mathrm{H}$, Hirose S. Serum cardiac troponin $\mathrm{T}$ in polymyositis/dermatomyositis [letter]. Lancet 1992; 340: 8821 .

143. Katus HA, Haller C, Muller BM, Scheffold T, Remppis A. Cardiac troponin $\mathrm{T}$ in end-stage renal disease patients undergoing chronic maintenance hemodialysis [letter]. Clin Chem 1995; 41: 1201-2.

144. Dillon MC, Calbreath DF, Dixon AM, et al. Diagnostic problem in acute myocardial infarction: CK-MB in the absence of abnormally elevated total creatine kinaselevels. Arch Intern Med 1982; 142: 33-8.
145. Adams J, Trent R, Rawles J. Earliest electrocardiographic evidence of myocardial infarction: implications for thrombolytic treatment. The GREAT Group. Br Med J 1993; 307: 409-13.

146. Selwyn AP, Fox K, Welman E, Shillingford JP. Natural history and evolution of $\mathrm{Q}$-waves during acute myocardial infarction. Br Heart J 1978; 40: 383-87.

147. Haiat $R, C$ Chiche P. Transient abnormal $Q$ waves in the course of ischemic heart disease. Chest 1974; 65: 140-44.

148. Boden WE, Gibson RS, Schechtman $K B$, et al. ST segment shifts are poor predicvtors of subsequent $Q$ waveevolution in acute myocardial infarction. A natural history study of early non- $Q$ wave infarction. Circulation 1989; 79 : 537-548.

149. Yusuf S, Pearson M, Sterry H, et al. The entry ECG in the early diagnosis and prognostic stratification of patients with suspected acute myocardial infarction. Eur Heart J 1984; 5: 690-6.

150. McGuiness JB, Begg TB, Semple T. First electrocardiogram in recent myocardial infarction. Br Med J 1976; 2: 449.

151. Cohen M, Scharpf S, Rentrop K. Prospective analysis of electrocardiographic variables as markers for extent and location of acute wall motion abnormalities observed during coronary angioplasty in human subjects. J Am Coll Cardiol 1987; 10: 17.

152. Mauri F, Gasparini M, Barbonaglia L, et al. Prognostic significance of the extent of myocardial injury in acute myocardial infarction treated by streptokinase (the GISSI trial). Am J Cardiol 1989; 63: 1291-5.

153. Cohen M, Hawkins L, Greenberg S, Fuster V. Usefulness of ST-segment changes in greater than or equal to 2 leads on the emergency room electrocardiogram in either unstable angina pectoris or non-Q-wave myo-cardial infarction in predicting outcome. Am J Cardiol 1991; 67: 1368-73. 
154. Karlsson JE, Bjorkholm A, Blomstrand $\mathrm{P}$, Ohlsson J, Wallentin L. Ambulatory ST-recording has no additional value to exercise test for identification of severe coronary lesions after an episode of unstable coronary artery disease in men. Int J Card Imaging 1993; 9: 281-9.

155. Krucoff MW, Croll MA, Pope JE, et al. Continuous 12-lead ST-segment recovery analysis in the TAMI 7 study. Performance of a noninvasive method for real-time detection of failed myocardial reperfusion. Circulation 1993; 88: $437-46$.

156. Dellborg M,Steg PG, Simoons M, et al. Vectorcardiographic monitoring toassess early vessel patency after reperfusion therapy for acute myo-cardial infarction. Eur Heart J 1995; 16: 21-9.

157. Lundin P, Eriksson SV, Strandberg LE, Rehnqvist N. Prognostic information from on-line vectorcardiography in acute myocardial infarction. Am J Cardiol 1994; 74: 1103-8.

158. Patel DJ, Holdright DR, Knight CJ, et al. Early continuous ST segment monitoring in unstable angina: prognostic value additional to the clinical characteristics and the admission electrocardiogram. Heart 1996; 75: 222-228.

159. Andersen K, Eriksson P, Källström G, Alveren E, Svensson A-M, Dellborg M. Contineuous vectorcardiography predicts clinical events in patients with unstable coronary disease. Eur Heart J 1996; 17: 575 (abstract).

160. Lundin P, Eriksson SV, Fredrikson M, Rehnqvist N. Prognostic information from on-line vectorcardiography in unstable angina pectoris. Cardiology 1995; 86: 60-6.

161. Butman S, Olson H, Butman L. Early exercise testing after stabilization of unstable angina: Correlation with coronary angiographic findings and subsequent cardiac events. Am Heart J 1986; 111: 11-18.

162. Swahn E, Areskog M, Berglund U, Walfridsson $\mathrm{H}$, Wallentin L. Predictive importance of clinical findings and a predischarge exercise test in suspected unstable coronary disease. Am J Cardiol 1987; 59: 208-14.
163. Wilcox I, Freedman SB, Allman KC, et al. Prognostic significance of a predischarge exercise test in risk stratification after unstable angina pectoris. J Am Coll Cardiol 1991; 18: 677-83.

164. Launbjerg J, Fruergaard P, Jacobsen HL, Madsen JK. Long-term risk factors from non-invasive evaluation of patients with acute chest pain, but without myocardial infarction. Eur Heart J 1995; 16: 30-7.

165. Nyman I, Wallentin L, Areskog M, Areskog NH, Swahn E. Risk stratification by early exercise testing after an episode of unstable coronary artery disease. The RISC Study Group. Int J Cardiol 1993; 39: 131-42.

166. Swahn E, Areskog M, Wallentin L. Early exercise testing after coronary care for suspected unstable coronary artery disease - safety and diagnostic value. Eur Heart J 1986; 7: 594-601.

167. Larsson $\mathrm{H}$, Areskog $\mathrm{M}$, Areskog $\mathrm{NH}$ et al. Should the exercise test (ET) be performed at discharge or one month later after an episode of unstable angina or non-Q-wave myocardial infarction? Int J Card Imaging 1991; 7: 7-14.

168. Juneau $\mathrm{M}$, Colles $\mathrm{P}$, Théroux $\mathrm{P}$, et al Symptom-limited versus low lewel exercise testing before hospital discharge after myocardial infarction. J Am Coll Cardiol 1992; 20: 927-33.

169. Krone R, Dwyer E, Greenberg H, Miller J, Gillespie J. Risk stratification in patients with first non-Q-wave infarction: Limited value of the early low-level exercise test after uncomplicated infarcts. J Am Coll Cardiol 1989; 14: 31-37.

170. Amanullah AM, Lindvall K, Bevegard S. Prognostic significance of exercise thallium-201 myocardial perfusion imaging compared to stress echocardiography and clinical variables in patients with unstable angina who respond to medical treatment. Int J Cardiol 1993; 39: 71-8.

171. van Daele M, McNeill AJ, Fioretti PM, et al. Prognostic value of dipyridamole sestamibi single-photon emission computed tomography and dipyridamolestress echocardiography for new cardiac events after an uncom-plicated myocardial infarction. J Am Soc Echocardiogr 1994; 7: 370-80. 
172. Larsson H. Myocardial ischemia as a risk indikator after an episode of unstable angina or non-Q-wave myocardial infarction. Thesis: Linköping, 1991.

173. Schröder K, Völler H, Dingerkus H, et al. Comparison of the diagnostic potential of four echocardiographic stress tests shortly after acute myocardial infarction: submaximal exercise, transesophageal atrial pacing, dipyridamole, and dobutamine-atropine. Am J Cardiol 1996; 77: 909-14.

174. Picano E, Landi P, Bolognese L, et al. Prognostic value of dipyridamole echocardiography early after uncomplicated myocardial infarction: a largescale, multicenter trial. The EPICStudy Group. Am J Med 1993; 95: 608-18.

175. Amanullah A, Lindvall K. Predischarge exercise echocardiography in patients with unstable angina who respond to medical treatment. Clin Cardiol 1992; 15: 417-423.

176. Castaner A, Roig E, Serra A, et al. Risk stratification and prognosis of patients with recent onset angina. Eur Heart J 1990; 11: 868-75.

177. Ahmed WH, Bittl JA, Braunwald E. Relation between clinical presentation and angiographic findings in unstable angina pectoris, and comparison with that in stable angina. Am J Cardiol 1993; 72: 544-50.

178. Feld S, Ganim M, Carell ES, et al. Comparison of angioscopy, intravascular ultrasound imaging and quantitative coronary angiography in predicting clinical outcome after coronary intervention in high risk patients. J Am Coll Cardiol 1996; 28: 97-105.

179. Jansson PA. Neural Networks: An overview. Analytical Chemistry 1991; 63: 357 A-362 A.

180. Baxt WG. Use of an artificial neural network for the diagnosis of myocardial infarction. Ann Intern Med 1991; 115: 843-8.

181. Furlong JW, Dupuy ME, Heinsimer JA. Neural network analysis of serial cardiac enzyme data. A clinical application of artificial machine intelligence. Am J Clin Pathol 1991; 96: 13441 .
182. Gillum RF, Fortman SP, Prineas RJ, Kottke TE. International diagnostic criteria for acute myocardial infarction and stroke. Am Heart J 1984; 108: 150158.

183. Jorgensen PJ, Horder M, Selmer J, Botker HE. Analytical evaluation of a sensitive enzyme immunoassay for determinations of creatine kinase isoenzyme MB. Clin Chem 1990; 36: $1502-5$.

184. Gerhardt W, Katus HA, Ravkilde J, Hamm CW. S-troponin-T as a marker of ischemic myocardial injury [letter]. Clin Chem 1992; 38: 1194-5.

185. Karlsson J-E, Björkholm A, Nylander E, Ohlsson J, Swahn E, Wallentin L. STchanges in ECG at rest or during exercise indicate a high risk of severe coronary lesions after an episode of unstable coronary artery disease. Int J Cardiol 1993; 42: 47-55.

186. Roberts R, Kleiman NS. Earlier diagnosis and treatment of acute myocardial infarction necessitates the need for a 'new diagnostic mind-set'. Circulation 1994; 89: 872-81.

187. Lee TH, Juarez G, CookEF, et al. Ruling out acute myocardial infarc-tion. A prospective multicenter validation of a 12-hour strategy for patients at low risk. N Engl J Med 1991; 324: 1239-46.

188. Brunelli C, Spallarossa P, Rosettin P, Caponetto $\mathrm{S}$. Recognition and treatment of unstable angina. Drugs 1996; 52: 196-208.

189. Jaffe AS. More rapid biochemical diagnosis of myocardial infarction: necessary? Prudent? Cost effective? [editorial; comment]. Clin Chem 1993; 39: 1567-9.

190. Roxin L-E, Venge P, Wide L. A fast and sensitive radioimmunoassay of human myoglobin for use in the early diagnosis of heart infarction. Clinica Chimica Acta 1980; 107: 129-134.

191. Cairns JA, Missirlis E, Walker WH Usefulness of serial determinations of myoglobin and creatine kinase in serum compared for assessment of acute myocardial infarction. Clin Chem 1983; 29: 469-73. 
192. Mair J, Artner DE, Lechleitner P, et al. Cardiac troponin T in diagnosis of acute myocardial infarction. Clin Chem 1991; 37: 845-52.

193. Gunnar RM, Passamani ER, Bourdillon PD, et al. Guidelines for the early management of patients with acute myocardial infarction. A report of the American College of Cardiology / American Heart Association Task Force on Assessment of Diagnostic and Therapeutic Cardiovascular Procedures (Subcommittee to Develop Guidelines for the Early Management of Patients with Acute Myocardial Infarction). J Am Coll Cardiol 1990; 16: 249 92.

194. Anderson H, Dellborg M, Markenvard $\mathrm{J}$, Jagenburg R, Herlitz J. [CK-MB is sufficient as a specific marker in the diagnosis of myocardial infarction]. Läkartidningen 1991; 88: 2890-2.

195. Newby LK, Gibler WB, Ohman EM, Christenson RH. Biochemical markers in suspected acute myocardial infarction: the need for early assessment [editorial; comment]. Clin Chem 1995; 41: 1263-5.

196. Braunwald E, Cannon C. Non-Q wave and ST segment depression myocardial infarction: Is there a role for thrombolytic therapy? [editorial; comment]. J Am Coll Cardiol 1996; 27: 1333-34.

197. Forsström JJ, Irjala K, Selén G, et al. Using data preprocessing and single layer perceptron to analyse laboratory data. Scan J Clin Lab Invest 1995; 55 (suppl): 75-81.

198. Herlitz J, Hjalmarson A, Waldenstrom J. Time lapse from estimated onset of acute myocardial infarction to peak serum enzyme activity. Clin Cardiol 1984; 7: 433-40.

199. Murphy JJ, Connell PA, Hampton JR. Predictors of risk in patients with unstable angina admitted to a district general hospital. Br Heart J 1992; 67: 395401.

200. Wallentin L, and the RISC group. Aspirin (75 mg/day) after an episode of unstable coronary artery disease: Long term effects on the risk for myocardial infarction, occurrence of severe angina and the need for revascularization. J Am Coll Cardiol 1991; 18: 1587-93.
201. Stubbs P, Collinson P, Moseley D, Greenwood T, Noble M. Prospective study of the role of cardiac troponin $\mathrm{T}$ in patients admitted with unstable angina. Br Med J 1996; 313: 262-264.

202. Wu AH, Abbas SA, Green S, et al. Prognostic value of cardiac troponin $\mathrm{T}$ in unstable angina pectoris. Am J Cardiol 1995; 76: 970-2.

203. de Winter RJ, Koster RW, Schotveld JH, Sturk A, van Straalen JP, Sanders GT. Prognostic value of troponin T, myo-globin, and CK-MB mass in patients presentering with chest pain without acute myocardial infarction. Heart 1996; 75: 235-239.

204. Cokkinos DV, Kouvaras G. Exercise testing after acute myocardial infarction. How much? How soon? Acta Cardiol 1990; 45: 75-85.

205. Nyman I. Signs and implications of ischemia in unstable coronary artery disease. Thesis: Linköping, 1993.

206. Krüger D, Stierle U, Kerner W, et al. No release of troponin $\mathrm{T}$ after short-lasting severe myocardial ischemia. Eur Heart J 1994; 15: 221 (abstract).

207. Jurlander B, Molani MA, Balu D, Ellis AK. Serum troponin T levels predicts coronary angigraphic findings in patients with unstable angina. Circulation 1995; 92: I-679 (Abstract).

208. Kondo K, Aoki H, Ohira K, et al. Does increased serum troponin $\mathrm{T}$ indicate clinical severity in unstable angina? Eur Heart J 1994; 15 Abstract Supplement: 1208.

209. Wilson RF, Marcus ML, Christensen BV, Talman C, White CW. Accuracy of exercise electrocardiography in detecting physiologically significant coronary arterial lesions. Circulation 1991; 83: 412-21.

210. Lewis BS, Poole WP. The DEFIANT study of left ventricular function and exercise performance after acute myocardial infarction. Doppler Flow and Echocardiology in Functional Cardiac Insufficiency: Assessment of Nisoldipine Therapy Study Group. Cardiovasc Drugs Ther 1994;2: 407-18. 





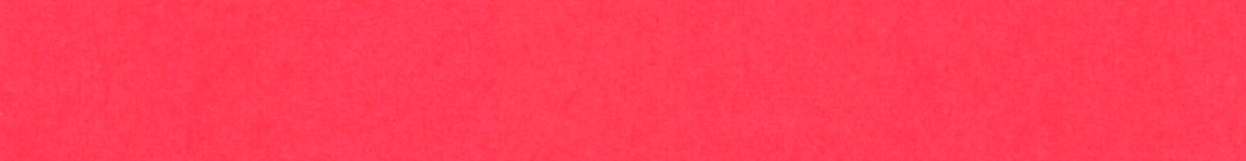

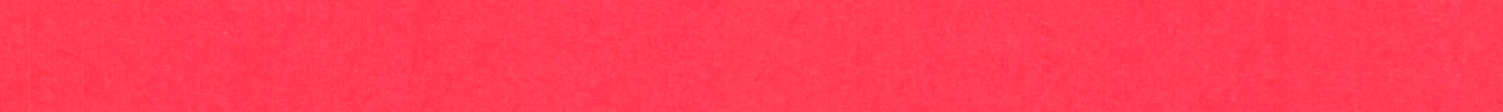

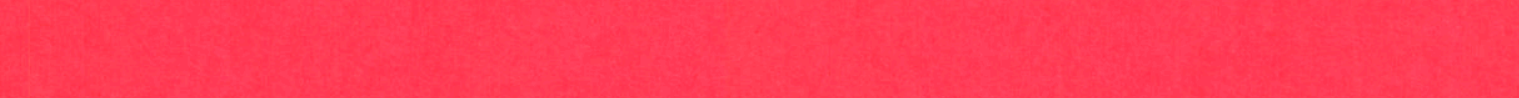

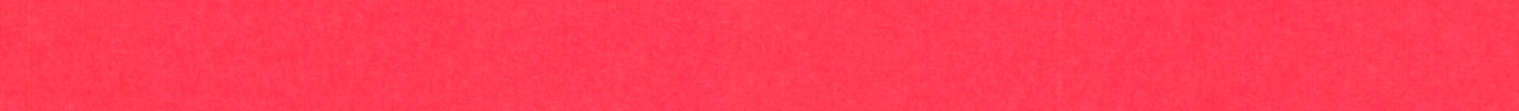

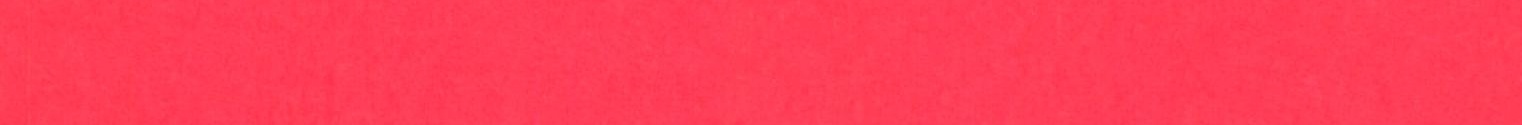

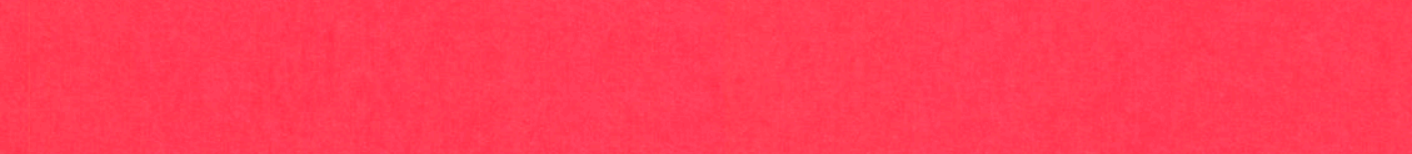

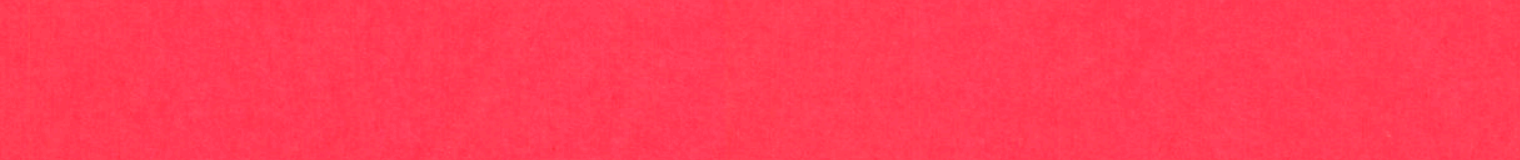

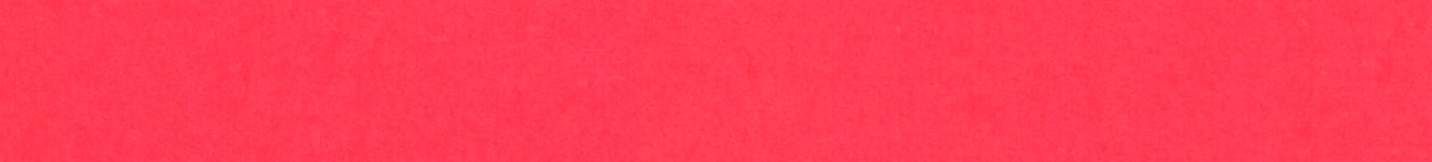

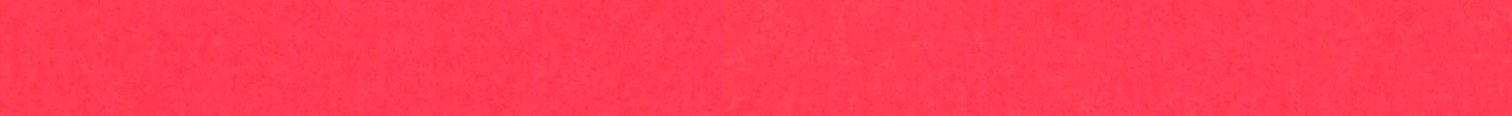

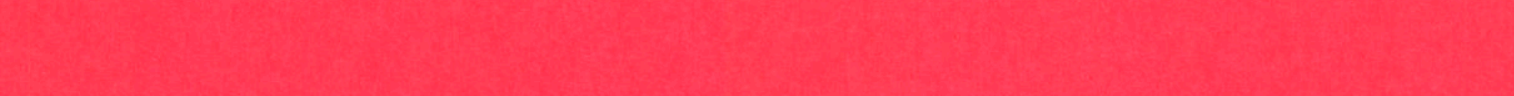

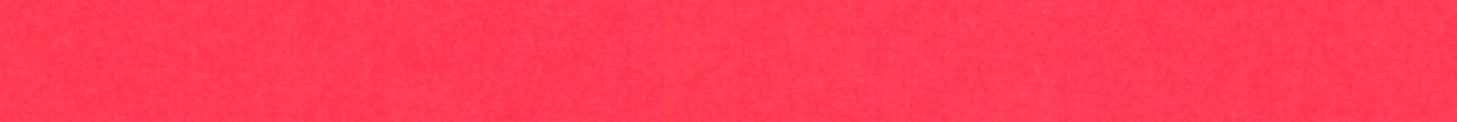

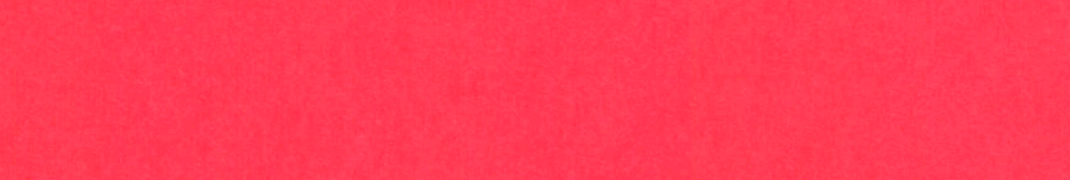

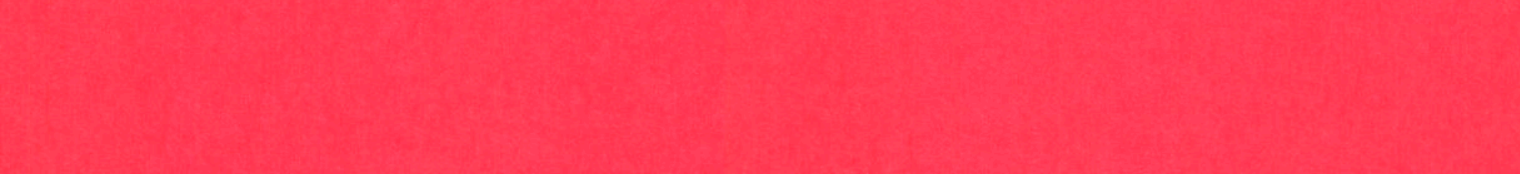

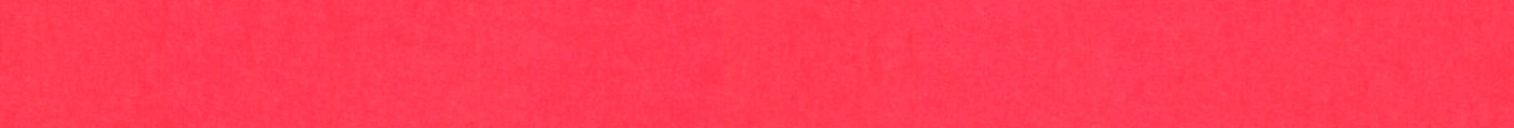

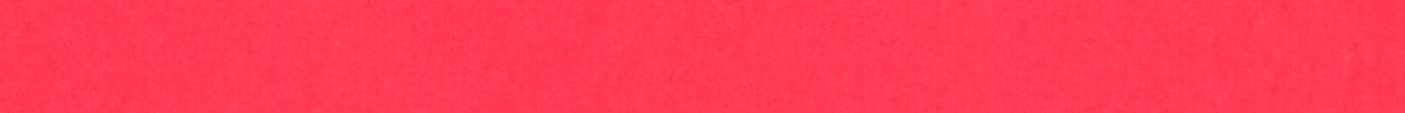

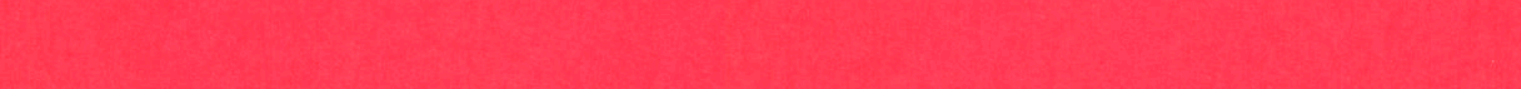

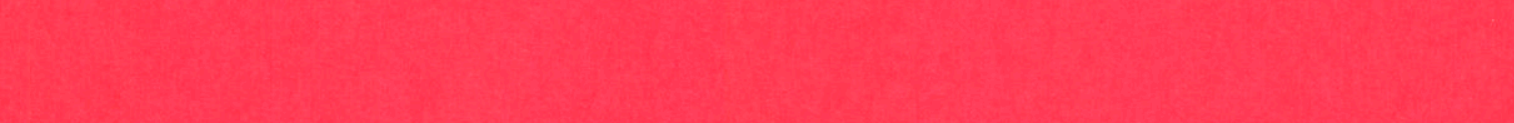
$6 x^{2}+2=0$

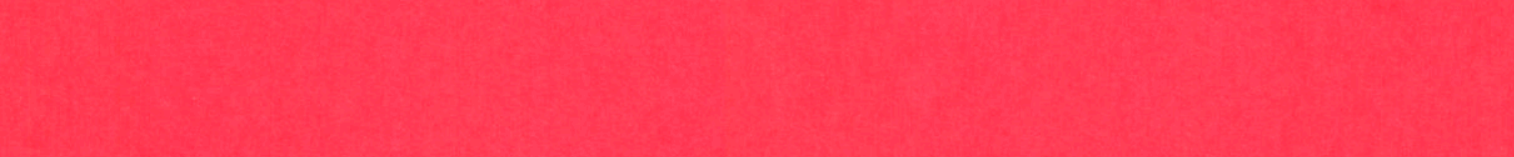

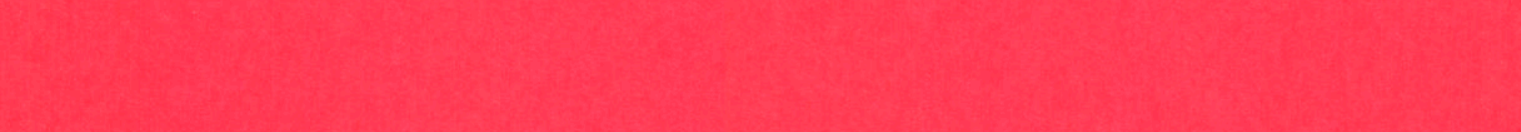

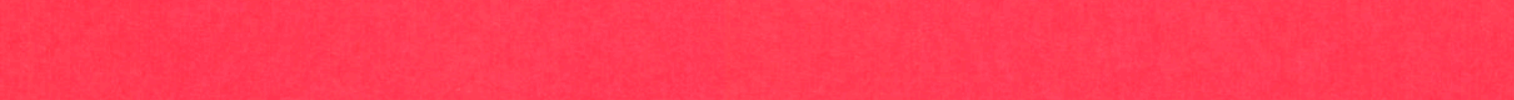

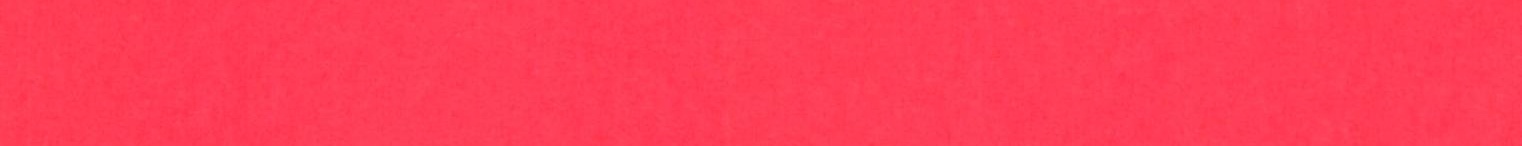

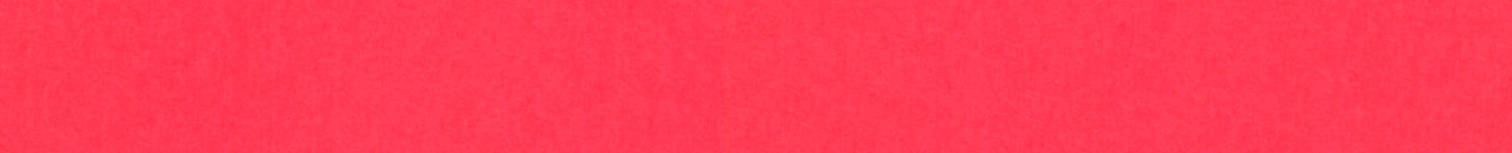

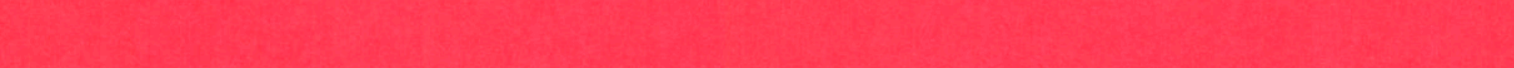
t.

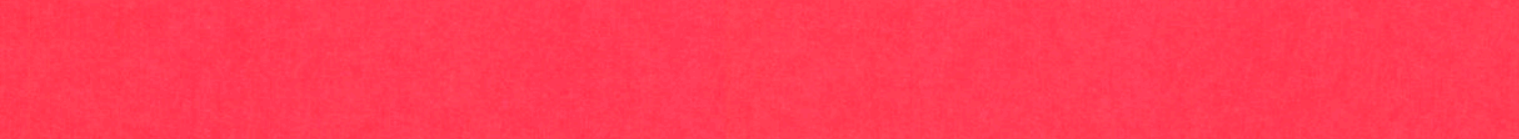

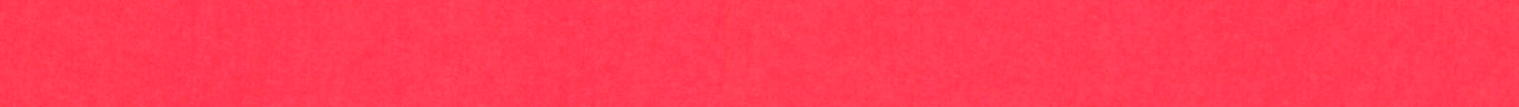

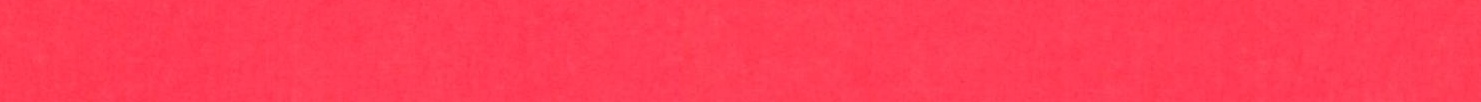

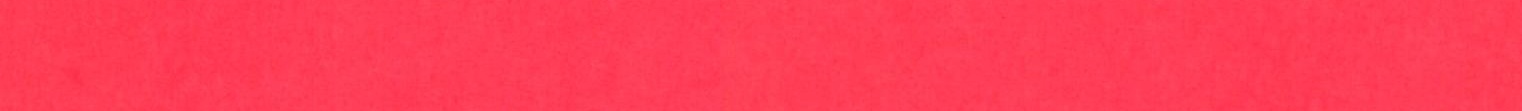
ast 


\section{Acta Universitatis Upsaliensis}

\section{Comprehensive Summaries of Uppsala Dissertations}

from the Faculty of Medicine

Editor: The Dean of the Faculty of Medicine

A doctoral dissertation from the Faculty of Medicine, Uppsala University, is usually a summary of a number of papers. A few copies of the complete dissertation are kept at major Swedish research libraries, while the summary alone is distributed internationally through the series Comprehensive Summaries of Uppsala Dissertations from the Faculty of Medicine. (Prior to July, 1985, the series was published under the title "Abstracts of Uppsala Dissertations from the Faculty of Medicine ".)

Distributor:

Almqvist \& Wiksell International

Stockholm, Sweden 